\title{
Synthesis, Structural and Magnetic Properties of Copper Doped Cerium Oxide Nanoparticles
}

\author{
Savan Suri \\ West Virginia University
}

Follow this and additional works at: https://researchrepository.wvu.edu/etd

\section{Recommended Citation}

Suri, Savan, "Synthesis, Structural and Magnetic Properties of Copper Doped Cerium Oxide Nanoparticles" (2010). Graduate Theses, Dissertations, and Problem Reports. 4662.

https://researchrepository.wvu.edu/etd/4662

This Thesis is protected by copyright and/or related rights. It has been brought to you by the The Research Repository @ WVU with permission from the rights-holder(s). You are free to use this Thesis in any way that is permitted by the copyright and related rights legislation that applies to your use. For other uses you must obtain permission from the rights-holder(s) directly, unless additional rights are indicated by a Creative Commons license in the record and/ or on the work itself. This Thesis has been accepted for inclusion in WVU Graduate Theses, Dissertations, and Problem Reports collection by an authorized administrator of The Research Repository @ WVU. For more information, please contact researchrepository@mail.wvu.edu. 


\title{
Synthesis, Structural and Magnetic Properties of Copper Doped Cerium Oxide Nanoparticles
}

\author{
Savan Suri \\ Thesis submitted to the \\ College of Engineering and Mineral Resources at West Virginia University \\ in partial fulfillment of the requirements for the degree of \\ Master of Science \\ in \\ Electrical Engineering
}

\author{
Dimitris Korakakis, Ph.D., Chair \\ Mohindar S. Seehra, Ph.D., co-Chair \\ Lawrence A. Hornak, Ph.D.
}

Lane Department of Computer Science and Electrical Engineering

\author{
Morgantown, West Virginia
}

2010
Keywords: Copper, Cerium oxide, Synthesis, Particle size, Paramagnetism \& Ferromagnetism




\section{Abstract \\ Synthesis, Structural and Magnetic Properties of Copper Doped Cerium Oxide Nanoparticles}

\section{Savan Suri}

In this thesis, synthesis, structural and magnetic properties of the undoped and copper doped cerium oxide nanoparticles have been investigated. The nanoparticles were prepared by sol-gel preparation method. Undoped samples were prepared with different particles sizes by annealing the as-prepared sample at different temperatures $\mathrm{T}_{\mathrm{a}}=200^{\circ} \mathrm{C}, 400^{\circ} \mathrm{C}, 550^{\circ} \mathrm{C}, 700^{\circ} \mathrm{C}$, $800^{\circ} \mathrm{C}$. The particle size varied from $3 \mathrm{~nm}$ to $42 \mathrm{~nm}$ with increasing annealing temperatures. Copper was doped into $\mathrm{CeO}_{2}$ by annealing the samples at $400^{\circ} \mathrm{C}$ in ultra high pure nitrogen. The nominal percentages of copper in doped cerium oxide were $2.5 \%, 5 \%, 7.5 \%$ and $10 \%$.

Structural characterization of the nanoparticles was done using transmission electron microscope (TEM) and x-ray diffraction (XRD). Inductive coupled plasma optical emission spectroscopy was done to detect the impurity concentrations of Iron $(\mathrm{Fe})$ which was found to be present in ppm levels. The nano-particles were found to be nearly spherical in shape in both undoped and doped samples. The particle sizes in undoped samples were found to be increasing with increase in annealing temperatures. As all the copper doped samples were annealed at same temperatures, they were all in the $5 \mathrm{~nm}$ size range. The particle size values from XRD and TEM were comparable. Lattice constant and the strain in undoped $\mathrm{CeO}_{2}$ nanoparticles was found to decrease with increase in particle size. In $\mathrm{Cu}$-doped $\mathrm{CeO}_{2}$, lattice constant was increasing with increase in doping concentration levels.

Magnetic properties of these nanoparticles were measured using a superconducting quantum interface device (SQUID) magnetometer. Susceptibility and hysteresis loops plots were plotted using magnetization data from SQUID. Increasing paramagnetism was found with decreasing particle size in the undoped samples which is attributed to increase in $\mathrm{Ce}^{3+}$ concentration. The small amount of ferromagnetism found in the undoped samples is suggested to originate from the $\mathrm{Fe}$ present in ppm levels. In $\mathrm{Cu}$-doped $\mathrm{CeO}_{2}$ nanoparticles, the paramagnetic and ferromagnetic parts were found to be increasing with increase in doping concentration of $\mathrm{Cu}$ in $\mathrm{CeO}_{2}$. The observed room temperature ferromagnetism in $\mathrm{Cu}$-doped $\mathrm{CeO}_{2}$ is suggested to result from the effects of copper doping. 


\section{Dedication}

To my beloved parents... 


\section{Acknowledgements}

I take this opportunity to acknowledge and extend my heartfelt gratitude to all of the people who have helped me throughout this journey. I am greatly indebted to Dr. Mohindar S. Seehra for his benevolent support, guidance and fervor encouragement during this research work. He is my mentor who has taught me how to learn patiently and do research. I am also extremely thankful to my committee members Dr. Dimitris Korakakis and Dr. Lawrence A. Hornak for their valuable suggestions in my research and academics. I thank Dr. Naresh Shah for carrying out TEM studies reported in this thesis. I express my gratitude to all my colleagues Mohita, Poornima, James and especially Dr. Vivek Singh for his constant support and valuable inputs. I am also very thankful to the professors who have taught me courses in the Electrical Engineering and Physics Departments. I also thank office staff members of the Physics Department viz. Sherry, Phil, Doug and Devon for their helping hands. Thanks to all my beloved friends Raghu, Kartheek, Krishna, Jyothi, Spoorthi, Srikanth, Jagadish, Charan and Eswar for their immense love and support. Finally I thank the U.S. Department of Energy for financially supporting this project (DOE contract \# DE-FC-26-05NT42456). 


\section{Table of Contents}

Synthesis, Structural and Magnetic Properties of Copper Doped Cerium Oxide Nanoparticles..... i

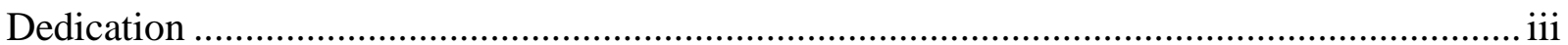

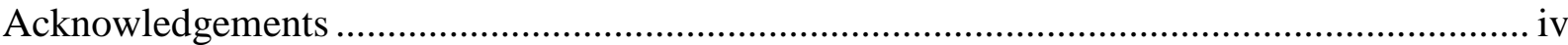

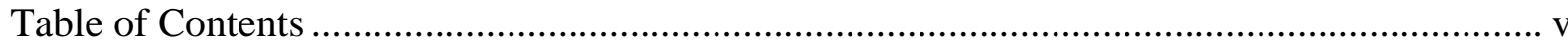

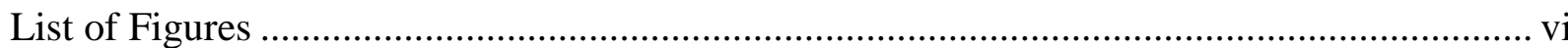

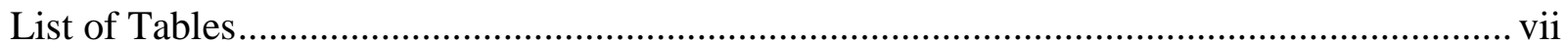

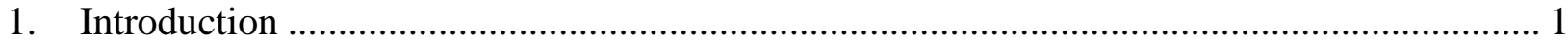

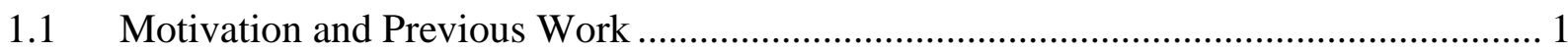

2. Synthesis \& Structural Characterization of $\mathrm{CeO}_{2}$ and $\mathrm{Cu}$-doped $\mathrm{CeO}_{2} \ldots \ldots \ldots \ldots \ldots \ldots \ldots \ldots \ldots \ldots \ldots . . . . . . . . . . . . .6$

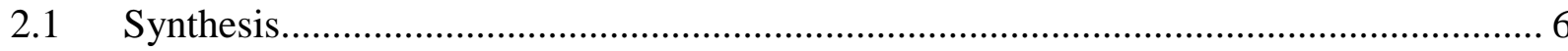

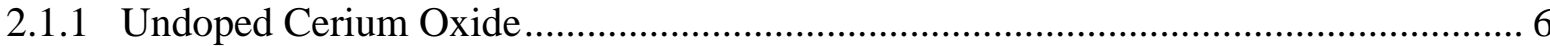

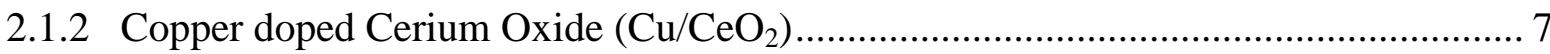

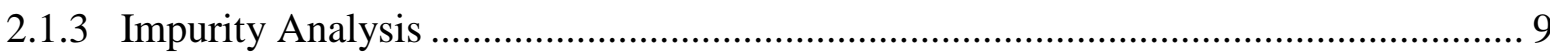

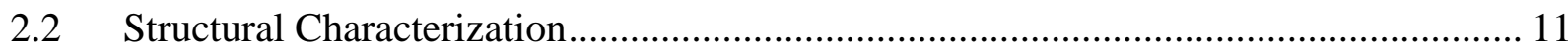

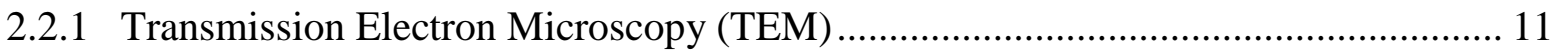

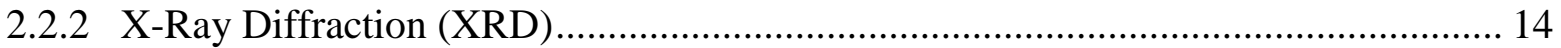

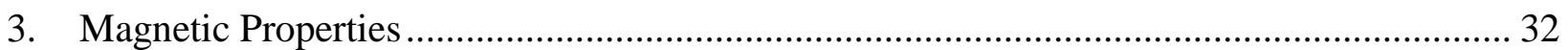

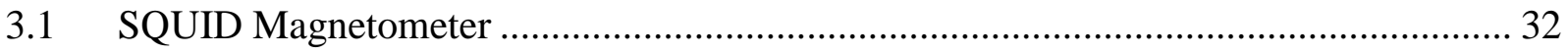

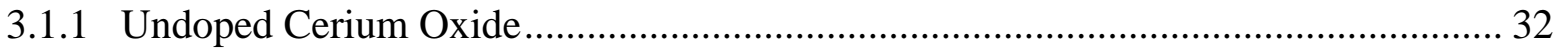

3.1.2 Cu-doped Cerium Oxide ..................................................................................... 43

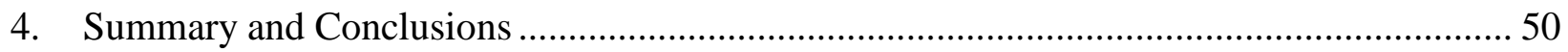

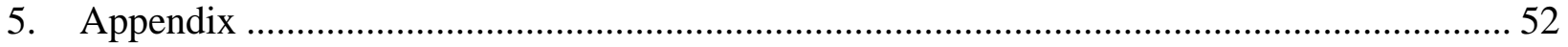

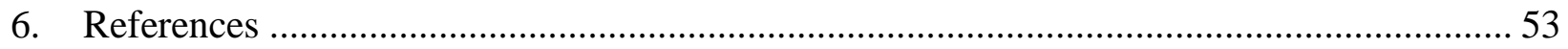




\section{List of Figures}

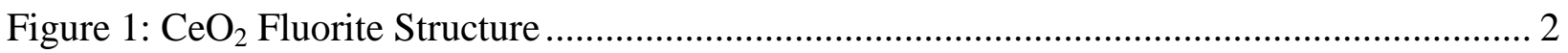

Figure 2: Flowchart for Sample Preparation of Undoped and 5\% Cu-doped $\mathrm{CeO}_{2} \ldots \ldots \ldots \ldots \ldots \ldots \ldots . . . . . .10$

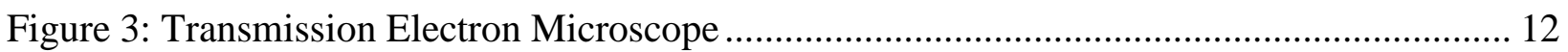

Figure 4: TEM images of (a) Undoped Sample (132nm x 132nm), (b) $\mathrm{Cu}_{0.025} \mathrm{Ce}_{0.975} \mathrm{O}_{2}(132 \mathrm{~nm} \mathrm{x}$

$132 \mathrm{~nm})$, (c) $\mathrm{Cu}_{0.05} \mathrm{Ce}_{0.95} \mathrm{O}_{2}(52 \mathrm{~nm} \times 52 \mathrm{~nm}),(d) \mathrm{Cu}_{0.075} \mathrm{Ce}_{0.925} \mathrm{O}_{2}(52 \mathrm{~nm} \times 52 \mathrm{~nm})$,

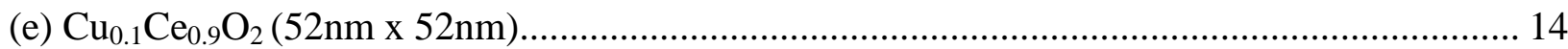

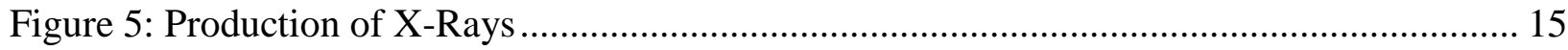

Figure 6: Energy Lines from Different Levels ......................................................................... 16

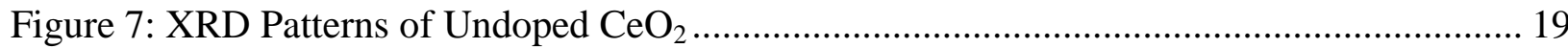

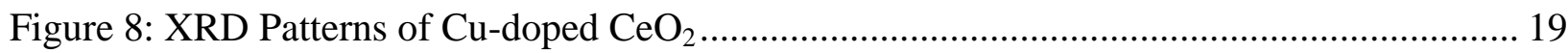

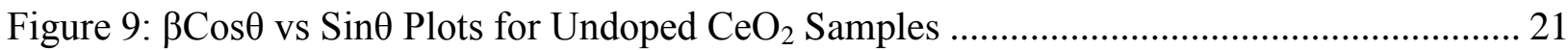

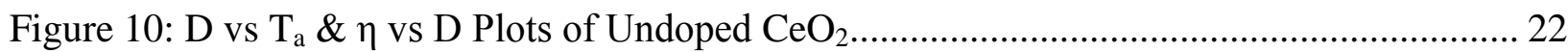

Figure 11: $\beta \operatorname{Cos} \theta$ vs $\operatorname{Sin} \theta$ Plots of $\mathrm{Cu}$-doped $\mathrm{CeO}_{2}$ Samples..................................................... 23

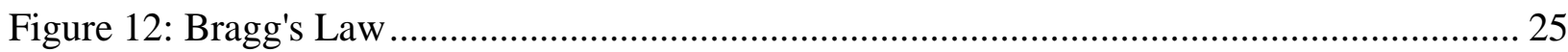

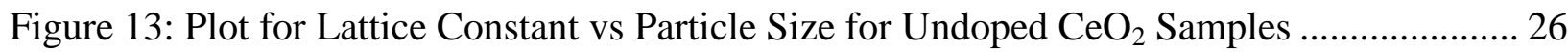

Figure 14: Lattice Constant vs Doping \% Plot of Cu-doped Samples.......................................... 27

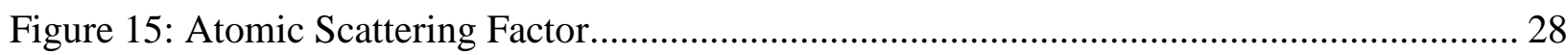

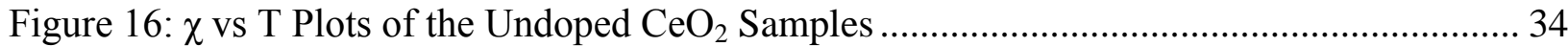

Figure 17: Fitted Chi Plots of Undoped $\mathrm{CeO}_{2}$ Samples............................................................... 37

Figure 18: ZFC \& FC Plot Comparisons of Undoped $\mathrm{CeO}_{2}$ Samples .......................................... 38

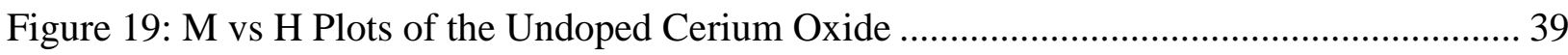

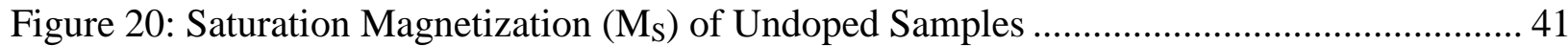

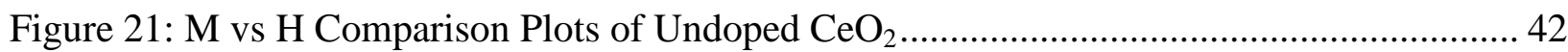

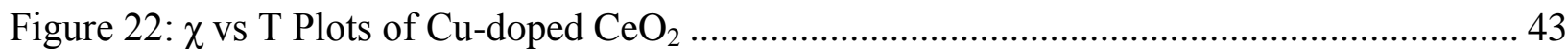

Figure 23: Curie-Weiss Fits to the $\chi$ vs $\mathrm{T}$ Data in $\mathrm{Cu}$-doped $\mathrm{CeO}_{2}$ Samples................................. 44

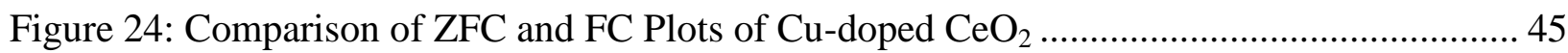

Figure 25: M vs H Plots for $\mathrm{Cu}$-doped Samples ........................................................................ 48

Figure 26: $\mathrm{M}_{\mathrm{S}}$ Comparison in Cu-doped Cerium Oxide Samples ............................................... 49

Figure 27: Comparison of $\mathrm{M}$ vs $\mathrm{H}$ in $\mathrm{Cu}$-doped $\mathrm{CeO}_{2}$ Samples .................................................. 49 


\section{List of Tables}

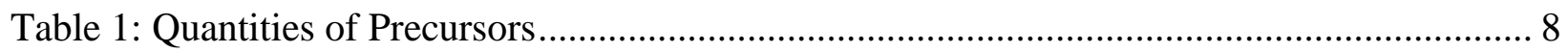

Table 2: Average Particle Size using TEM Analysis................................................................. 13

Table 3 : Targets often used in X-Ray Diffraction Studies ..................................................... 17

Table 5: Particle Size and Strain for Undoped $\mathrm{CeO}_{2}$ Samples from XRD Patterns ...................... 21

Table 6: Particle Size and Strain of $\mathrm{Cu}$-doped $\mathrm{CeO}_{2}$ Samples................................................... 23

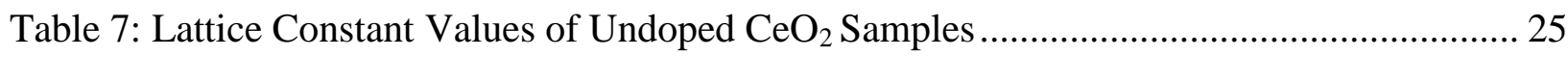

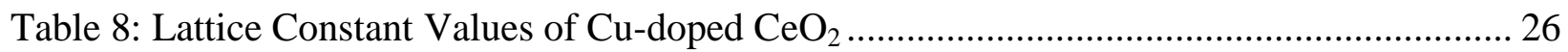

Table 10: Parameters Derived from M vs H Plots ....................................................................... 41

Table 11: Magnetic Moment $(\mu)$ per Copper Atom Calculations from $\chi$ vs T ............................. 45

Table 12: Magnetic Parameters Extracted using M vs H Plots ................................................... 48 


\section{Introduction}

\subsection{Motivation and Previous Work}

Cerium is a soft gray rare earth element with atomic number 58, atomic mass 140.12 and electronic configuration $[\mathrm{Xe}] 4 \mathrm{f}^{1} 5 \mathrm{~d}^{1} 6 \mathrm{~s}^{2}$. It has a variable electronic structure by which it can change the relative occupancy of electronic levels with only small amounts of energy. This gives rise to its dual valency states i.e. oxidation states of $3^{+}$and $4^{+}$. Ionic radius of $\mathrm{Ce}^{4+}$ is $0.97 \AA$ and of $\mathrm{Ce}^{3+}$ is $1.143 \AA$ [1]. It has a crystalline structure with face centered cubic lattice. Cerium oxide $\left(\mathrm{CeO}_{2}\right)$ is a stable oxide compound of the cerium. It is also called ceria, ceric $\left(\mathrm{Ce}^{4+}\right)$ oxide, and cerium dioxide. Cerium oxide adopts the classic face centered cubic fluorite structure. The unit cell consists of $\mathrm{Ce}^{4+}$ ions placed in face centered cubic arrangement and oxygen atoms in the tetrahedral interstitials. Sometimes, crystalline $\mathrm{CeO}_{2}$ exhibits minor defects in which $\mathrm{Ce}^{4+}$ ions are reduced to $\mathrm{Ce}^{3+}$ state in an oxygen deficient state. Lattice parameter of bulk $\mathrm{CeO}_{2}$ is $0.541 \mathrm{~nm}$ [2].In $\mathrm{CeO}_{2}$ lattice structure, $\mathrm{Ce}^{4+}$ has a coordination number of 8 and $\mathrm{O}^{2-}$ has a coordination number of 4 . With coordination number 4 , oxygen has ionic radius of $1.38 \AA$ [1]. Bulk cerium oxide is diamagnetic in nature. In general, $\mathrm{CeO}_{2}$ nanoparticles have an advantage of having large surface area per unit volume. Due to their large surface area to volume ratio (with respect to bulk) these nanoparticles have high chemical interaction and reactivity. This is the main purpose of preparing and understanding the ceria particles at the nano scale. 


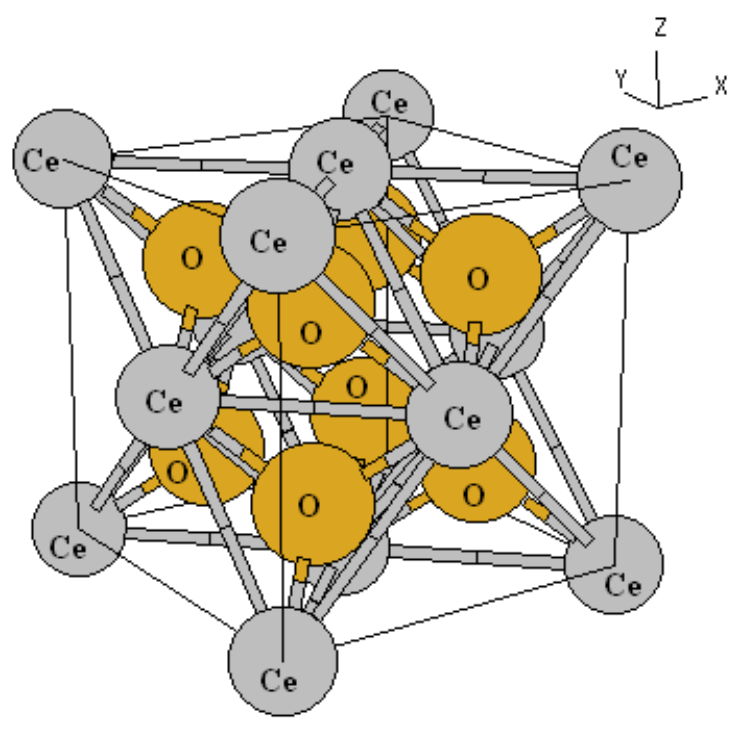

Figure 1: $\mathrm{CeO}_{2}$ Fluorite Structure

Catalytically, cerium and its oxides are very active as it has attained much attention due to its applications in a number of areas. Due to its ease to switch between $\mathrm{Ce}^{3+}$ and $\mathrm{Ce}^{4+}$ ionic states, $\mathrm{CeO}_{2}$ can absorb and release oxygen which is an important catalytic property. And even $\mathrm{Ce}^{3+}$ has a high affinity to absorb oxygen [3], a mechanism useful to absorb large amounts of oxygen and release. Due to its extraordinary UV absorption properties cerium oxide nanoparticles are used in cosmetics [4]. It is used as a catalyst in oxygen gas sensors [5], ultra precise polishing, and electronic ceramics. Due its excellent ionic conduction, low conduction activation energy, lower work temperature and lower cost in comparison with zirconia based solid oxide fuel cell (SOFC), cerium oxide is used as a efficient catalyst in SOFC [6].

Many attempts were made by research groups to find magnetism in many of the oxides of metals. In this, transitional metal doped rare earth elements have attained special attention. It has been claimed that even undoped non-magnetic oxides are showing room temperature ferromagnetism at nanoscale. Being a controversial topic of research, nanoparticles of $\mathrm{CeO}_{2}$ are 
claimed to be ferromagnetic instead of being diamagnetic. Bulk $\mathrm{CeO}_{2}$ is purely diamagnetic. Sundaresan et. al. $[7,8]$ have claimed the discovery of ferromagnetism in nano-particles of nonmagnetic oxides such as $\mathrm{CeO}_{2}, \mathrm{Al}_{2} \mathrm{O}_{3}, \mathrm{ZnO}, \mathrm{In}_{2} \mathrm{O}_{3}$ and $\mathrm{SnO}_{2}$ at room temperature. The origin of ferromagnetism in these samples is assumed to be due to exchange interactions between localized electron spin moments resulting from oxygen vacancies at the surface of nanoparticles. Liu et. al. [9] also reported ferromagnetism in undoped cerium oxide and found saturation magnetization to be fairly flat and decreasing coercive field with increasing temperature. Using photoluminescence results, Liu et. al. argued that the oxygen vacancies are not responsible for the ferromagnetism observed in size-controlled $\mathrm{CeO}_{2}$ nanostructures. Fernandes et. al. [10] proposed the possibility of intrinsic point defects as the effective source of RTFM in nanoscale $\mathrm{CeO}_{2}$. In contrast to previous reports, they report that not only oxygen vacancies are responsible for RTFM, but also that cerium vacancies contribute to the observed ferromagnetic character. Other studies have claimed that experimental artifacts are the reason behind room temperature ferromagnetism in the undoped $\mathrm{CeO}_{2}[9,10]$. Apart from magnetic studies, structural analysis and characterization have also been done on $\mathrm{CeO}_{2}$ nanoparticles. Tsunekawa et. al. [11, 12] reported lattice expansions with decreasing particles size in nanosized $\mathrm{CeO}_{2}$ particles. In their theoretical study, they attributed the observed lattice expansion to the decrease of the electrostatic force caused by the valence reduction of Ce ions in the ceria. They also reported increased ratio of $\mathrm{Ce}^{3+} / \mathrm{Ce}^{4+}$ concentration with decrease in particle size. Deshpande et. al.[2] have also observed the increase in the lattice constant of $\mathrm{CeO}_{2}$ nanoparticles with decreasing particles size which is attributed to increase in concentration of $\mathrm{Ce}^{3+}$ ions and oxygen vacancies in the crystal. They explain that when $\mathrm{Ce}^{3+}$ ion replaces $\mathrm{Ce}^{4+}$ ion in $\mathrm{CeO}_{2}$ structure, a high strain is produced in the lattice which causes the lattice to expand or relax to ease the strain. Zhang et. 
al.[13] report that in larger lattice parameter in nanocrystalline $\mathrm{CeO}_{2}$ indicates smaller emigration enthalpy of an oxygen vacancy, resulting in a higher ionic conductivity and more efficient fuel cells.

Recently, noble metal-free catalysts are beginning to be explored as catalysts due to high cost and less abundance of noble metals. In particular, the basemetals like copper and copperbased catalysts have attracted much attention in heterogeneous catalysis because of their superior catalytic behavior. The redox properties of the copper-ceria interface are proposed to dominate the steam methane reforming (SMR) catalytic activity over $\mathrm{Cu} / \mathrm{CeO} 2 / \gamma-\mathrm{Al}_{2} \mathrm{O}_{3}$ catalysts to produce hydrogen $[14,15]$. The enhanced reducibility of copper species is suggested to be responsible for the high catalytic activity for catalyst with low $\mathrm{Cu} / \mathrm{Ce}$ ratio. Large number of $\mathrm{Cu}-$ ions on the film enhances the catalytic behavior of the catalyst. There is also an urge to produce spintronic devices which needs magnetic semiconductors [16]. The current semiconductor technology, e.g. transistor mechanism, is purely based on the physics and the engineering of charge of an electron. But for controlling the flow of electrons with their spins, instead of the charge, need magnetic semiconductors. Increasing demand for development of multifunctional materials lead to discovery of room temperature ferromagnetism (RTFM) in transition metal doped rare oxides. RTFM has been reported by few research groups with $\mathrm{Co}, \mathrm{Ni}, \mathrm{Fe}$ doped $\mathrm{CeO}_{2}$ with interesting results $[17,18,19]$. Experimental artifacts, segregation of secondary ferromagnetic phases, magnetic clusters, and indirect exchange mediated by carriers (electrons and holes associated with impurities) have been used to explain the room temperature ferromagnetism in several non-magnetic oxides [20]. An issue whether $\mathrm{Cu}$ doped $\mathrm{CeO}_{2}$ is intrinsically a room temperature ferromagnet or not has received recent attention. Work by Slusser et. al. [21] has reported room temperature ferromagnetism in copper doped cerium oxide 
thin films. They have observed a systematic decrease in lattice constant with increase in copper doping concentration. Some of the physical and chemical properties of copper doped cerium oxide have been explained by Wang et. al [22]. Using XRD and density function calculations it was found that parts of the fluorite structure of the cerium oxide was highly distorted with multiple cation-oxygen distances. With increase in copper doping content, increases in surface area, oxygen vacancies, strain in lattice and magnetism have been observed. Catalytic and physico-chemical properties of active sites present in the copper doped ceria have been studied by Kais et. al. [23] by electron paramagnetic studies (EPR) studies. This works explains the EPR studies to prove proper doping of copper into ceria lattice in several annealed samples.

In this work, powder samples of undoped and $\mathrm{Cu}$-doped $\mathrm{CeO}_{2}$ nanoparticles have been prepared to investigate the structural and magnetic characteristics of the samples in order to verify the recent results on magnetism in $\mathrm{Cu}$-doped $\mathrm{CeO}_{2}$ thin films [21]. Undoped samples were prepared with particle size variation and $\mathrm{Cu}$-doped samples were prepared with different $\mathrm{Cu}$ doping. These powder samples were prepared by the sol-gel technique and the procedure of undoped $\mathrm{CeO}_{2}$ and $\mathrm{Cu}$-doped $\mathrm{CeO}_{2}\left(\mathrm{Cu}_{\mathrm{x}} \mathrm{Ce}_{1-\mathrm{x}} \mathrm{O}_{2}, \mathrm{x}=0,0.025,0.05,0.075\right.$ and 0.10$)$ nanoparticles is described. In the next section, Structural characteristics of the nanoparticles were determined using room temperature $\mathrm{x}$-ray diffraction (XRD) and transmission electron microscopy (TEM). Magnetic properties and electronic state of copper in $\mathrm{Cu} / \mathrm{CeO}_{2}$ nanoparticles were determined using superconducting quantum interference device (SQUID) magnetometer and electron magnetic resonance (EMR) spectroscopy. Results of these investigations on the structural and magnetic properties of undoped and $\mathrm{Cu}$-doped $\mathrm{CeO}_{2}$ nanoparticles are described in this thesis. 


\section{Synthesis \& Structural Characterization of $\mathrm{CeO}_{2}$ and $\mathrm{Cu}$-doped $\mathrm{CeO}_{2}$}

\subsection{Synthesis}

\subsubsection{Undoped Cerium Oxide}

All the chemical reactions are surface area phenomenon. Larger is the surface area more is the amount of reaction. Smaller particles have larger surface to volume ratio. Therefore for catalytic applications, finer particles of ceria are fabricated to increase surface area in order to enhance the reaction or catalytic efficiency. Usually particles of $1-100 \mathrm{~nm}$ range are considered to be nanoparticles. The undoped cerium nanoparticles were synthesized using wet chemical solgel process which is a low-cost and low-temperature method. This method also allows one to finely control the chemical composition of the end products. The preparation process consists of gelation of the chemical solution, centrifuging, drying and annealing. Following the procedure used by Liu et al. [9], $4.3414 \mathrm{~g}$ of cerium nitrate hexahydrate $\left(\mathrm{Ce}\left(\mathrm{NO}_{3}\right)_{3} \cdot 6 \mathrm{H}_{2} \mathrm{O}\right)$ (Alfa Aesar $99.5 \%$ ) is taken into $50 \mathrm{ml}$ of $50 \%$ distilled $\mathrm{H}_{2} \mathrm{O}+50 \%$ polyethylene glycol (Sigma Aldrich, PEG200) and stirred well until the salt is completely dissolved in the solution. Usually solvent plays an important role in determining particle size of the nanoparticles. Next, the solution is heated to $50^{\circ} \mathrm{C}$ to enhance the chemical kinetics while forming of the gel. If the temperature is too low, the process of gelation will be too slow and if the temperature of the solution is high, thick solid lumps are formed and particles are not well dispersed in the solution. The process is not exothermic; therefore additional heat is needed to fasten the process of gelation. After the temperature becomes constant, $4 \mathrm{M}$ sodium hydroxide $(\mathrm{NaOH})$ is added slowly or drop wise into the solution to form the precipitate or the gel. The gel is allowed to form slowly making the nanoparticle network uniform and stronger. Speeding up the precipitation causes to form a weak 
and cloudy gel which is non-uniform. The $\mathrm{NaOH}$ is added until the $\mathrm{pH}$ of the solution is $>11$. The use of the $\mathrm{NaOH}$ is to break the nitrate bonds and form Cerium oxides. Usually acids and bases act as a catalyst and enhance the gelation rate; hence the sol gel process is $\mathrm{pH}$ sensitive. When the base comes in contact with the sol, a thick viscous gel is formed on the surface and this blocks the underlying sol to gelate. Hence the solution is to be stirred properly to ensure the complete and uniform gelation of the solution. Sometimes too much agitation or stirring causes breakage of the gel network. However in our case we are not concerned about the nanoparticle network but are concerned only with uniformity of the precipitation. Schematically, the primary chemical reaction involved in the process in shown below.

$$
\mathrm{Ce}\left(\mathrm{NO}_{3}\right)_{3} \cdot 6 \mathrm{H}_{2} \mathrm{O}+3 \mathrm{NaOH}+\mathrm{H}_{2} \mathrm{O}+\mathrm{PEG} \rightarrow \mathrm{CeO}_{2}+3 \mathrm{NaNO}_{3}+8 \mathrm{H}_{2} \mathrm{O}+\mathrm{PEG}
$$

Note that cerium in cerium nitrate is in +3 state and in cerium oxide it is in +4 state. Now as nanoparticles are precipitated they are centrifuged and separated from the solution. After separation, a grayish paste is left which is dried for $24 \mathrm{hrs}$ at room temperature. After drying, the sample turns into bright yellow cerium oxide $\left(\mathrm{CeO}_{2}\right)$ powder which is annealed at temperatures $\mathrm{T}_{\mathrm{a}}=200^{\circ} \mathrm{C}, 400^{\circ} \mathrm{C}, 550^{\circ} \mathrm{C}, 700^{\circ} \mathrm{C}$ and $800^{\circ} \mathrm{C}$ in air for 2 hours each. So in total there are 6 undoped samples to be analyzed viz. as-prepared $\left(25^{\circ} \mathrm{C}\right), 200^{\circ} \mathrm{C}, 400^{\circ} \mathrm{C}, 550^{\circ} \mathrm{C}, 700^{\circ} \mathrm{C}$ and $800^{\circ} \mathrm{C}$.

\subsubsection{Copper doped Cerium Oxide $\left(\mathrm{Cu} / \mathrm{CeO}_{2}\right)$}

The preparation of copper doped cerium oxide traces the steps for preparing cerium oxide with small changes. Dopant copper is added in atomic proportions with respect to the cerium. copper (II) nitrate hemi(pentahydrate) $\mathrm{Cu}\left(\mathrm{NO}_{3}\right)_{2} \cdot 5 / 2 \mathrm{H}_{2} \mathrm{O}$ (Alfa Aesar 99.5\%) is mixed with cerium nitrate hexahydrate $\mathrm{Ce}\left(\mathrm{NO}_{3}\right)_{3} \cdot 6 \mathrm{H}_{2} \mathrm{O}$ (Alfa Aesar 99.5\%) in appropriate atomic ratios to 
prepare copper doped cerium oxides. $\mathrm{Cu}_{\mathrm{x}} \mathrm{Ce}_{(1-\mathrm{x})} \mathrm{O}_{2}$ where $\mathrm{x}=0.025,0.05,0.075,0.1 . \mathrm{Cu}_{\mathrm{x}} \mathrm{Ce}_{-\mathrm{x}} \mathrm{O}_{2}$ with $\mathrm{x}=0.025,0.05,0.075 \& 0.1$ will be further denoted in the thesis as $2.5 \%, 5 \%, 7.5 \%$ and $10 \% \mathrm{Cu}$-doped $\mathrm{CeO}_{2}$ samples. Calculation for amounts to be mixed is given in the Appendix. The amount of samples taken to mix in atomic ratio concentration is given Table 1below.

Table 1: Quantities of Precursors

\begin{tabular}{|c|c|c|}
\hline $\mathbf{C u} \%$ & $\mathbf{C e}\left(\mathrm{NO}_{\mathbf{3}}\right)_{\mathbf{3}} \cdot \mathbf{6} \mathbf{H}_{\mathbf{2}} \mathbf{0}(\mathrm{g})$ & $\mathbf{C u}\left(\mathrm{NO}_{\mathbf{3}}\right)_{\mathbf{2}} \cdot \mathbf{2} \frac{\mathbf{1}}{\mathbf{2}} \mathbf{H}_{\mathbf{2}} \mathbf{O}(\mathbf{g})$ \\
\hline $\mathbf{2 . 5}$ & 4.3414 & 0.0606 \\
\hline $\mathbf{5}$ & 4.3414 & 0.1245 \\
\hline $\mathbf{7 . 5}$ & 4.3414 & 0.1918 \\
\hline $\mathbf{1 0}$ & 4.3414 & 0.2628 \\
\hline
\end{tabular}

The above mixtures are taken into a $50 \mathrm{ml}$ each of $50 \%$ distilled $\mathrm{H}_{2} \mathrm{O}+50 \%$ polyethylene glycol (Sigma Aldrich, PEG200) solution and stirred thoroughly until the salts are completely dissolved to form a crystal blue solution. Next the solution is heated to $50^{\circ} \mathrm{C}$ and $4 \mathrm{M} \mathrm{NaOH}$ is added drop wise into the solution to form a dark green color gel. The complete process is performed while stirring the solution moderately and maintaining temperature at $50^{\circ} \mathrm{C}$. The gel is centrifuged to separate the nanoparticles from the solution. After decanting the solution, a green color paste remains and is dried at room temperature for $24 \mathrm{hrs}$. After drying, each sample is mixed well and annealed at $400^{\circ} \mathrm{C}$ for 2 hours in the presence of inert ultra high pure nitrogen. Metals when subjected to high temperatures instantly react with oxygen, sulfur, and other elements and compounds present in atmosphere to form oxides, sulfides etc. Hence annealing in presence of inert atmosphere is very important to preserve the integrity of the metal to be doped and prevent the sample to get impure. So there are 4 samples of $\mathrm{Cu}$-doped cerium oxides prepared viz. $2.5 \%, 5 \% 7.5 \%$ and $10 \%$ copper doped into cerium oxide. Figure 2 shows the flowchart for the preparation of the undoped and 5\% doped cerium oxide samples. 


\subsubsection{Impurity Analysis}

Even though lot of care is taken while preparing the sample, contamination is possible in most of the chemical processes. So it is very important to check for any contamination in the prepared samples. As the study is more about magnetic properties of the samples, a test for presence of ubiquitous Iron $(\mathrm{Fe})$ has been conducted using inductively coupled plasma - optical emission spectroscopy (ICP-OES) at Gailbraith Labs Inc., Knoxville, TN. ICP-OES is a highly sensitive technique for elemental analysis to trace impurities to ppm levels. Atoms in plasma emit light with characteristic wavelength for each element. The intensity of the peak gives the concentration of the element. Elemental analysis has been done on an undoped $\mathrm{CeO}_{2}$ sample and $\mathrm{Cu}_{0.05} \mathrm{Ce}_{0.95} \mathrm{O}_{2}$ sample. Results provided by the Gailbraith Lab show that as prepared undoped sample $\left(25^{\circ} \mathrm{C}\right)$ has $18 \mathrm{ppm}$ of iron concentration and $\mathrm{Cu}_{0.05} \mathrm{Ce}_{0.95} \mathrm{O}_{2}$ has 20ppm of iron concentration. These are likely to be present as iron oxides in the precursor salts used for preparation of the samples. 
Undoped Cerium

Oxide

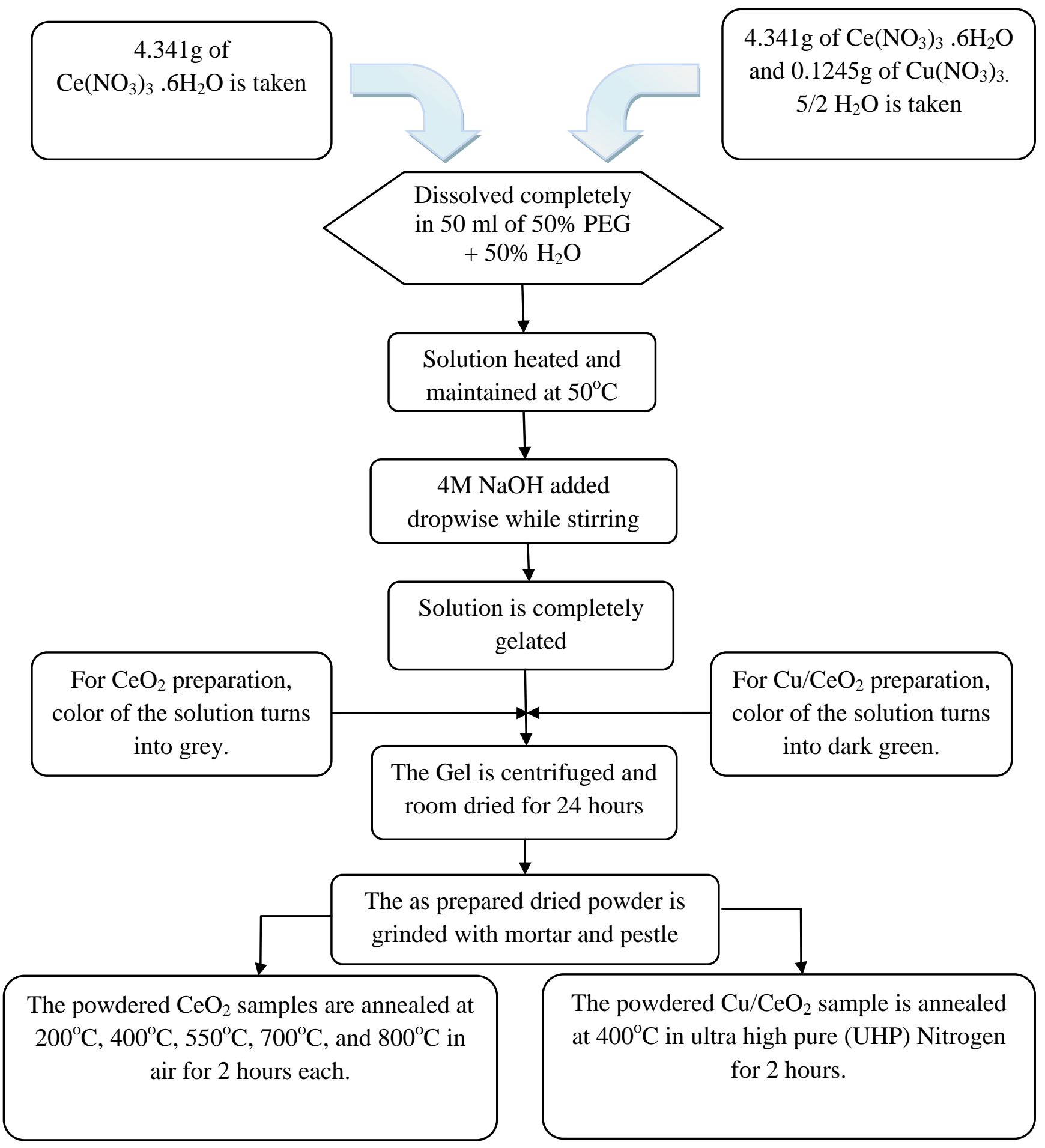

5\% Cu-doped

Cerium Oxide

$4.341 \mathrm{~g}$ of $\mathrm{Ce}\left(\mathrm{NO}_{3}\right)_{3} \cdot 6 \mathrm{H}_{2} \mathrm{O}$

$5 / 2 \mathrm{H}_{2} \mathrm{O}$ is taken

Figure 2: Flowchart for Sample Preparation of Undoped and 5\% Cu-doped $\mathrm{CeO}_{2}$ 


\subsection{Structural Characterization}

The structural characterization of the samples was done using X-Ray diffraction (XRD) and Transmission Electron Microscope (TEM). In this characterization, changes in particle sizes, lattice constants and planes participating in diffraction of $\mathrm{CeO}_{2}$ and $\mathrm{Cu} / \mathrm{CeO}_{2}$ are observed using these techniques.

\subsubsection{Transmission Electron Microscopy (TEM)}

Transmission electron Microscope (TEM) uses a beam of highly energetic electrons to examine materials on the micro to nano scale. TEM overcomes the limitations of light microscope (due to its wavelength of $400 \mathrm{~nm}-750 \mathrm{~nm}$ ) with magnification of only $500 \mathrm{x}-1000 \mathrm{x}$ and a resolution of 0.2 micrometers. TEM functions exactly as their optical counterparts that it uses a focused beam of electrons as light source at much lower wavelength of energetic electrons and makes it possible to get a resolution of thousand times better than with a light microscope to gain detailed information on its structure and composition of the materials. If an electron with mass $m$ is accelerated through a potential $\mathrm{eV}$ ( $\mathrm{V}$ in volts), then wavelength of the electron is

$$
\lambda=\sqrt{\frac{h^{2}}{2 m e V}}=\frac{1.23 n m}{\sqrt{V}}
$$

Thus for an accelerating voltage of $100 \mathrm{~V}$, wavelength of the beam will be just at atomic scale to get diffracted by electrons. A bunch of electrons is created in ultra high vacuum using electron guns. This bunch is accelerated towards the specimen placed at positive electrical potential. Before hitting the sample, the electron beam is focused into a thin, monochromatic beam by the condenser lenses, which also control the brightness of the beam, and condenser aperture. The electrons which are elastically scattered transmit through the sample and pass through objective lens which forms the image display. If the sample is too thin there will be little 
diffraction and if the sample is too thick there will be too much of scattering which gives blurred image. Objective area aperture and selected area aperture are used to choose elastically scattered electrons. Finally the beam goes into projector lens which expands the beam onto a phosphor screen or seen in a monitor.

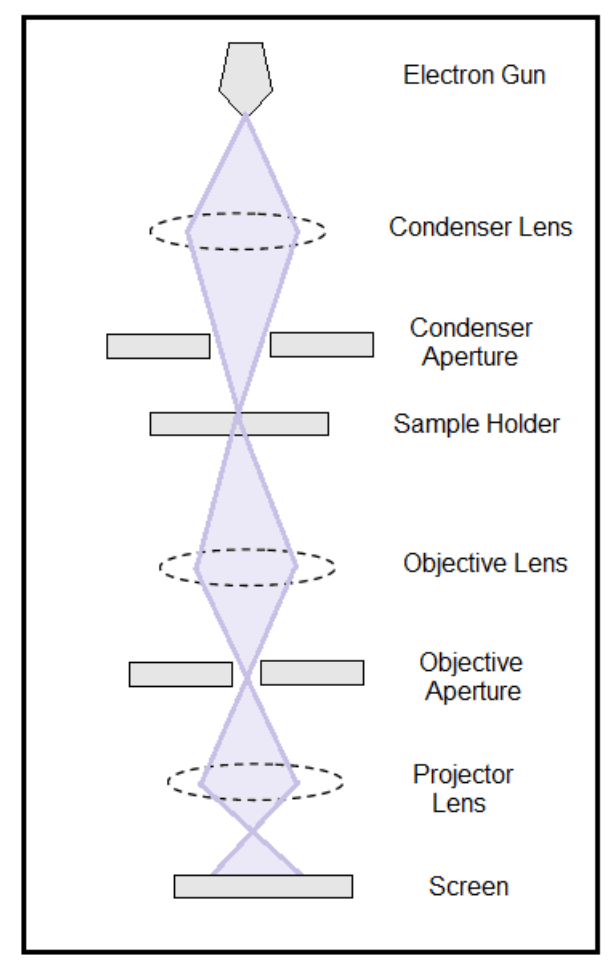

\section{Figure 3: Transmission Electron Microscope}

Different kinds of images can be produced by controlling the apertures and types of interacted electrons. Basically three kinds of electrons participate during the interaction First are the unscattered electrons which transmit through the sample without any interaction giving Bright Field Image. Second are the elastically scattered electrons i.e. diffracted electrons which show diffraction patterns. These patterns can yield information about orientation, lattice arrangements and phase of the examined sample. Dark Field Images are obtained if diffracted beams are selected by the objective aperture. Third one is inelastically scattered electron which 
can be utilized for electron energy loss spectroscopy (EELS) and Kikuchi bands. The operation of TEM requires an ultra high vacuum environment under a high voltage. In transmission microscopy, sample's structure and atomic columns can be physically seen giving the compositional and crystallographic information.

\subsubsection{TEM Data analysis}

TEM micrograph image gives information about the particle sizes and their morphology. Images in Figure 4 show that most of the nanoparticles are nearly spherical in shape and the atomic planes show the crystallinity of the particles. Sizes of approximately $10-15$ particles have been measured and an average has been taken. Figure 4 (a) shows the bright field image of undoped $\mathrm{CeO}_{2}$ sample annealed at $\mathrm{T}_{\mathrm{a}}=400^{\circ} \mathrm{C}$. Similarly, bright field images of $2.5 \%, 5 \%, 7.5 \%$ and $10 \% \mathrm{Cu}$-doped $\mathrm{CeO}_{2}$ have been shown in figures 4(b), 4(c), 4(d) and 4(e) respectively. As all the above samples are annealed at same temperature similar particle sizes are expected for each of them. Table 2 shows the average particle size of the undoped and doped $\mathrm{CeO}_{2}$ samples.

Table 2: Average Particle Size using TEM Analysis

\begin{tabular}{|c|c|}
\hline Cu \% & $\begin{array}{c}\text { Avg. Particles Sizes } \\
\text { (nm) }\end{array}$ \\
\hline $\mathbf{0}\left(\mathbf{T}_{\mathbf{a}}=\mathbf{4 0 0}^{\mathbf{0}} \mathbf{C}\right)$ & $6.5 \pm 0.5$ \\
\hline $\mathbf{2 . 5}$ & $7.0 \pm 0.6$ \\
\hline $\mathbf{5}$ & $5.5 \pm 0.6$ \\
\hline $\mathbf{7 . 5}$ & $5.3 \pm 0.5$ \\
\hline $\mathbf{1 0}$ & $6.6 \pm 0.4$ \\
\hline
\end{tabular}




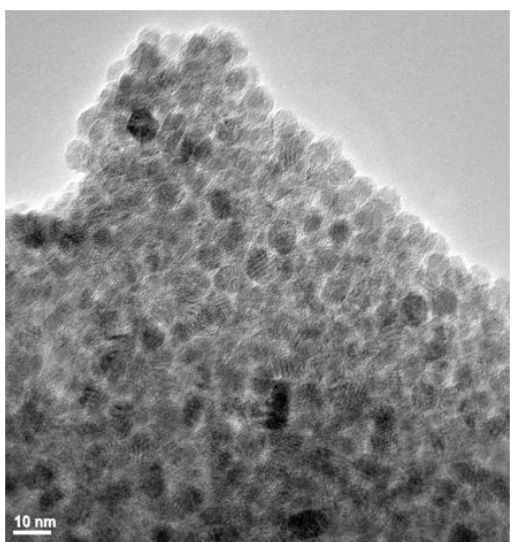

(a)

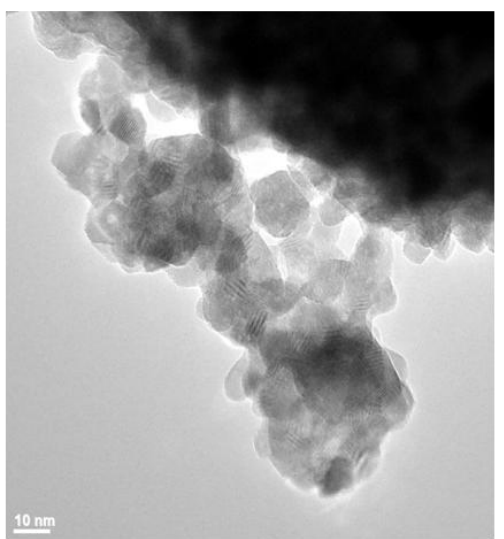

(b)

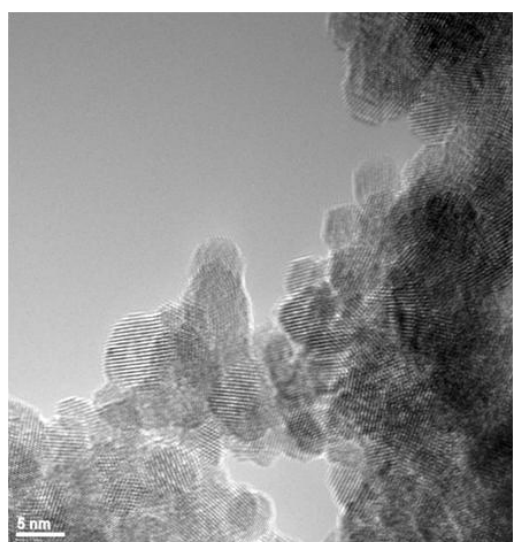

(c)

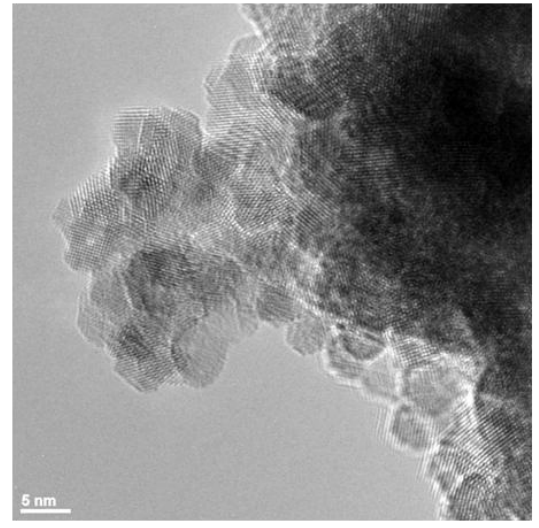

(d)

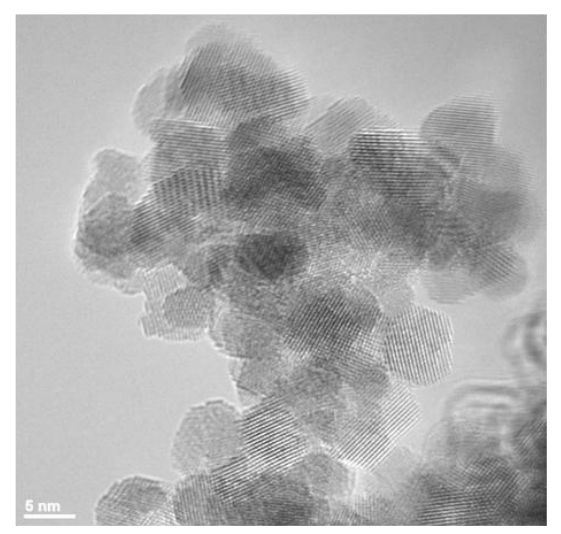

(e)

Figure 4: TEM images of (a) Undoped Sample $(132 \mathrm{~nm} \times 132 \mathrm{~nm})$, (b) $\mathrm{Cu}_{0.025} \mathrm{Ce}_{0.975} \mathrm{O}_{2}$ $(132 \mathrm{~nm} \times 132 \mathrm{~nm})$, (c) $\mathrm{Cu}_{0.05} \mathrm{Ce}_{0.95} \mathrm{O}_{2}(52 \mathrm{~nm} \times 52 \mathrm{~nm})$, (d) $\mathrm{Cu}_{0.075} \mathrm{Ce}_{0.925} \mathrm{O}_{2}(52 \mathrm{~nm} \times 52 \mathrm{~nm})$, (e) $\mathrm{Cu}_{0.1} \mathrm{Ce}_{0.9} \mathrm{O}_{2}(52 \mathrm{~nm} \times 52 \mathrm{~nm})$

\subsubsection{X-Ray Diffraction (XRD)}

X-Ray diffraction is a powerful elemental analysis technique which relies on Von Laue's discovery (1912) of x-ray diffraction by crystalline substances. These diffracted rays give us the information on structural arrangement of atoms in the matter. X-ray is a part of electromagnetic wave spectrum with wavelength of 0.01 to $10 \mathrm{~nm}$ (for visible its $390-750 \mathrm{~nm}$ ). X-rays with wavelength 0.2 to $2.5 \AA$ are used for diffraction studies. They exhibit dual nature i.e. in some conditions behaving like a particle and in other conditions behaving like wave. The theoretical 
explanation on XRD in this section is based on the book "X-ray diffraction procedures for polycrystalline and amorphous materials" by H.P. Klug and L.E. Alexander [24]. The X-ray technique mainly consists of an x-ray emitter, sample holder and detector.

X-rays are generally produced by two types of interactions between atoms and incoming high speed electrons. One being when a high speed electron collides with a target atom it dislocates a tightly bound inner core electron by exciting the atom. The excited atom deexcites when an electron from outer shell falls into the vacant inner shell and releases an x-ray. The energy of this photon is the difference between the transition levels and has characteristics unique to the atom involved.
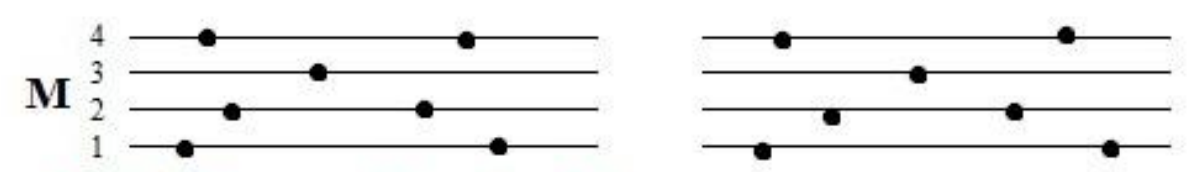

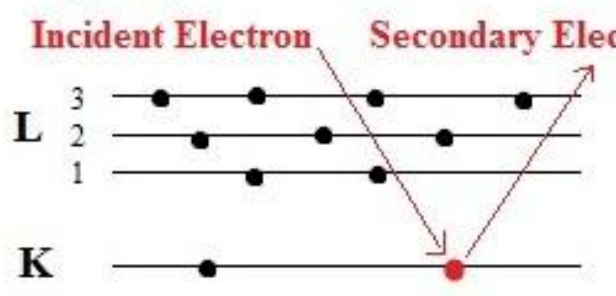

1. Knock out State

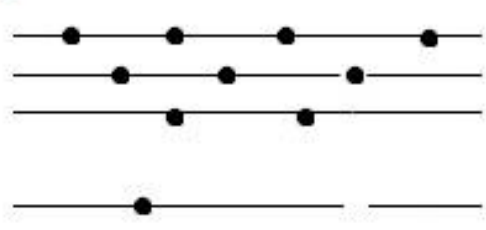

2. Excitation State

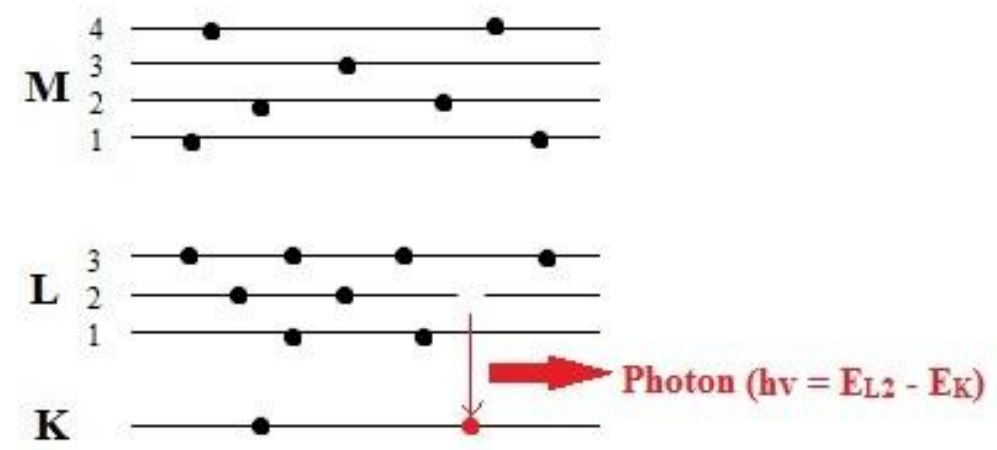

3. De-Excitation State

Figure 5: Production of X-Rays 
Another way of producing an x-ray is when the high speed electron is slowed by the electromagnetic force of a nucleus of an atom. The reduced energy $\Delta \mathrm{E}$ changes into $\mathrm{x}$-ray photon with frequency $v$.

$$
\Delta \mathrm{E}=\mathrm{hu}, \text { where } \mathrm{v} \text { is Planck's constant }
$$

X-rays produced like this are independent of the atoms being bombarded. Spectrum consists of two parts, a continuous spectra composed of wide band wavelengths called white or general radiation resulting from the deceleration of the high-energy electrons by the electric fields of the target atoms. It becomes more intense and shifts towards higher frequencies when the energy of the accelerated particles is increased. When a high enough voltage is applied, characteristic radiation lines are produced which superimpose on the continuous background. These peaks are characteristic to the element and the order of length of wavelength produced by atomic shells is $\mathrm{N}>\mathrm{M}>\mathrm{L}>\mathrm{K}$. For a $\mathrm{K}$ shell vacancy, if an $\mathrm{L}$ shell electron fills the vacancy $\mathrm{K}_{\alpha}$ line is emitted and if $M$ shell electron fills the vacancy $K_{\beta}$ line is emitted. $K_{\alpha}$ is more intense and longer wavelength line and has two closely bounded lines or doublets $\mathrm{K}_{\alpha 1}$ and $\mathrm{K}_{\alpha 2}$ with intensity ratios 2:1 respectively. Similarly, $\mathrm{K}_{\beta}$ is less intense and is a lower wavelength line which also has doublets $\mathrm{K}_{\beta 1}$ and $\mathrm{K}_{\beta 2}$. This is shown in figure 6 below. Usually $\mathrm{K}_{\beta}$ lines are filtered in XRD studies due to their low intensities. Similarly, filling L shell vacancy emits L series lines. The wavelength of the emitted photon depends on the transition level and element used at anode.

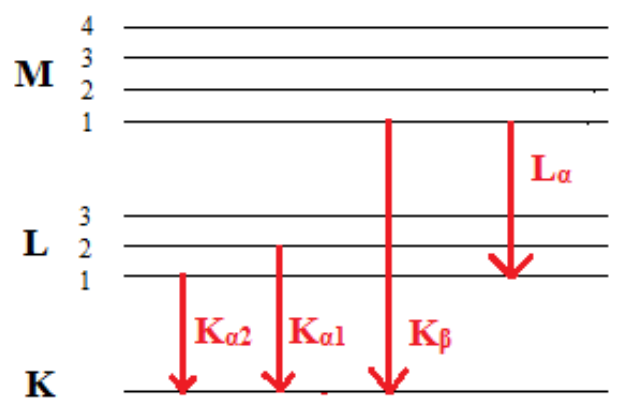

Figure 6: Energy Lines from Different Levels 
Emitted X-rays are filtered to make it monochromatic i.e. allowing only useful $\mathrm{K}_{\alpha}$ lines and removing $\mathrm{K}_{\beta}$, continuous and even fluorescent X-rays and also collimated before the radiation strikes the sample. This removes unnecessary and harmful radiation and simplifies the data analysis. The produced x-rays are directed towards the sample and get diffracted from the sample without change in the wavelength (coherent or Bragg Scattering). The diffracted X-rays are detected using a detector which determines the quality, reliability and throughput of the pattern. The position and intensity of the observed peaks in the diffraction pattern lead to knowledge of fundamental properties like size, shape and orientation of the unit cell.

Table 3 : Targets often used in X-Ray Diffraction Studies

\begin{tabular}{|c|c|c|c|c|c|}
\hline Element & $\begin{array}{c}\mathbf{K}_{\boldsymbol{\alpha} \mathbf{1}} \\
(\mathbf{\AA})\end{array}$ & $\begin{array}{c}\mathbf{K}_{\boldsymbol{\alpha} \mathbf{2}} \\
(\mathbf{\AA})\end{array}$ & $\begin{array}{c}\text { Unresolved } \mathbf{K}_{\boldsymbol{\alpha}} \\
(\boldsymbol{\AA})\end{array}$ & $\begin{array}{c}\mathbf{K}_{\boldsymbol{\beta} \mathbf{1}} \\
(\mathbf{\AA})\end{array}$ & $\begin{array}{c}\text { Excitation } \\
\text { Potential } \\
(\mathbf{k V})\end{array}$ \\
\hline $\mathrm{Ag}$ & 0.5594 & 0.5638 & 0.5608 & 0.497 & 25.52 \\
\hline $\mathrm{Mo}$ & 0.7093 & 0.7135 & 0.7107 & 0.6322 & 20.00 \\
\hline $\mathrm{Cu}$ & 1.5405 & 1.5443 & 1.5418 & 1.3806 & 8.98 \\
\hline $\mathrm{Ni}$ & 1.6579 & 1.6617 & 1.6591 & 1.4881 & 8.33 \\
\hline $\mathrm{Co}$ & 1.7889 & 1.7928 & 1.7902 & 1.6082 & 7.71 \\
\hline $\mathrm{Fe}$ & 1.93604 & 1.9399 & 1.9373 & 1.7435 & 7.11 \\
\hline $\mathrm{Cr}$ & 2.2897 & 2.2936 & 2.291 & 2.0702 & 5.99 \\
\hline
\end{tabular}

The most useful range of wavelength for diffraction purpose is 0.56 to $2.29 \AA$. Elements like $\mathrm{Ag}, \mathrm{Mo}, \mathrm{Cu}, \mathrm{Co}, \mathrm{Fe} \mathrm{Cr}$ and $\mathrm{Ni}$ falling in this range are used to produce $\mathrm{x}$-rays for diffraction studies. Table 3 shows the targets often used in x-ray diffraction studies [24]. The radiation from lower atomic number elements is readily absorbed by windows and air. The heavier atoms produce highly intense radiation which is harder to process. The most commonly used element for XRD studies is copper due to strong $\mathrm{K}_{\alpha}$ and $\mathrm{K}_{\beta}$ lines and its high thermal conductivity which helps to cool while operation. The wavelength of the radiation emitted corresponding to the minimum voltage required to excite an atom is called quantum wavelength. Wavelength limits of 
the radiation and the distribution of the intensity within are determined by the magnitude of the applied voltage. With increasing potential on the tube, intensity of the wavelengths also increases. Practically voltages far higher than critical excitation voltage are applied to get optimum intensity of the characteristic lines with respect to continuous spectrum. According to theoretical studies of Witty and Wood [25], a factor of 3.5 to 5 is practically used with respect to critical excitation voltage. For example excitation potential of copper is $8.98 \mathrm{kV}$. But for practical diffraction application $30-50 \mathrm{kV}$ of voltage is used. Table 3 shows some of the elements used in diffraction studies and their respective excitation voltages.

Room temperature XRD patterns were taken on Rigaku diffractometer with $\mathrm{CuK}_{\alpha}$ radiation with a wavelength of $0.5418 \mathrm{~nm}$. Data scans were taken from $5^{\circ}$ to $100^{\circ}$ in $0.06^{\circ}$ steps with a time interval of 5 seconds. Applied voltage was $30 \mathrm{kV}$ and filament current was $40 \mathrm{~mA}$. Studies were carried on samples annealed at $\mathrm{T}_{\mathrm{a}}=25^{\circ} \mathrm{C}, 200^{\circ} \mathrm{C}, 400^{\circ} \mathrm{C}, 550^{\circ} \mathrm{C}, 700^{\circ} \mathrm{C}$ and $800^{\circ} \mathrm{C}$ for undoped $\mathrm{CeO}_{2}$ as shown in Figure 8. Also XRD studies were done on $\mathrm{T}_{\mathrm{a}}=400^{\circ} \mathrm{C}$ annealed samples of $\mathrm{Cu}_{\mathrm{x}} \mathrm{Ce}_{1-\mathrm{x}} \mathrm{O}_{2}$ with $\mathrm{x}=0.025,0.05,0.075$ and 0.1 showed in Figure 9. Note that from Figures $8 \& 9$, the intensity of the peaks can be related to the intesity factors described above especially with atomic structure factor. In Figure 7, XRD patterns of undoped samples clearly show no formation of any impurities apart from crystalline $\mathrm{CeO}_{2}$. Similalrly, $\mathrm{Cu}$ doped samples show no phase of copper or any other oxides of copper suggesting successful doping of copper into $\mathrm{CeO}_{2}$ lattice. All peak in undoped and doped samples were matched to the cubic $\mathrm{CeO}_{2}$ reference lines obtained using PDF\# 01-73-6328 in ICDD powder diffraction database. 


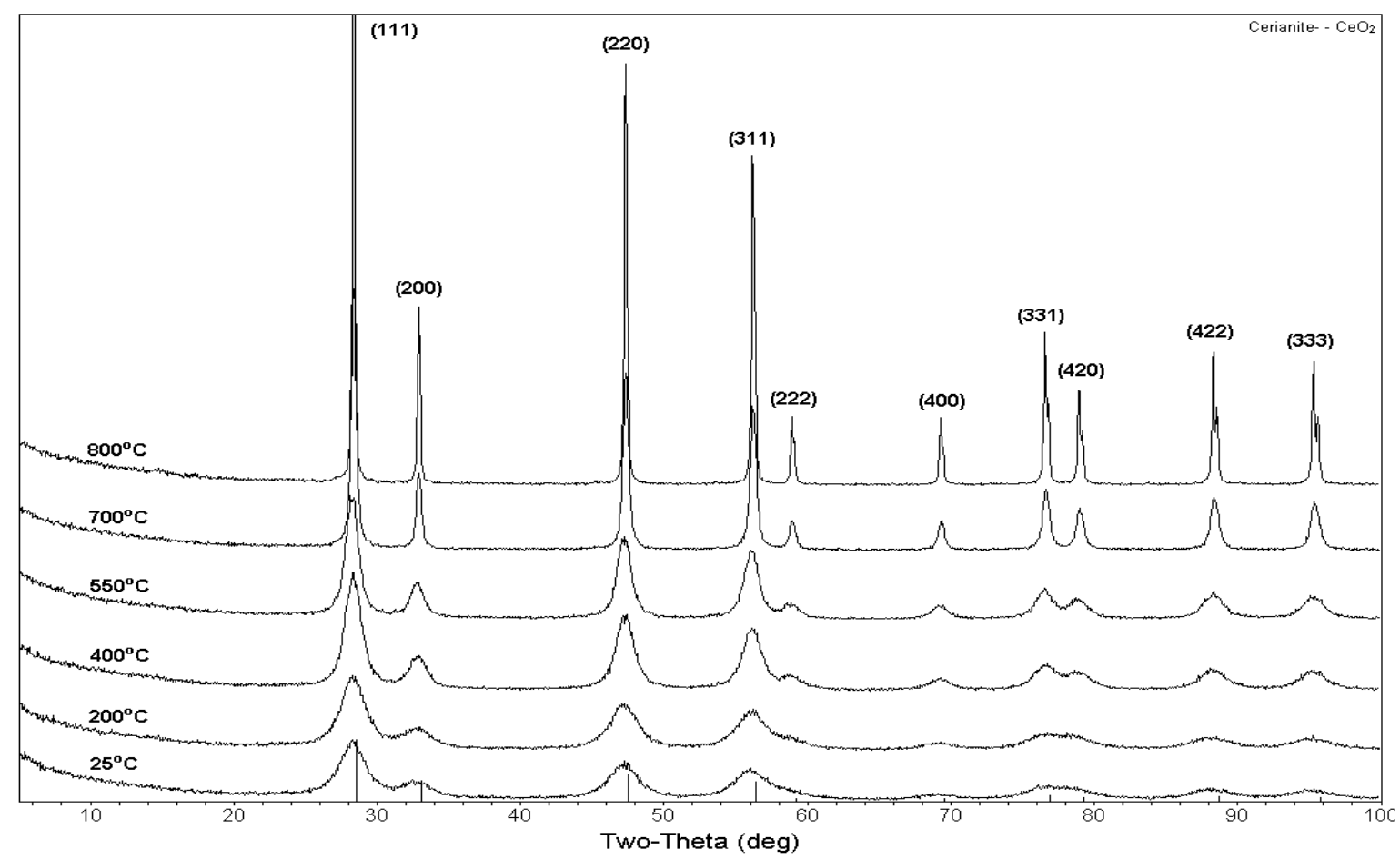

Figure 7: XRD Patterns of Undoped $\mathrm{CeO}_{2}$

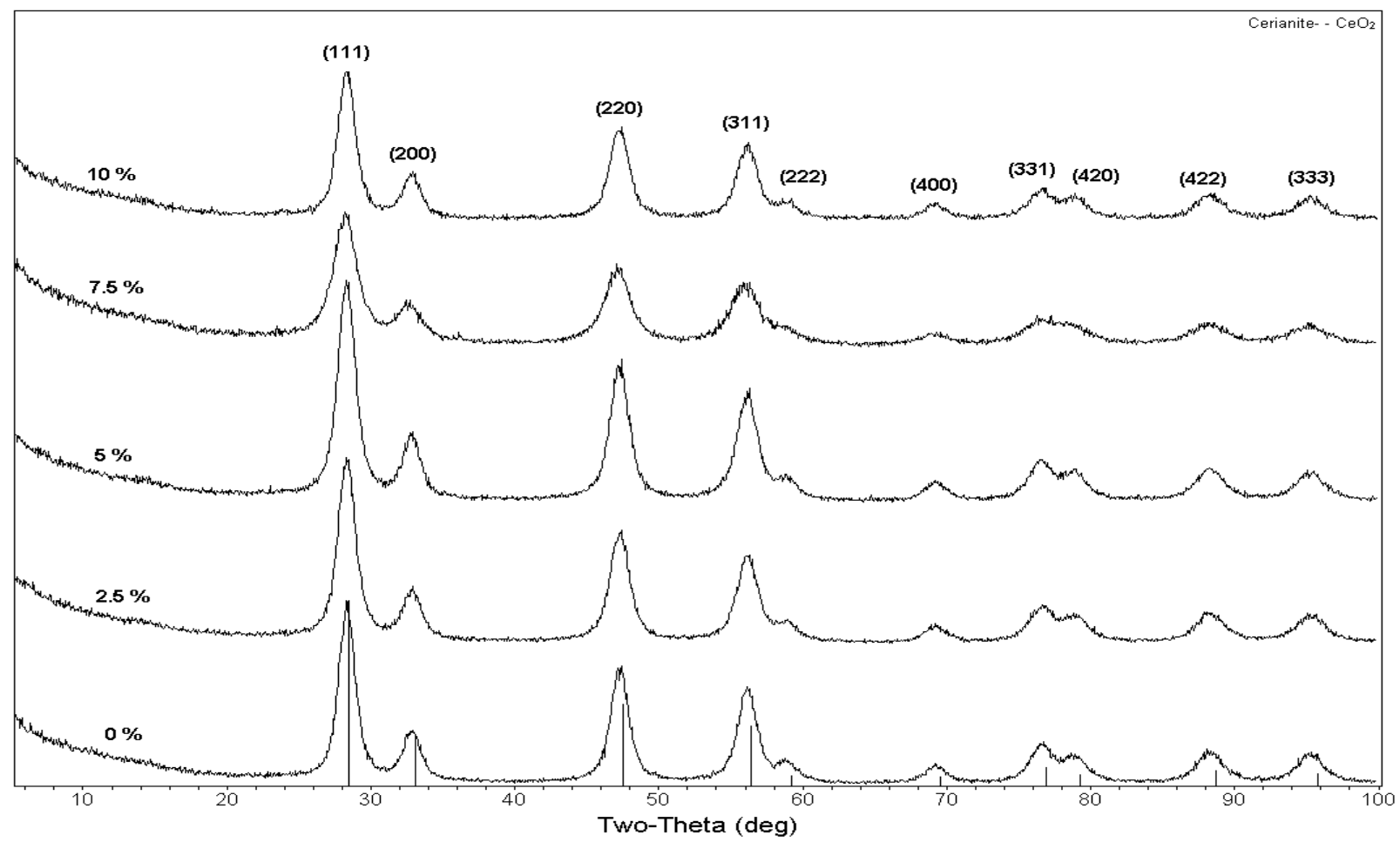

Figure 8: XRD Patterns of Cu-doped $\mathrm{CeO}_{2}$ 


\subsubsection{Particle Size Calculations}

As mentioned above, X-ray diffraction can be used to calculate the grain sizes of the particles. Modified Debye -Sherrer relation or Williamson-Hall relation [26] is used to evaluate the size and strain broadening by measurement of peak width. The Williamson-Hall relation is,

$$
\beta \operatorname{Cos} \theta=\eta \operatorname{Sin} \theta+\frac{o .89 \lambda}{D} \text { where } \beta^{2}=\beta_{M}^{2}-\beta_{s}^{2}
$$

where $\beta$ is corrected full width at half maximum (in radians), $\quad \theta$ is angle of diffraction (in degrees), $\eta$ is the strain in the lattice, $\lambda$ is the wavelength of incident beam $(1.5418 \AA), D$ is the calculated grain size, $\beta_{M}$ is the FWHM of the measured peak in the pattern and $\beta_{S}$ is the FWHM of a standard sample $\left(\mathrm{SiO}_{2}\right)$ representing instrumental width [32]. In Figure 7, the width of peaks of undoped $\mathrm{CeO}_{2}$ samples reduces with increase in annealing temperatures suggesting that particle sizes tend to become larger with increasing annealing temperatures due to thermodynamically driven Oswald ripening. From the above equation (2.9), reduction in peak widths infers increase in particle size and/or reduction in strain. Since all $\mathrm{Cu}$-doped samples are annealed at same temperature, peak widths of the samples are unchanged. As the grain size becomes larger and larger, the FWHM of the diffraction peaks become smaller and smaller and at a stage it will be nearly equal to instrumental width $\beta_{\mathrm{S}}$. This produces large errors in $\beta$ and so D cannot be calculated accurately. Therefore, this relationship can be used only for the samples with crystalline sizes less than $\sim 100 \mathrm{~nm}$. Using the plot $\beta \operatorname{Cos} \theta$ vs $\operatorname{Sin} \theta, \mathrm{D}$ is determined from the intercept $(0.89 \lambda / D)$ and the strain $(\eta)$ from the slope. Figure 10 and figure 12 show the $\beta \operatorname{Cos} \theta$ vs $\operatorname{Sin} \theta$ plots for undoped and doped samples respectively with the calculated values of $D$ and $\eta$ shown in Tables 5 and 6. 


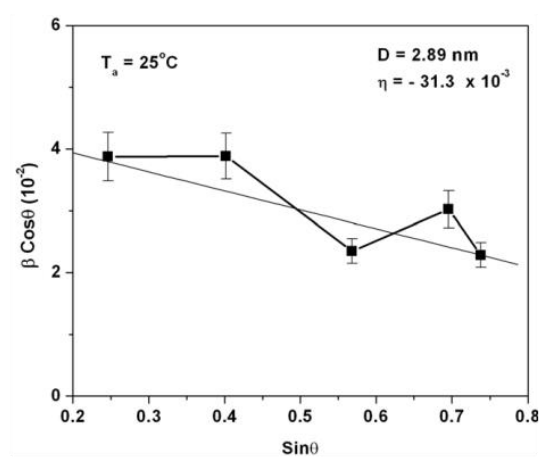

(a)

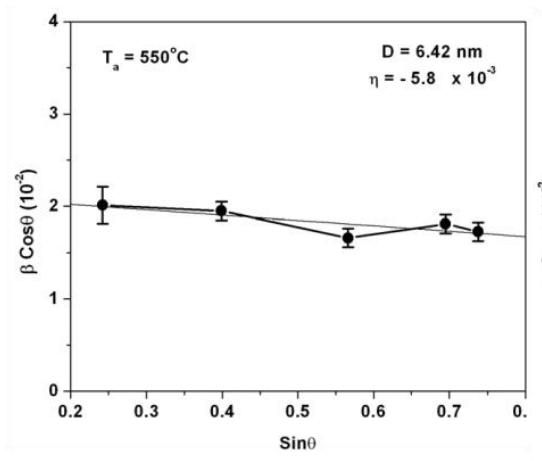

(c)

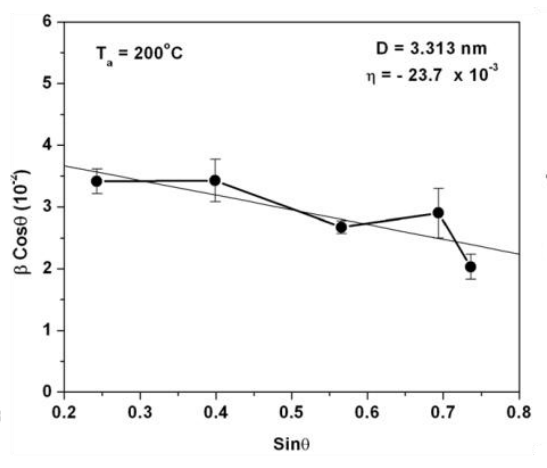

(b)

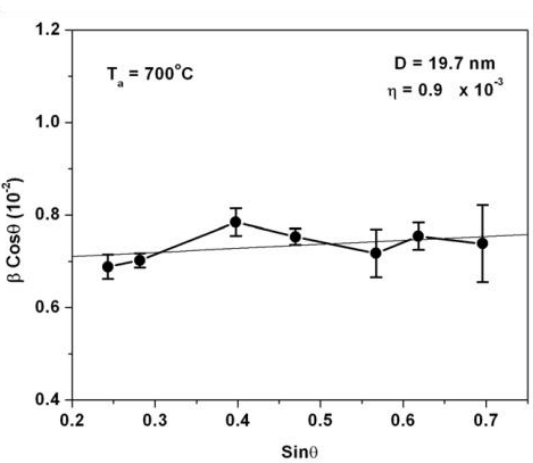

(d)

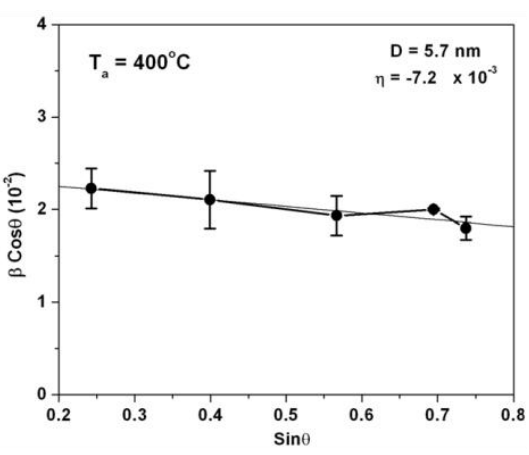

(c)

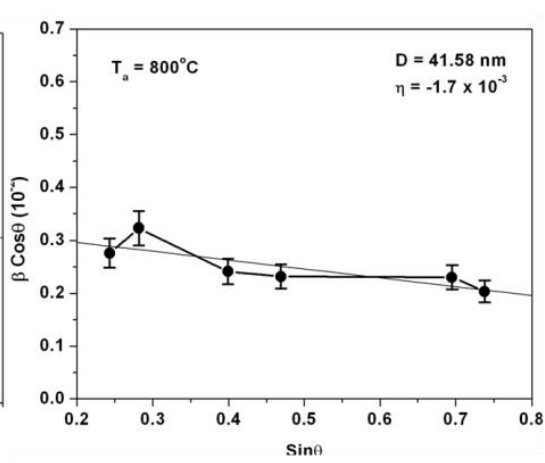

(e)

Figure 9: $\beta \operatorname{Cos} \theta$ vs $\operatorname{Sin} \theta$ Plots for Undoped $\mathrm{CeO}_{2}$ Samples

Table 4: Particle Size and Strain for Undoped $\mathrm{CeO}_{2}$ Samples from XRD Patterns

\begin{tabular}{|c|c|c|}
\hline $\left.\mathbf{T}_{\mathbf{a}} \mathbf{}^{\mathbf{}} \mathbf{C}\right)$ & $\begin{array}{c}\text { Particle Size (nm) } \\
(\mathbf{D})\end{array}$ & $\begin{array}{c}\text { Strain } \\
(\mathbf{( 1 0}\end{array}$ \\
\hline $\mathbf{2 5}$ & $2.9 \pm 0.3$ & $-31.3 \pm 1$ \\
\hline $\mathbf{2 0 0}$ & $3.3 \pm 0.2$ & $-23.7 \pm 0.2$ \\
\hline $\mathbf{4 0 0}$ & $5.7 \pm 0.8$ & $-7.2 \pm 0.6$ \\
\hline $\mathbf{5 5 0}$ & $6.4 \pm 0.3$ & $-5.8 \pm 0.3$ \\
\hline $\mathbf{7 0 0}$ & $19.7 \pm 0.9$ & $0.9 \pm 1.2$ \\
\hline $\mathbf{8 0 0}$ & $41.6 \pm 0.5$ & $-1.7 \pm 0.7$ \\
\hline
\end{tabular}

As expected it can be observed from Table 5 that annealing the samples to higher temperatures has caused increase in particle size. Again increase in particle size is due to Oswald ripening where smaller particles dissolve over time to reform into a larger particle while heating. And this formation affects the strain in the sample. It can be observed a uniform decrease in 
strain with increasing particle size. Larger particles have lower surface area per unit volume thus reducing the strain. High strain in the lattice may lead to lattice expansions to relieve the strain. Figure 11 shows the variations in particle size and strains of undoped samples with respect to annealing temperature $\left(\mathrm{T}_{\mathrm{a}}\right)$.

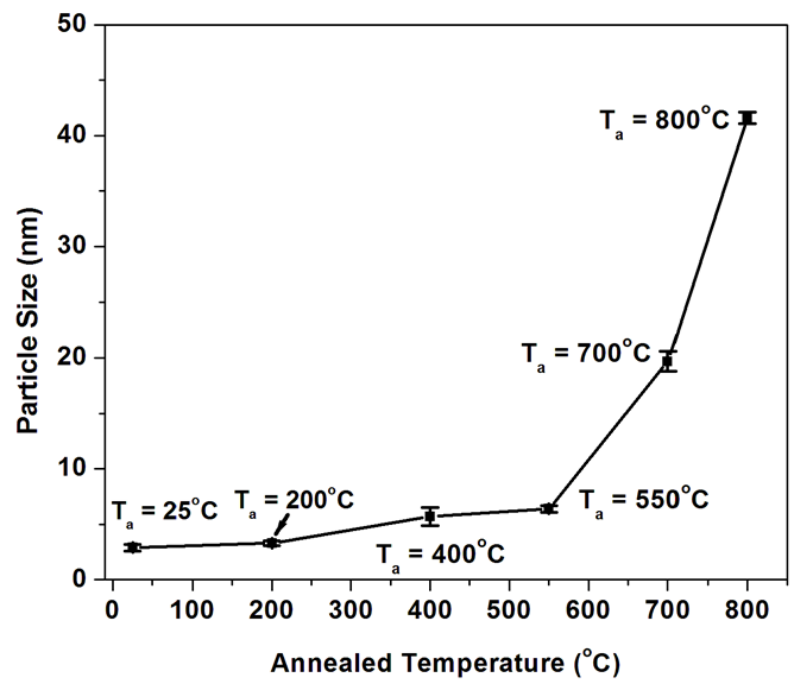

(a)

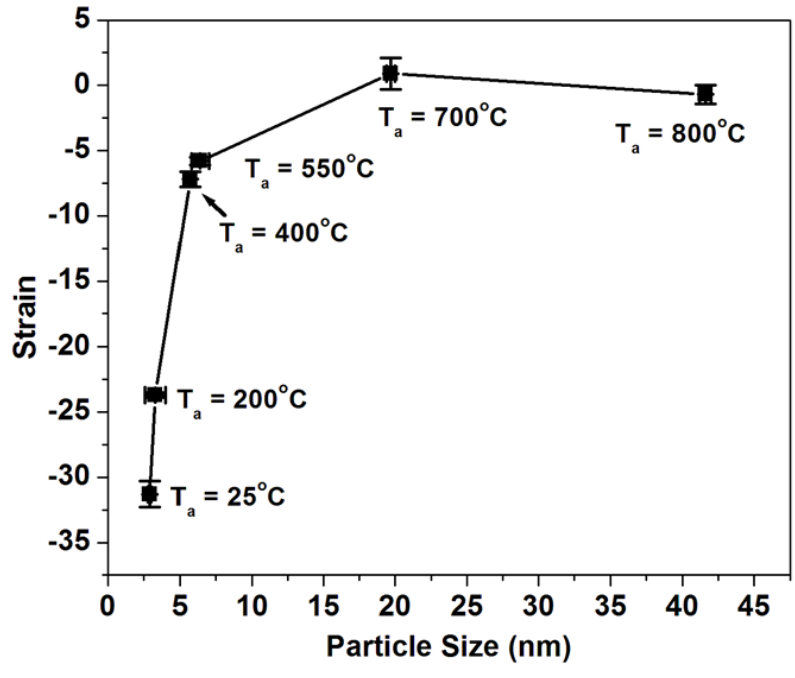

(b)

Figure 10: D vs $\mathrm{T}_{\mathrm{a}} \& \boldsymbol{\eta}$ vs D Plots of Undoped $\mathrm{CeO}_{2}$ 

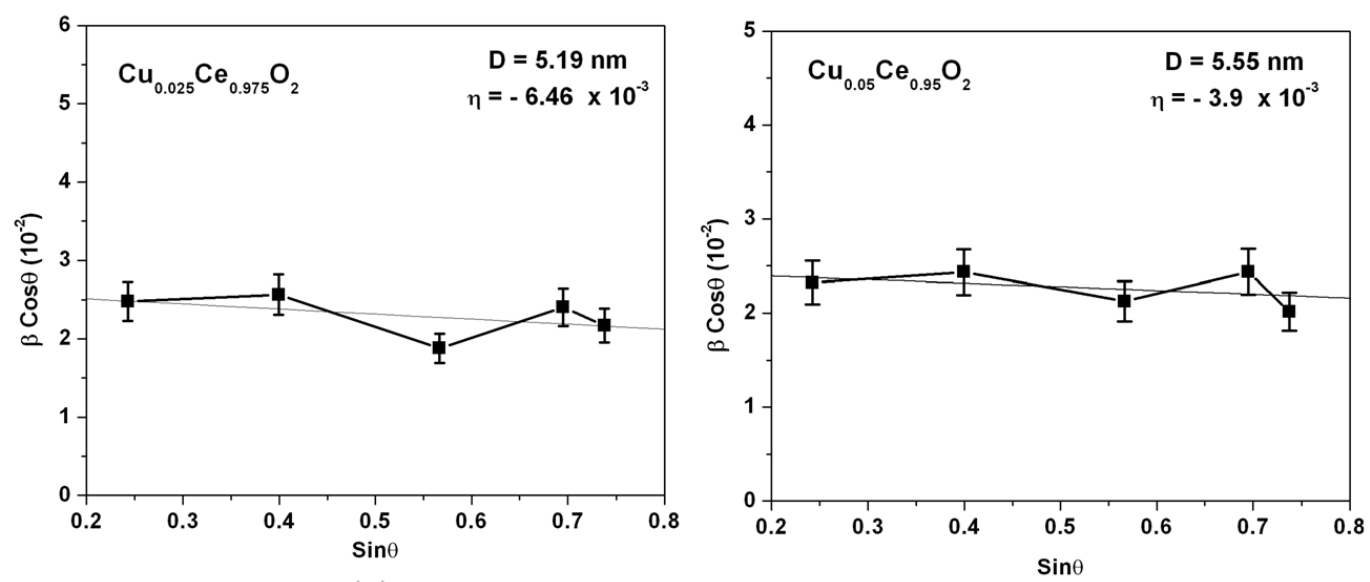

(a)

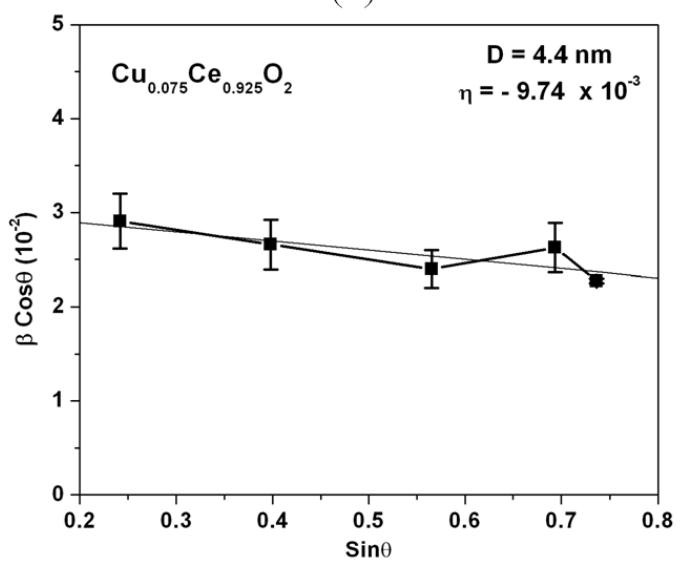

(c) (b)

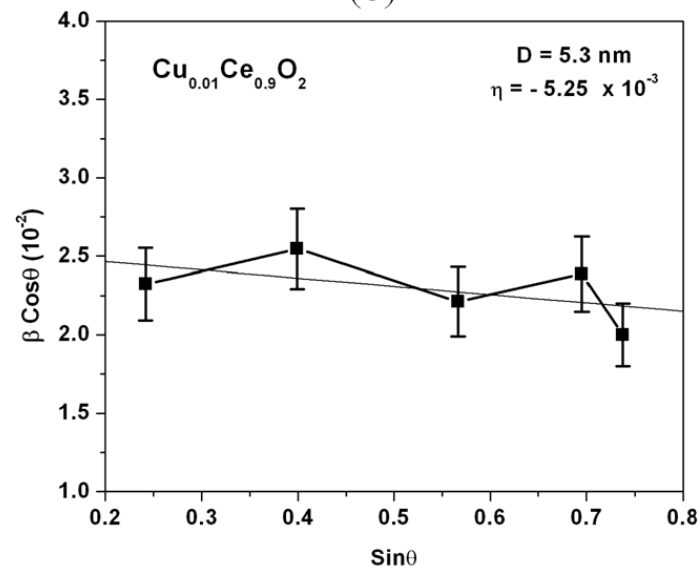

(d)

Figure 11: $\beta \operatorname{Cos} \theta$ vs $\operatorname{Sin} \theta$ Plots of $\mathrm{Cu}$-doped $\mathrm{CeO}_{2}$ Samples

Table 5: Particle Size and Strain of Cu-doped $\mathrm{CeO}_{2}$ Samples

\begin{tabular}{|c|c|c|c|}
\hline Cu \% & $\begin{array}{c}\text { Particle Size (nm) } \\
\text { (XRD) }\end{array}$ & $\begin{array}{c}\text { Particle Size (nm) } \\
\text { (TEM) }\end{array}$ & $\begin{array}{c}\text { Strain } \mathbf{( 1 0}^{-3} \text { ) } \\
(\boldsymbol{\eta})\end{array}$ \\
\hline $\mathbf{2 . 5}$ & $5.2 \pm 0.3$ & $7.0 \pm 0.6$ & $-6.5 \pm 0.4$ \\
\hline $\mathbf{5}$ & $5.5 \pm 0.3$ & $5.5 \pm 0.6$ & $-3.9 \pm 0.6$ \\
\hline $\mathbf{7 . 5}$ & $4.4 \pm 0.5$ & $5.3 \pm 0.5$ & $-9.7 \pm 0.1$ \\
\hline $\mathbf{1 0}$ & $5.3 \pm 0.1$ & $6.6 \pm 0.4$ & $-5.3 \pm 0.5$ \\
\hline
\end{tabular}

Table 6 shows the particle size and strain calculations for $\mathrm{Cu}$-doped cerium oxides. As all the samples are annealed at same temperature $\left(\mathrm{T}_{\mathrm{a}}=400^{\circ} \mathrm{C}\right)$ there is no significant difference in the size of the particles. TEM calculates physical particle size and XRD calculates grain size. At 
nanoscale grain size and particle size are considered to be almost equal. TEM and XRD data match to an extent with difference of $1 \mathrm{~nm}$ approximately. No systematic change in strain has been noticed with $\mathrm{Cu}$-doping concentration whereas Wang et. al. [22] have reported increase in strain with increasing $\mathrm{Cu}$-doping concentration.

\subsubsection{Lattice Constant}

Planes in crystalline structure contribute to diffraction of the x-rays. The x-ray interaction with crystalline planes can be explained using Bragg's law, one of the groundbreaking principles on which x-ray diffraction study is based. A simple geometric interpretation for constructive interference was given by William Lawrence Bragg in 1912. According to Bragg's law, when a monochromatic radiation of wavelength $\lambda$ strikes the atomic planes with spacing $d$ and with an angle $\theta$ then,

$$
2 d \operatorname{Sin} \theta=n \lambda
$$

i.e. the path difference between the waves reflected by successive planes should be an integral multiple of the respective wavelength $(n \lambda)$ for diffraction to occur. This is the one of the conditions for maximum intensity. As mentioned above cerium oxide has a fluorite structure i.e. it is a cubic system. Using simple geometry, the relationship between the lattice constant $(a)$ i.e. the distance between the atoms in a diffracting plane and the distance between diffracting planes $d_{h k l}$ in a fluorite structure is

$$
a=d_{h k l} \sqrt{h^{2}+k^{2}+l^{2}}
$$

where $(h k l)$ is the corresponding Miller indices of the plane. Using equations (2.11) and (2.12),

$$
n \lambda=a \frac{2 \sin \theta}{\sqrt{h^{2}+k^{2}+l^{2}}}
$$


In Figure 12, the rays scattered at A and B must be in phase for a constructive interference. The path difference $\mathrm{CB}+\mathrm{BD}$ must be an integral multiple of the incident wavelength.

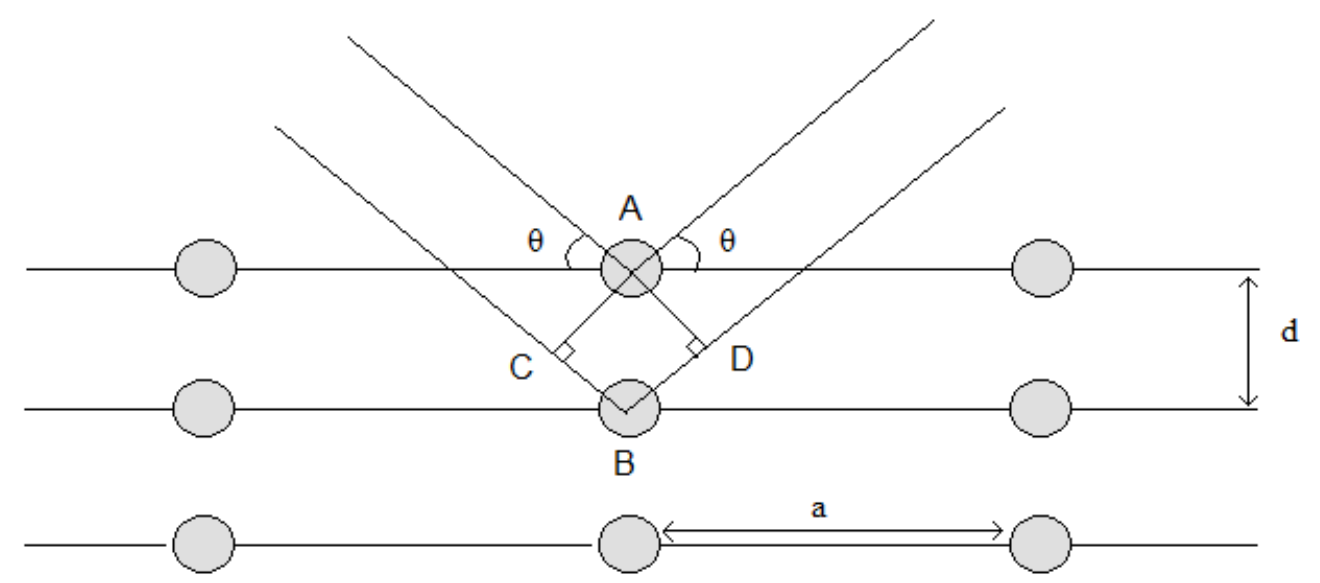

Figure 12: Bragg's Law

From equations $2.11 \& 2.12$, variations in the lattice constant $(a)$, d-spacing of the planes of the cerium oxide crystal can be calculated which helps to understand the mechanism of doping in the lattice. All the calculations have been done with reference to (220) peak. Table $7 \& 8$ show the lattice constant values of undoped and $\mathrm{Cu}$-doped cerium oxides respectively.

Table 6: Lattice Constant Values of Undoped $\mathrm{CeO}_{2}$ Samples

\begin{tabular}{|c|c|}
\hline $\mathbf{T}_{\mathbf{a}}\left({ }^{\mathbf{0}} \mathbf{C}\right)$ & Lattice Constant $(\mathbf{\AA})$ \\
\hline $\mathbf{2 5}$ & $5.467 \pm 0.001$ \\
\hline $\mathbf{2 0 0}$ & $5.467 \pm 0.001$ \\
\hline $\mathbf{4 0 0}$ & $5.466 \pm 0.001$ \\
\hline $\mathbf{5 5 0}$ & $5.465 \pm 0.001$ \\
\hline $\mathbf{7 0 0}$ & $5.454 \pm 0.001$ \\
\hline $\mathbf{8 0 0}$ & $5.453 \pm 0.003$ \\
\hline
\end{tabular}




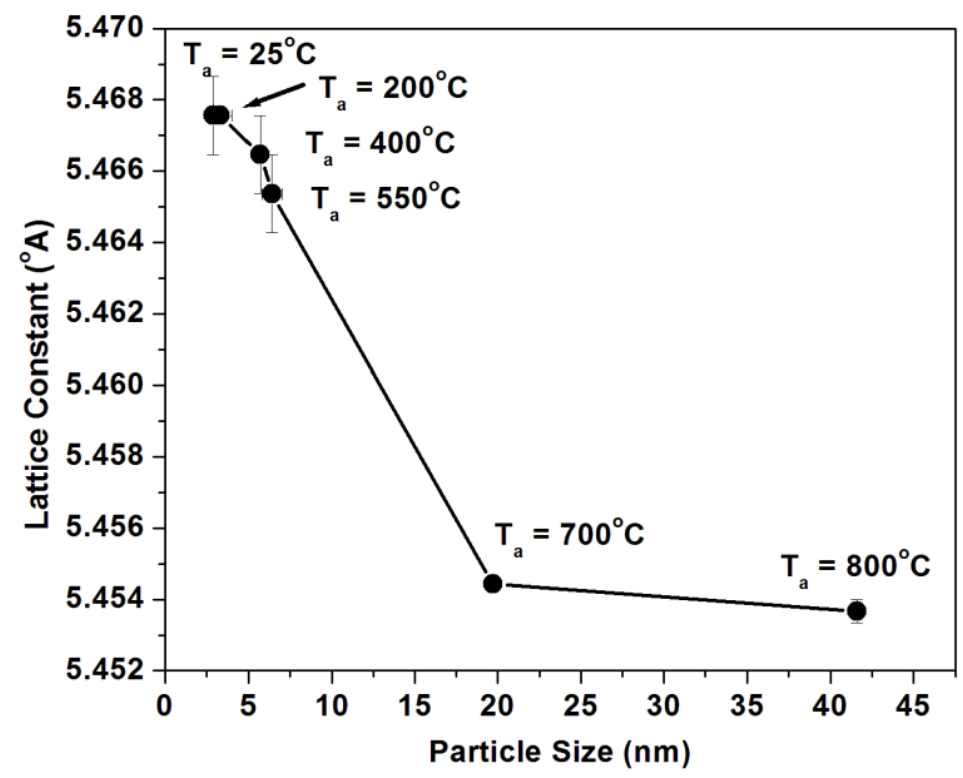

Figure 13: Plot for Lattice Constant vs Particle Size for Undoped $\mathrm{CeO}_{2}$ Samples

From particle size measurements for undoped samples, it has been found that with increasing annealing temperatures the particle sizes increases (Figure 13). With increment in particle size decrement in d-spacing $(d)$ is observed. As $d$-spacing is directly proportional to lattice constant $(a)$, with annealing temperatures there is a decrease in lattice constant $(a)$. The same phenomenon was reported by Tsunekawa et. al. [11,12]. Zou et. al. [27] suggested that surface stress on ceria particles may be the reason behind the change in the lattice parameter.

Table 7: Lattice Constant Values of $\mathrm{Cu}$-doped $\mathrm{CeO}_{2}$

\begin{tabular}{|c|c|}
\hline $\mathbf{C u} \%$ & Lattice Constant $(\AA)$ \\
\hline $\mathbf{2 . 5}$ & $5.4606 \pm 0.0005$ \\
\hline $\mathbf{5}$ & $5.4638 \pm 0.0006$ \\
\hline $\mathbf{7 . 5}$ & $5.4785 \pm 0.0003$ \\
\hline $\mathbf{1 0}$ & $5.4620 \pm 0.0009$ \\
\hline
\end{tabular}




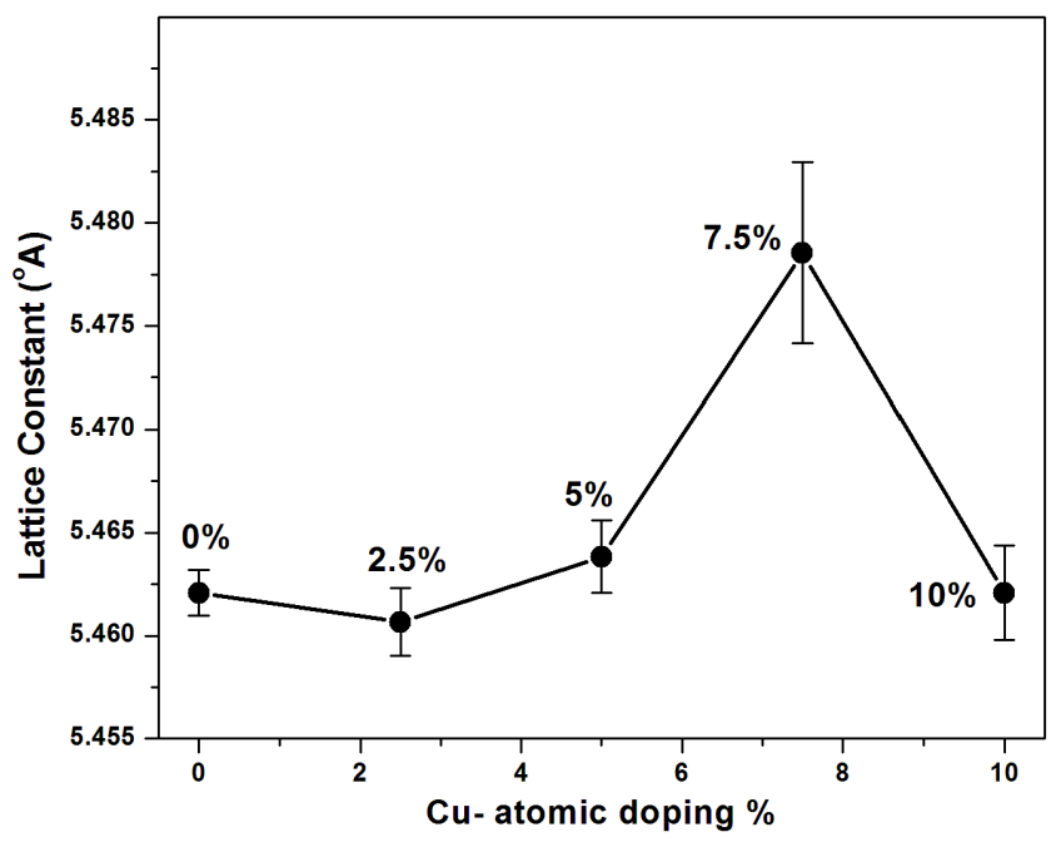

Figure 14: Lattice Constant vs Doping \% Plot of Cu-doped Samples

In $\mathrm{Cu}$-doped samples, with increasing $\mathrm{Cu}$-doping percentage increase in lattice constant has been observed up to $7.5 \%$ and at $10 \%$ there is a sudden decrease. In many transition metal doped semiconductor oxides systems, the dopants substitutionally occupy host sites at lower concentrations only and above a certain limit, additional interstitial incorporation of dopant occurs [28]. This might be one of the reasons for sudden change at $10 \%$. However, no uniform change in particle size has been noticed with changing doping concentrations.

\subsubsection{Intensity of Lines and Structure Factor}

In this section factors affecting the intensity of $\mathrm{CeO}_{2}$ peaks in XRD spectrum are briefly discussed. The analysis is based on the atomic positions of cerium and oxygen atoms in the crystal lattice. In powder X-ray diffraction, the intensity I is given by [24]

$$
I=\left|F_{h k l}\right|^{2} * p * \frac{\left(1+\operatorname{Cos}^{2} 2 \theta\right)}{\operatorname{Sin}^{2} 2 \theta \operatorname{Cos} \theta} * P O * \mu
$$

where $F_{h k l}$ is structure factor $=\sum_{j=1}^{N} f_{j} e^{-M_{j}} \exp \left\{2 \pi i\left(h x_{j}+k y_{j}+l z_{j}\right)\right\}$ 
In the above equations, $f_{j}$ is the atomic scattering factor of the $j^{\text {th }}$ atom with coordinates $\left(x_{j}, y_{j}, z_{j}\right)$ in the unit cell, $(h k l)$ is the Miller indices, $F_{h k l}$ is the atomic structure factor, $p$ is the multiplicity factor, $\left(1+\operatorname{Cos}^{2} 2 \theta\right) /\left(\operatorname{Sin}^{2} 2 \theta \operatorname{Cos} \theta\right)$ is the Lorentz-polarization factor, $\exp \left(-M_{j}\right)$ is the Debye Waller temperature factor, $\mathrm{PO}$ is the preferential orientation factor and $\mu$ is the absorption factor. A brief note on all the factors is discussed below. Atoms possess some finite sizes which are of the same magnitude as of the wavelength of an x-ray and the intensity of the scattering is directly proportional to the number of electrons in an atom. As the electrons are not concentrated at a point but scattered in the volume of the atom, the diffraction has a partial destructive interference and hence a net reduction in intensity of the radiation is observed. Atomic scattering factor $\left(f_{j}\right)$ is the ratio of the amplitude of the coherent scattered radiation from an atom to that from a single electron situated at the atomic center. For $\theta=0, f_{j}$ is maximum and equals to atomic number $(\mathrm{Z})$ of the atom. As $\theta$ increases, wave scattered by individual electrons become more and more out of the phase and eventually $f_{j}$ decreases. Therefore intensity of the lines at higher angles tends to be smaller in general as shown in figure 15.

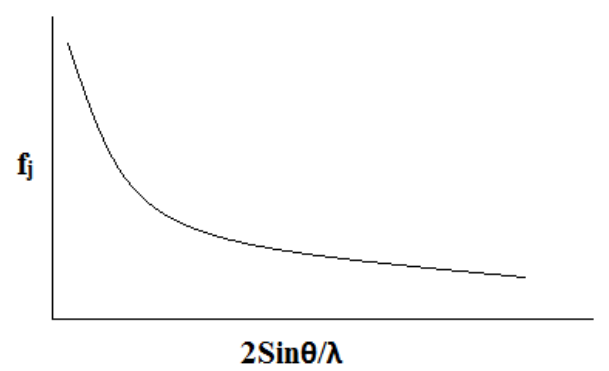

\section{Figure 15: Atomic Scattering Factor}

The characteristic radiation from an x-ray tube is considered to be unpolarized, but such radiation after being scattered or diffracted is polarized. The amount of polarization depends on the angle through which it is scattered or diffracted. More polarize is the beam more is the intensity seen in the spectra. For powder diffraction, polarization factor is $\left(1+\cos ^{2} 2 \theta\right)$. Beam divergence and polychromatism contribute to the plane's chance to reflect by virtue of its 
orientation or length of time it is position to reflect. Lorentz factor arises from the fact that the area of the peak depends on the value of $\theta$ involved. The intensity is proportional to $1 / \operatorname{Sin}^{2} \theta$ called polychromatic Lorentz factor. Therefore as $2 \theta$ increases, the intensity of the peaks in the diffraction pattern reduces. For powder diffraction, Lorentz factor is $1 /\left(\sin ^{2} 2 \theta \cos \theta\right)$.

Cystals with more than one kind of atom in a unit cell can be referred to as interpenetrating lattices. The observed reflection is a composite of the reflected waves from individual lattices with same wavelengths and periods but different amplitudes resulting from their partial interferences. These effects due to atomic arrangements in the intensity from a plane is called structure factor $F_{(h k l)}$. It is the ratio of the amplitude scattered by plane relative to the amplitude scattered by single electron. If $(h k l)$ are the Miler indices of the set of the diffracted planes, and $f_{j}$ is the atomic scattering factor of the $j^{\text {th }}$ atom with position $\left(x_{j}, y_{j}, z_{j}\right)$ in the lattice then structure factor $\left(F_{h k l}\right)$ in the exponential form is expressed as,

$$
F_{h k l}=\sum_{j=1}^{N} f_{j} \exp \left\{2 \pi i\left(h x_{j}+k y_{j}+l z_{j}\right)\right\}
$$

As $\mathrm{CeO}_{2}$ has an face centered cubic lattice, the cerium atoms $\left(\mathrm{Ce}^{4+}\right)$ are situated at $(0,0,0),(1 / 2,1 / 2,0),(1 / 2,0,1 / 2)$ and $(1 / 2,1 / 2,0)$ positions. Similarly, oxygen atoms are present in tetrahedral interstitials of the unit sell at $(1 / 4,1 / 4,1 / 4),(1 / 4,1 / 4,3 / 4),(1 / 4,3 / 4,1 / 4),(1 / 4,3 / 4,3 / 4)$, $(3 / 4,1 / 4,1 / 4),(3 / 4,1 / 4,3 / 4),(3 / 4,3 / 4,1 / 4),(3 / 4,3 / 4,3 / 4)$ positions. Scattering factor is same for all cerium ions $\left(f_{1}\right)$ and same for all oxygen atoms $\left(f_{2}\right)$. Hence total structure factor contribution from cerium atoms is,

$$
F_{h k l_{1}}=f_{1}\left(1+e^{\pi i(k+l)}+e^{\pi i(h+l)}+e^{\pi i(h+k)}\right)
$$

and from oxygen atoms is,

$$
\begin{array}{r}
F_{h k l_{2}}=f_{2}\left(e^{\frac{\pi}{2} i(h+k+l)}+e^{\frac{\pi}{2} i(h+k+3 l)}++e^{\frac{\pi}{2} i(h+3 k+l)}+e^{\frac{\pi}{2} i(h+3 k+3 l)}+e^{\frac{\pi}{2} i(3 h+k+l)}+\right. \\
\left.e^{\frac{\pi}{2} i(3 h+k+3 l)}+e^{\frac{\pi}{2} i(3 h+3 k+l)}+e^{\frac{\pi}{2} i(3 h+3 k+3 l)}\right)(2.7) .
\end{array}
$$


Therefore, the total structure factor contribution from both the atoms is,

$$
F_{h k l}=F_{h k l_{1}}+F_{h k l_{2}}
$$

It follows from the equation (2.6) that $F_{h k l 1}$ is zero unless $(h k l)$ are all either even or odd. On the other hand, $F_{h k l 2}$ is also zero if $(h k l)$ are all odd. Since intensity of the peaks $(I)$ is directly proportional to square of the structure factor $\left(\left|F_{h k \mid}\right|^{2}\right)$, oxygen atoms do not contribute at all for the lines (111), (311), (331) and (333). Contributions by cerium and oxygen atoms to the each peak intensity are explained below in Table 9.

Table 9: Structure Factor Contribution from Cerium \& Oxygen Atoms in XRD Diffraction

\begin{tabular}{|c|c|c|c|c|c|c|}
\hline Plane & $\mathbf{2 \theta}$ & $\begin{array}{c}\text { Ce } \\
\text { Contribution }\end{array}$ & $\begin{array}{c}\text { O } \\
\text { Contribution }\end{array}$ & $\begin{array}{c}\text { Ce + O } \\
\text { Contribution }\end{array}$ & $\begin{array}{c}\text { Contributing } \\
\text { Atoms }\end{array}$ & $\boldsymbol{p}$ \\
\hline$(111)$ & 28.48 & $4 \mathrm{f}_{1}$ & 0 & $4 \mathrm{f}_{1}$ & $\mathrm{Ce}$ & 8 \\
\hline$(200)$ & 33.02 & $4 \mathrm{f}_{1}$ & $-8 \mathrm{f}_{2}$ & $4 \mathrm{f}_{1}-8 \mathrm{f}_{2}$ & $\mathrm{Ce}, \mathrm{O}_{2}$ & 6 \\
\hline$(220)$ & 47.40 & $4 \mathrm{f}_{1}$ & $+8 \mathrm{f}_{2}$ & $4 \mathrm{f} 1+8 \mathrm{f} 2$ & $\mathrm{Ce}, \mathrm{O}_{2}$ & 12 \\
\hline$(311)$ & 56.29 & $4 \mathrm{f}_{1}$ & 0 & $4 \mathrm{f}_{1}$ & $\mathrm{Ce}$ & 24 \\
\hline$(222)$ & 59.07 & $4 \mathrm{f}_{1}$ & $-8 \mathrm{f}_{2}$ & $4 \mathrm{f} 1+8 \mathrm{f} 2$ & $\mathrm{Ce}, \mathrm{O}_{2}$ & 8 \\
\hline$(400)$ & 69.41 & $4 \mathrm{f}_{1}$ & $8 \mathrm{f}_{2}$ & $4 \mathrm{f}_{1}+8 \mathrm{f}_{2}$ & $\mathrm{Ce}, \mathrm{O}_{2}$ & 6 \\
\hline$(331)$ & 76.73 & $4 \mathrm{f}_{1}$ & 0 & $4 \mathrm{f}_{1}$ & $\mathrm{Ce}$ & 24 \\
\hline$(420)$ & 79.14 & $4 \mathrm{f}_{1}$ & $-8 \mathrm{f}_{2}$ & $4 \mathrm{f}_{1}+8 \mathrm{f}_{2}$ & $\mathrm{Ce}, \mathrm{O}_{2}$ & 48 \\
\hline$(422)$ & 88.48 & $4 \mathrm{f}_{1}$ & $+8 \mathrm{f}_{2}$ & $4 \mathrm{f}_{1}+8 \mathrm{f}_{2}$ & $\mathrm{Ce}, \mathrm{O}_{2}$ & 24 \\
\hline$(333)$ & 95.46 & $4 \mathrm{f}_{1}$ & 0 & $4 \mathrm{f}_{1}$ & $\mathrm{Ce}$ & 8 \\
\hline
\end{tabular}

In theoretical calculations, the diffracted ray is considered from only one atomic plane but in reality diffracted planes from similar planes superimpose to form a stronger intensity ray which is accounted by the factor $p$ called multiplication factor. This factor depends on the symmetry of the atomic crystal. The multiplication factor $(p)$ for a line is number of $(h k l)$ lines planes with same d-spacing. For example the miller indices triplet (111) has a total of 8 combinations including positive and negative values. So the diffraction line has intensity contribution from all these 8 planes and hence 8 times stronger than one (111) plane. The 
magnitudes of $\mathrm{p}$ for various (hkl) lines are listed in Table 4. When a radiation is passed through the crystal, the radiation is partially absorbed which decreases the amount of beam reflected. This is due to scattering and partly due to increase in thermal energy. And finally, the intensity of the diffraction pattern decreases as the temperature of the substance increases. This is due to increase in vibrations of the atoms i.e. the atoms displace from their mean position on the average. 


\section{Magnetic Properties}

As mentioned in first chapter, there are several reports of finding magnetism in diamagnetic cerium oxide. $\mathrm{As} \mathrm{Cu}^{0}$ and $\mathrm{CeO}_{2}$ both are diamagnetic it would be very interesting to see whether doping copper into cerium oxide would show magnetism or not. If ferromagnetism is shown then, magnetism may be an intrinsic property of the material. Usually there are two kinds of magnetic measurements done. One is measuring magnetization $\mathrm{M}$ per unit mass by a magnetometer in a static field $\mathrm{H}$ and other is magnetic resonance in which additional radio frequency field with frequency $v$ is applied to cause transitions between Zeeman levels. In this thesis changes in magnetization $\mathrm{M}$ observed with change in particles sizes for undoped samples and with change in doping concentration for doped samples are reported as a function of temperature and magnetic field using a magnetometer.

\subsection{SQUID Magnetometer}

\subsubsection{Undoped Cerium Oxide}

A commercial superconducting quantum interface device (SQUID) magnetometer was used for magnetization measurements. Reciprocating sample option (RSO) mode of operation was used in which each measurement is taken by rapidly moving the sample in between the SQUID pickup coils. The sample is moved up and down sinusoidally in between the pickup coils and SQUID response for the magnetic moment of the sample is measured. Magnetic property measurement system (MPMS) MultiVu software is used to collect and analyze the data. The data is collected at different range of temperatures i.e. from $2 \mathrm{~K}$ to $370 \mathrm{~K}$. The sample is put in a transparent drinking straw and is attached to the tip of a long rod placed inside the dewar. The magnetic data is corrected for the straw with diamagnetic susceptibility of $-2.3 \times 10^{-8} \mathrm{emu}$, 
leading to:

$M_{\text {measured }}=M_{\text {sample }}+M_{\text {straw }}$
Therefore, $\quad M_{\text {sample }}=M_{\text {measured }}+H * 2.3 \times 10^{-8}$ emu

In Eq.(3.2), $\mathbf{M}_{\text {measured, }} \mathbf{M}_{\text {sample}}, \mathbf{M}_{\text {straw }}$ and $\mathrm{H}$ are the measured magnetization, actual magnetization of the sample, diamagnetic component of the straw and applied magnetic field in Oersteds (Oe) respectively. In this work, magnetization $M$ was measured as a function of temperature from $2 \mathrm{~K}$ to $370 \mathrm{~K}$ in a fixed applied field $\mathrm{H}$ and as a function of magnetic field up to $\pm 65 \mathrm{kOe}$ at selected temperatures. The magnetic susceptibility is $\chi=\mathrm{M} / \mathrm{H}$. In the $\chi$ vs $\mathrm{H}$ measurements, the sample is initially cooled to $2 \mathrm{~K}$ in zero magnetic field. After reaching $2 \mathrm{~K}$, a fixed field is applied and the temperature is increased stepwise to $370 \mathrm{~K}$, while taking the data at each temperature. This mode gives the Zero Field Cooled (ZFC) case. Once $370 \mathrm{~K}$ is reached, the sample is cooled stepwise back to $2 \mathrm{~K}$ in the same field, while taking the data at each stabilized temperature. This is the Field Cooled (FC) case. In this work, $\chi$ vs T measurements were taken at 500 Oe. SQUID measurements of undoped $\mathrm{CeO}_{2}$ samples have been taken on the $\mathrm{T}_{\mathrm{a}}=25^{\circ} \mathrm{C}$ (as prepared), $400^{\circ} \mathrm{C} \& 800^{\circ} \mathrm{C}$ annealed samples. All of the $\mathrm{Cu}$-doped samples $\mathrm{Cu}_{\mathrm{x}} \mathrm{Ce}_{1-}$ ${ }_{x} \mathrm{O}_{2}(\mathrm{x}=0.025,0.05,0.075 \& 0.1)$ annealed at $400^{\circ} \mathrm{C}$ have been run for SQUID measurements.

Figure 16 shows the $\chi$ vs $\mathrm{T}$ plots for undoped $\mathrm{CeO}_{2}$ samples. The bump in Figure 16 (a) near $75 \mathrm{~K}$ for the ZFC case is likely due to trapped oxygen in the straw. Using modified Curie law, a fitting is done to one of the curves ( $\mathrm{ZFC}$ or $\mathrm{FC}$ ) to calculate the magnetic moment per atom in the samples. This fitting also provides important magnetic values like Curie constant (C) and molecular field constant $(\lambda)$. 


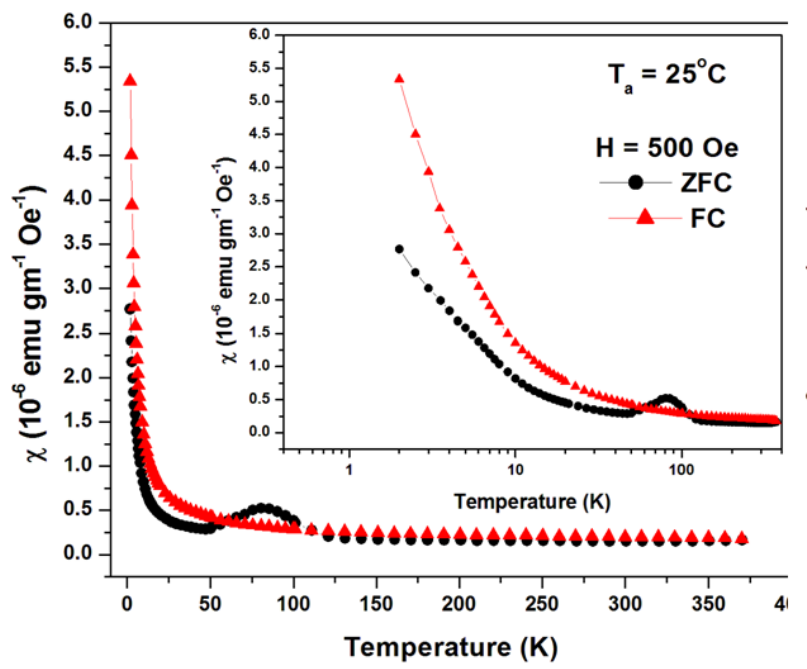

(a)

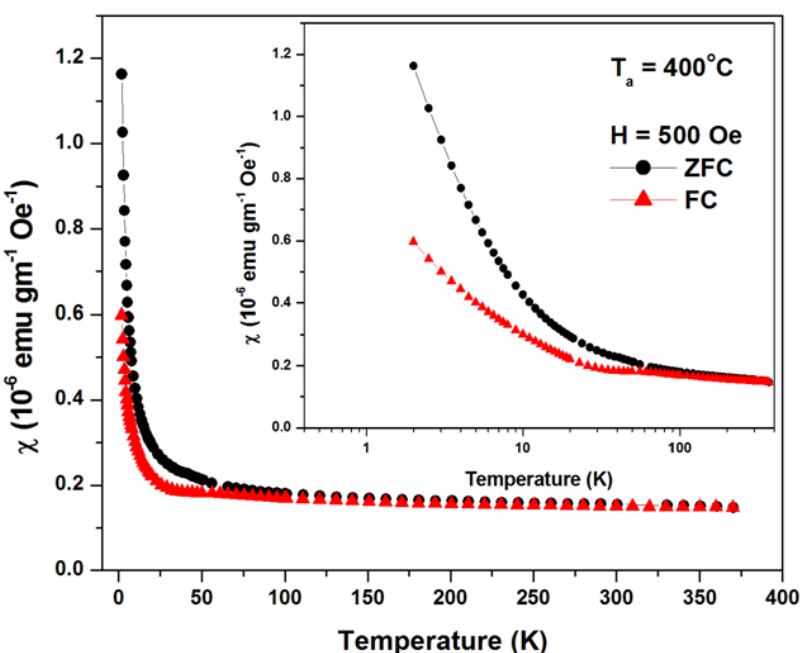

(b)

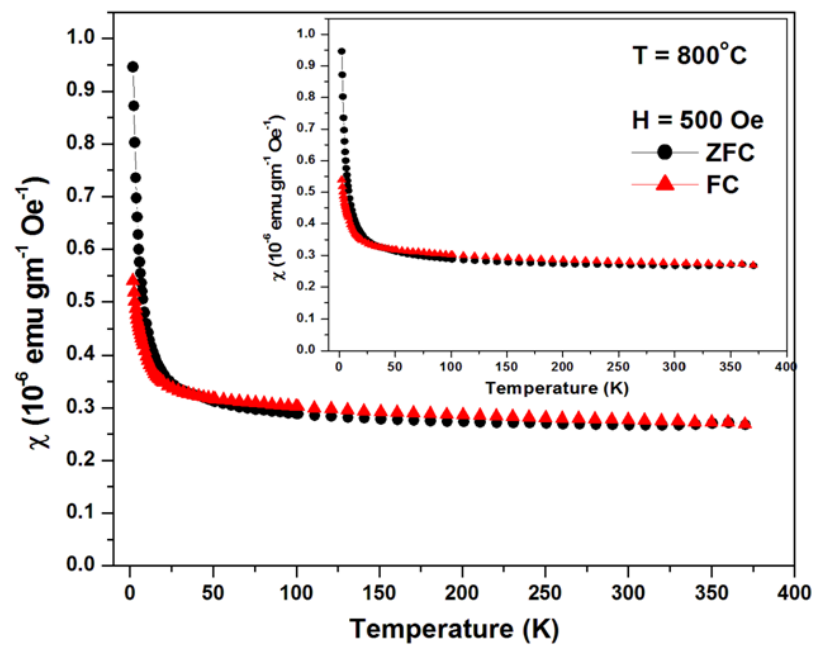

(c)

Figure 16: $\chi$ vs $\mathrm{T}$ Plots of the Undoped $\mathrm{CeO}_{2}$ Samples

The magnetization $M$ per mole of $N$ (Avogadro number) number of electrons each with a magnetic dipole moment $\mu$ is $\mathrm{M}=\mathrm{N} \mu$ when they are perfectly aligned. As electron magnetic dipole is caused by the spin of the electron it can be written in terms of angular spin moment as $\mu / \mu_{B}=g \sqrt{S(S+1)}$ where $\mu_{\mathrm{B}}$ is the Bohr magneton, $\mathrm{g}$ is the g-factor and $\mathrm{S}$ is the magnitude of the spin. g-factor is a dimensionless magnetic moment constant which characterizes magnetic moment and gyromagnetic ratio of an electron. Currently accepted g-value for a free electron is -2.002319 [29]. However, in solids, g-value of the electron can be quite different from 2 due to 
the effects of crystal field and spin-orbit interaction. The magnetization of the non-interacting dipoles is directly proportional to the applied magnetic field $\mathrm{H}$ and inversely proportional to the temperature T. This is called the Curie Law [29].

$$
\begin{gathered}
M=\frac{C H}{T}, \text { where } C=\frac{N \mu^{2}}{3 k} \\
\text { Hence, } \chi=\frac{C}{T}
\end{gathered}
$$

In Eq. 3.3, $\mathrm{C}$ is the Curie constant, $\mathrm{k}$ is Boltzmann constant and $\chi$ is the interaction susceptibility. Weiss replaced all electron-electron interaction by an effective field $H_{\text {int }}=\lambda M$ where $\lambda$ is molecular field constant, thus modifying the Curie law to

$$
M=\frac{C\left(H+H_{\text {int }}\right)}{T}=\frac{C(H+\lambda M)}{T}
$$

From equation 3.5,

$$
\begin{gathered}
\chi=\frac{M}{H}=\frac{\frac{C}{T}}{1-\frac{C \lambda}{T}}=\frac{C}{T-C \lambda} \\
\chi=\frac{C}{T-\theta}, \text { where } \theta=\mathrm{C} \lambda
\end{gathered}
$$

Equation (3.6) is called the Curie-Wiess law. If $\theta$ is positive then the materials is ferromagnetic and if $\theta$ is negative then the material is antiferromagnetic. Curie law best fits to the paramagnetic materials or paramagnetic part of the data. Below is brief explanation for finding magnetic moment using $\chi$ vs T plot. Using the modified Curie- Weiss law:

$$
\chi=\chi_{o}+\frac{C}{T-\theta}
$$

where $\chi_{0}$ takes into account other contribution to susceptibility such as from diamagnetism $\left(-\chi_{d} H\right)$ of inner cores which is negative and Van Vleck susceptibility $\left(\chi_{v v} H\right)$ which is positive. Both $\chi_{\mathrm{d}}$ and $\chi_{\mathrm{vv}}$ are usually temperature independent. Using $\chi$ vs $1 / \mathrm{T}$ plot, y-intercept in the limit 
$1 / \mathrm{T} \rightarrow 0$ yields $\chi_{0}$. Values of $\mathrm{C}$ and $\theta$ are found by plotting a graph $1 /\left(\chi-\chi_{0}\right)$ vs $\mathrm{T}$ where $-\theta / \mathrm{C}$ is the $\mathrm{y}$-intercept and $1 / \mathrm{C}$ is slope of the plot. $\left(\chi-\chi_{0}\right)$ is the magnetic susceptibility remained after removal of diamagnetic and Van Vleck magnetic parts. Now the magnetic moment per Bohr magneton $\left(\mu / \mu_{\mathrm{B}}\right)$ in undoped samples is calculated using the equation given below,

$$
\frac{\mu}{\mu_{B}}=\sqrt{\frac{3 k_{B} * \text { Mol.Wt*C}}{\left(N * \mu^{2}{ }_{B}\right)}}
$$

where Mol. Wt. is the molecular weight of the copper doped ceria. The values of $\chi_{\mathrm{o}}, \mathrm{C}$ and $\theta$ and are adjusted accordingly to fit the curve. As noted later, the magnitude of $\mathrm{C}$ so determined from the $\chi$ vs T at low fields contains both the paramagnetic and ferromagnetic components. 


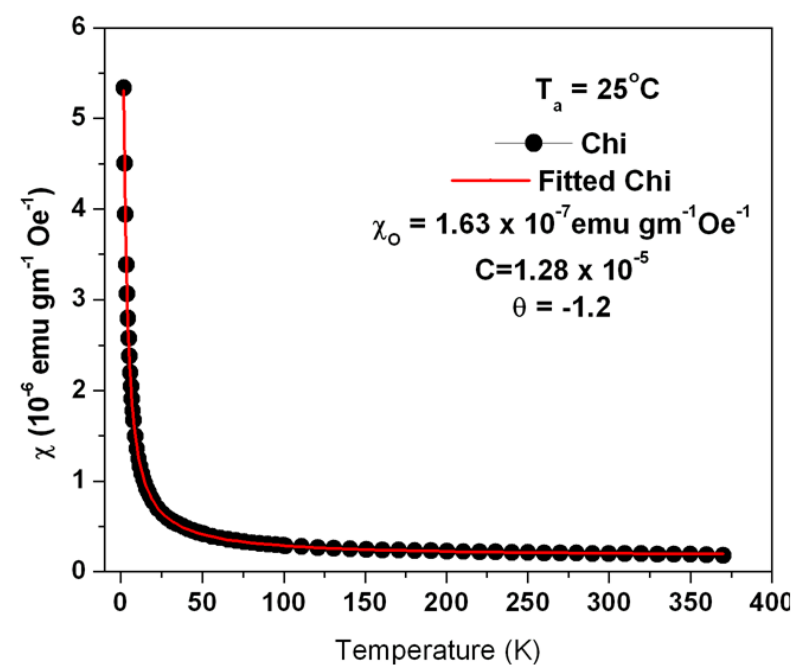

(a)

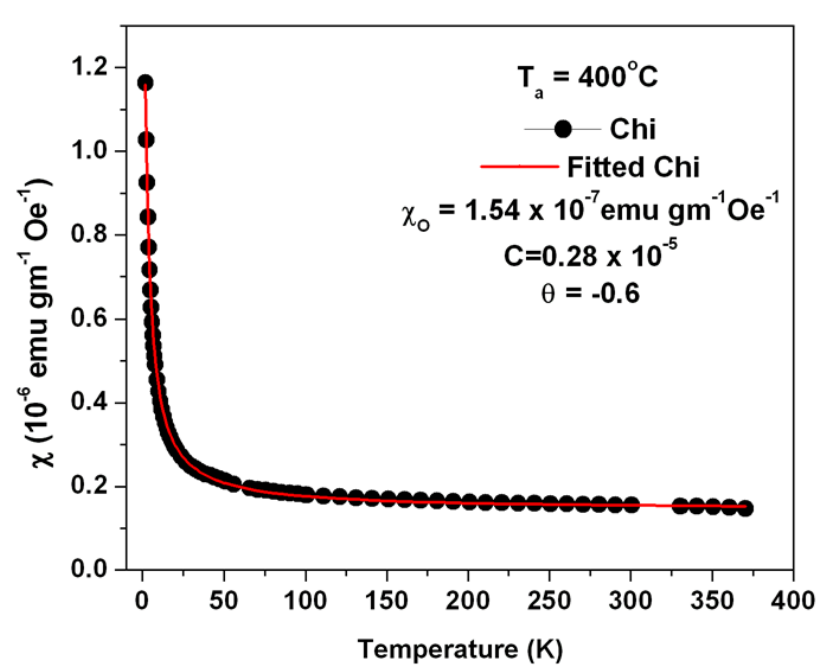

(b)

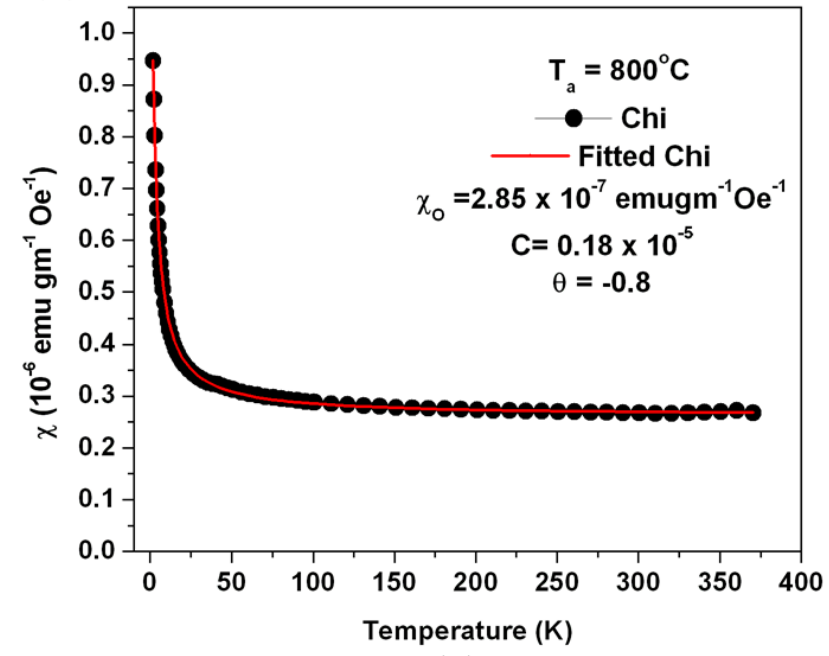

(c)

Figure 17: Fitted Chi Plots of Undoped $\mathrm{CeO}_{2}$ Samples

Table 10: Parameters of the Fit to Modified Curie-Weiss Law

\begin{tabular}{|c|c|c|c|c|}
\hline $\mathrm{T}_{\mathrm{a}}\left({ }^{0} \mathrm{C}\right)$ & $\begin{array}{c}\text { Particle Size (nm) } \\
\text { (XRD) }\end{array}$ & 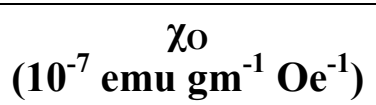 & $\begin{array}{c}C \\
\left(10^{-5} \mathrm{emu} \mathrm{K} \mathrm{g}^{-1} \mathrm{Oe}^{-1}\right)\end{array}$ & $\begin{array}{c}\Theta \\
(\mathbf{K})\end{array}$ \\
\hline 25 & 2.9 & $1.63 \pm 0.10$ & $1.28 \pm 0.04$ & $-1.2 \pm 0.1$ \\
\hline 400 & 5.7 & $1.54 \pm 0.20$ & $0.28 \pm 0.02$ & $-0.6 \pm 0.2$ \\
\hline 800 & 42 & $2.90 \pm 0.10$ & $0.18 \pm 0.01$ & $-0.8 \pm 0.2$ \\
\hline
\end{tabular}

Parameters derived in Table 10 show that there is steady reduction in Curie constant with increase in particle size. This can be attributed to reduction in $\mathrm{Ce}^{3+}$ ions in the particles [30]. From this it can be concluded that with decreasing particle size there is increase in paramagnetic 
component of magnetization. This is possible only by increase in contribution from $\mathrm{Ce}^{3+}$ ions. And the negative values of $\theta$ show that the interaction between the dipoles is antiferrromagnetic. Antiferromagnetism is case where magnetic dipoles are aligned anti parallel to each other in an applied magnetic field. This reduces the effective magnetism due to dipole-dipole interaction. Figure 18 below shows the comparison of $\mathrm{ZFC}$ and $\mathrm{FC}$ plots of undoped $\mathrm{CeO}_{2}$. These graphs show an increasing magnetic susceptibility with decreasing annealing temperatures thus decreasing particle size. This is true both at $300 \mathrm{~K}$ and at $5 \mathrm{~K}$. This effect therefore can be related to the nanosize effects in $\mathrm{CeO}_{2}$.

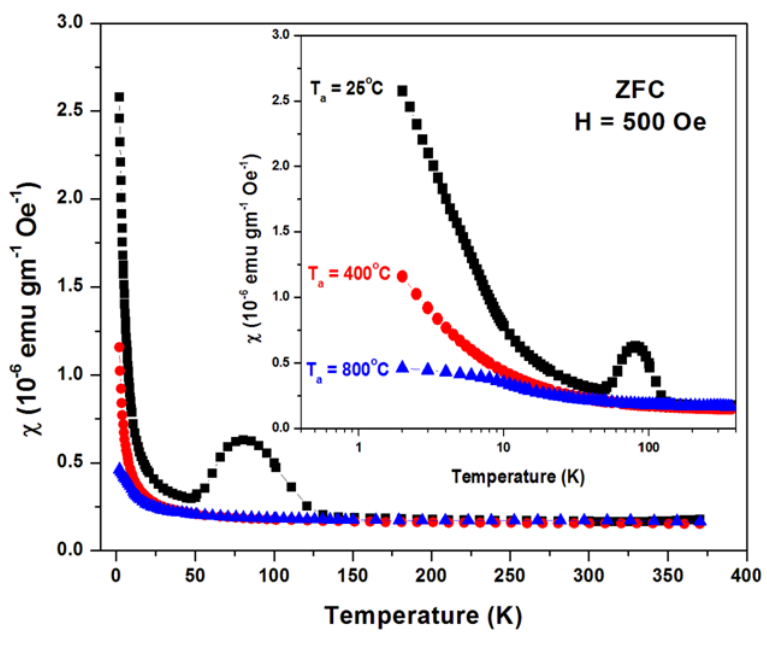

(a)

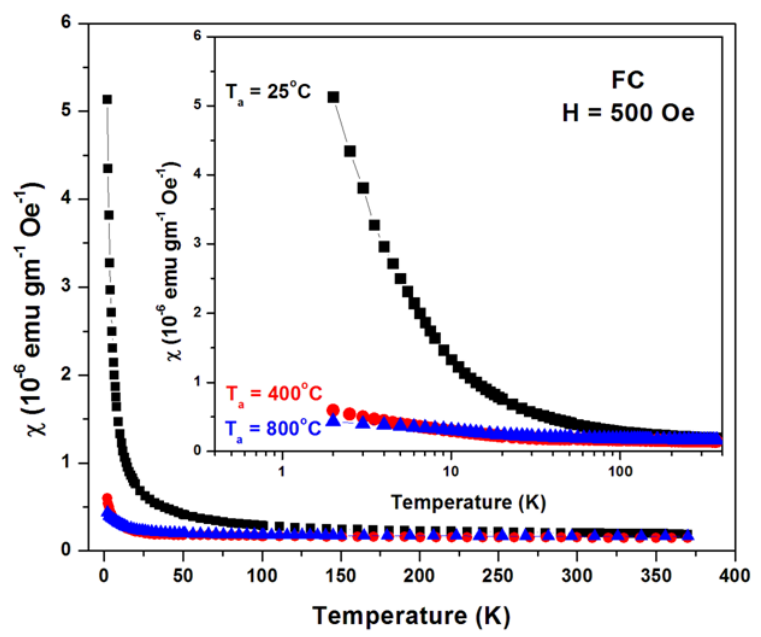

(b)

Figure 18: ZFC \& FC Plot Comparisons of Undoped $\mathrm{CeO}_{2} \mathrm{Samples}$

Additional information on the nature of magnetism is determined from the $\mathrm{M}$ vs $\mathrm{H}$ plots which are usually linear for paramagnets and non-linear for ferromagnets. If hysteresis is observed, then remanence $\mathrm{M}_{\mathrm{R}}$ and coercivity $\mathrm{H}_{\mathrm{C}}$ are measured which yield important information on the ferromagnetic state. As shown in Fig.19, a very small hysteresis is observed both at $300 \mathrm{~K}$ and $5 \mathrm{~K}$, with coercivity $\mathrm{H}_{\mathrm{C}} \sim 50 \mathrm{Oe}$. But plots at $300 \mathrm{~K}$ are more non-linear and show more ferromagnetism. The results are similar for the three undoped samples annealed at $\mathrm{T}_{\mathrm{a}}=25^{\circ} \mathrm{C}$, $400^{\circ} \mathrm{C}$ and $800^{\circ} \mathrm{C}$. 


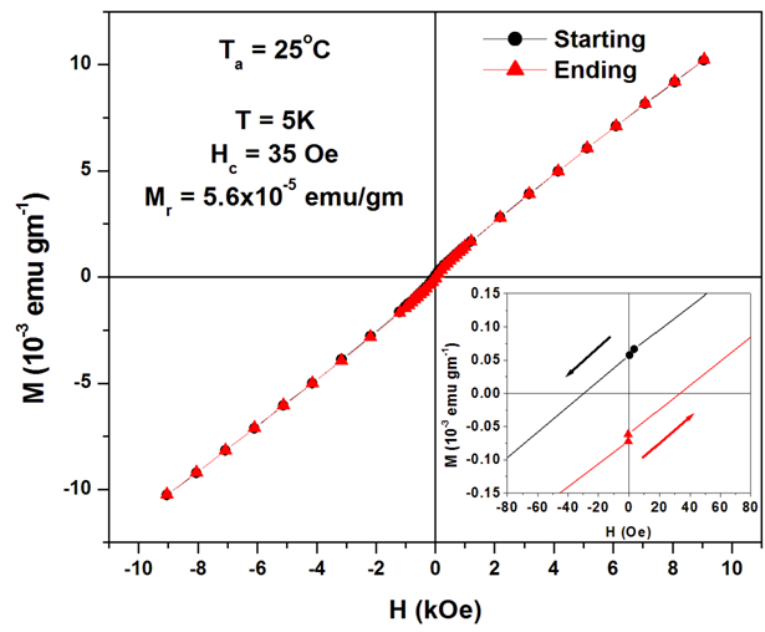

(a)

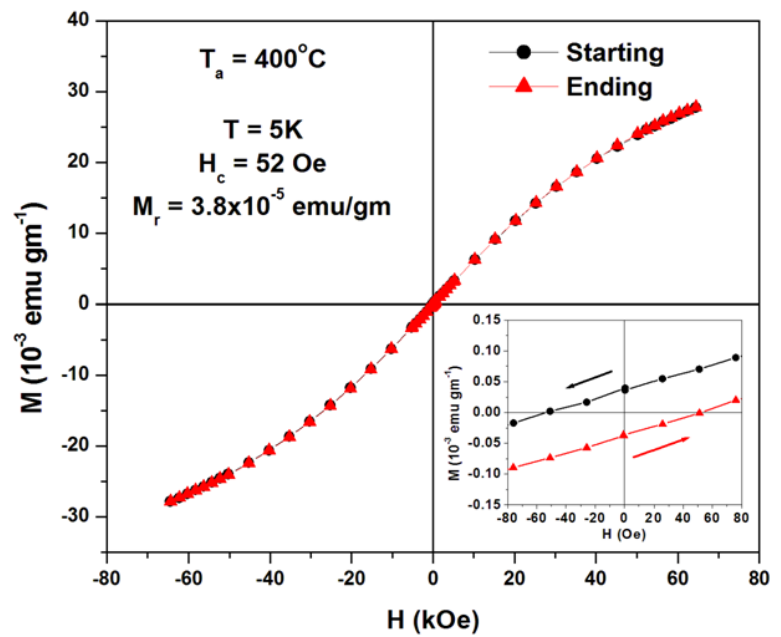

(c)

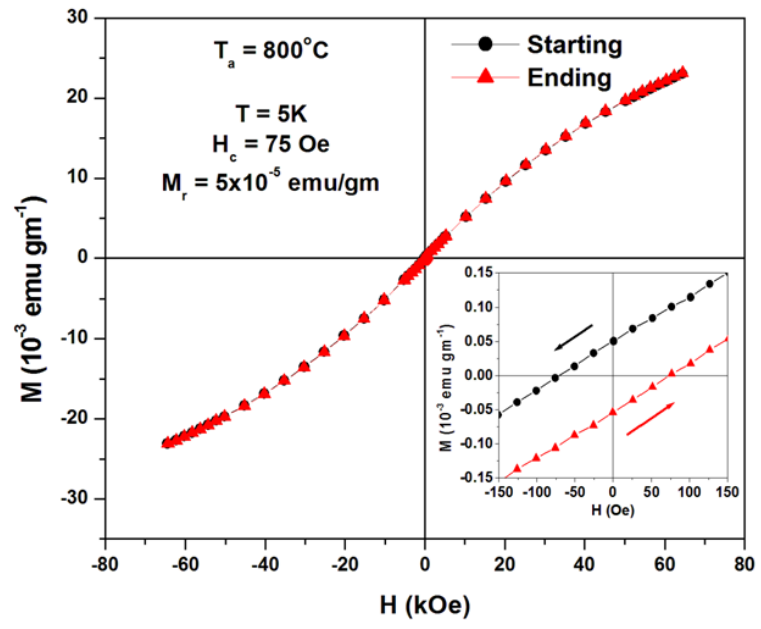

(e)

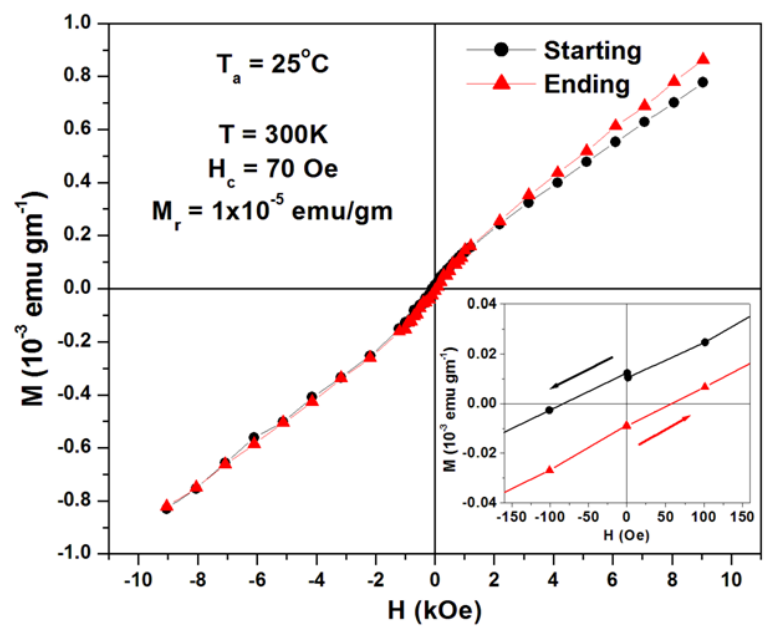

(b)

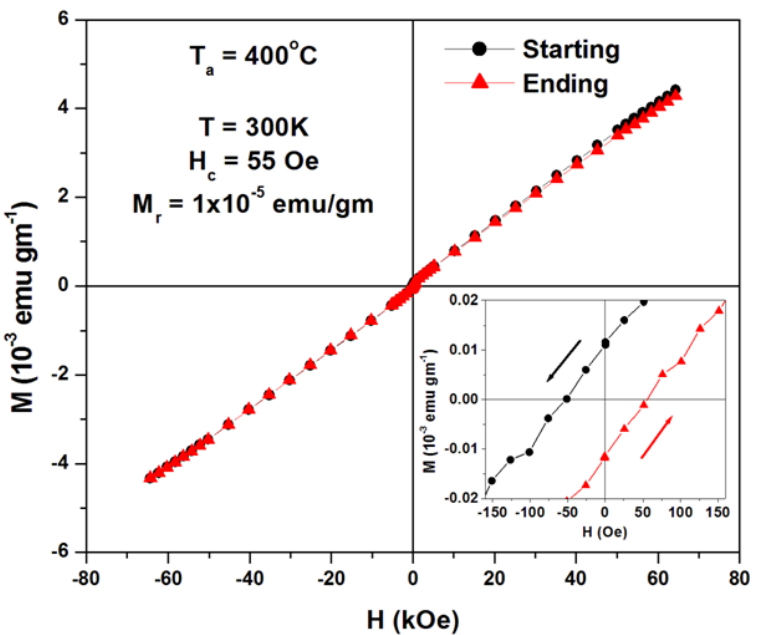

(d)

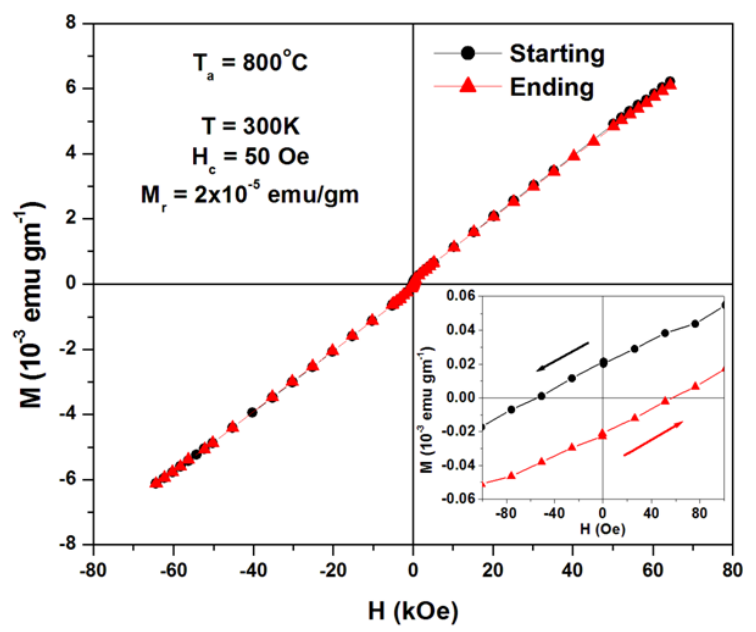

(f)

Figure 19: M vs H Plots of the Undoped Cerium Oxide 
The graphs in Figure 19 show the presence of both ferromagnetism and paramagnetism in undoped samples. Uniform increase in magnetism at higher fields (straight positive slope) and the hysteresis at the centre in the $\mathrm{M}$ vs $\mathrm{H}$ curves show the paramagnetic and ferromagnetic part magnetization of the samples respectively. Ferromagnetic part of the graphs can be retrieved from the graphs in Figure 19 by removing the paramagnetic part. The slope of the hysteresis curve at higher fields gives paramagnetic susceptibility $\left(\chi_{\mathrm{P}}\right)$ since the ferromagnetic component is expected to saturate at higher fields. Subtracting the paramagnetic magnetization $\left(\chi_{\mathrm{P}} \mathrm{H}\right)$ from the magnetization of the sample (M) gives the ferromagnetic part of the plot (Fig. 20). The saturation magnetization $\mathrm{M}_{S}$, magnetic moment per atom $\left(\mu / \mu_{\mathrm{B}}\right)$, can be calculated using the equation

$$
\frac{\mu}{\mu_{B}}=\frac{M_{S} * M o l . W t}{N * \mu_{B}}
$$

where Mol. Wt. is the molecular weight of cerium oxide (172.11). Table 10 below shows the parameters derived from the $\mathrm{M}$ vs $\mathrm{H}$ plots taken at room temperature $(300 \mathrm{~K})$. In table $10, \mathrm{H}_{\mathrm{C}}$ is the coercive field and $M_{R}$ is the remanence. Remanence is the $M$ value at $H=0$ in the hysteresis loops (see inset of Fig. 19). 


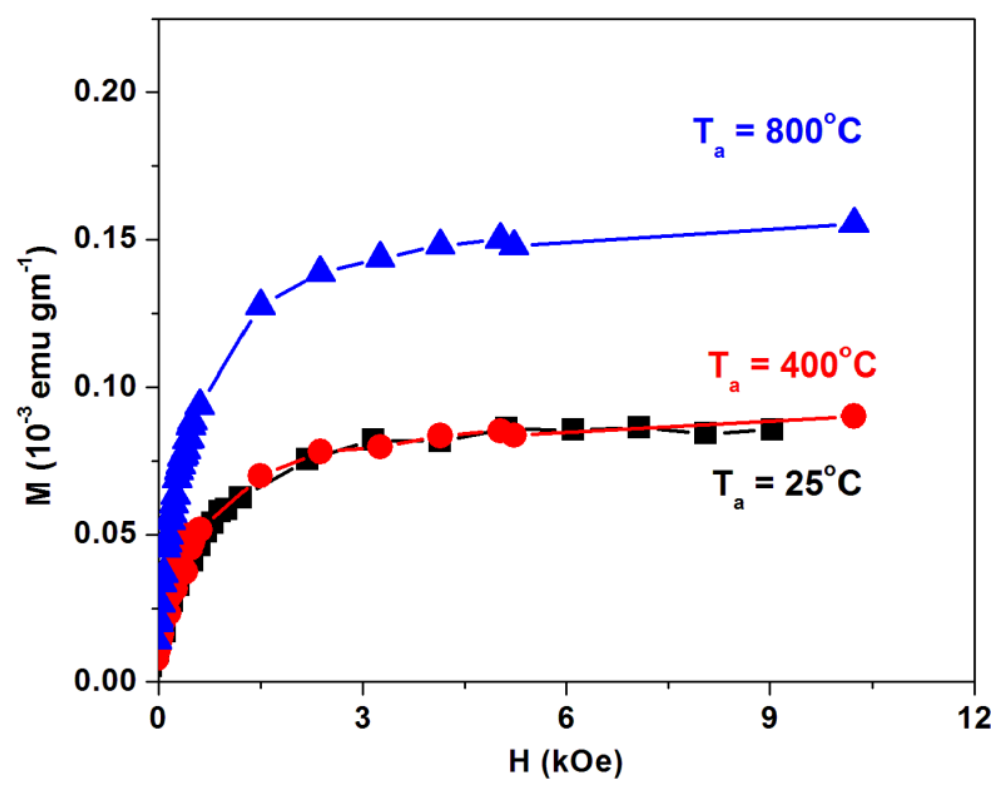

Figure 20: Saturation Magnetization $\left(\mathrm{M}_{S}\right)$ of Undoped Samples

Table 8: Parameters Derived from M vs H Plots

\begin{tabular}{|c|c|c|c|c|c|}
\hline $\begin{array}{c}\mathrm{T}_{\mathrm{a}} \\
\left({ }^{\circ} \mathrm{C}\right)\end{array}$ & $\begin{array}{c}\chi_{P} \\
\left(10^{-7} \mathrm{emu} \mathrm{g}^{-1} \mathrm{Oe}^{-1}\right)\end{array}$ & $\begin{array}{c}\mathbf{H}_{\mathrm{C}} \\
(\mathbf{O e})\end{array}$ & $\begin{array}{c}\mathrm{M}_{\mathrm{R}} \\
\left(10^{-5} \stackrel{\text { emu g }}{-1}\right)\end{array}$ & $\begin{array}{c}\mathrm{M}_{\mathrm{S}} \\
\left(10^{-4} \stackrel{\mathrm{emu} \mathrm{g}}{\mathrm{e}} \mathrm{g}^{-1}\right)\end{array}$ & $\begin{array}{c}\mu / \mu_{B} \\
\left(10^{-4}\right)\end{array}$ \\
\hline 25 & 0.72 & 70 & 1 & 0.86 & 0.026 \\
\hline 400 & 0.68 & 55 & 1 & 0.85 & 0.025 \\
\hline 800 & 0.94 & 50 & 2 & 1.50 & 0.050 \\
\hline
\end{tabular}

Figure 21 compares the $300 \mathrm{~K}$ and $5 \mathrm{~K} \mathrm{M}$ vs $\mathrm{H}$ plots of as prepared and $\mathrm{T}_{\mathrm{a}}=400^{\circ} \mathrm{C}$ and $800^{\circ} \mathrm{C}$ annealed samples of undoped ceria. The linear slopes at higher magnetic fields suggest the paramagnetism in the sample and non-linear at lower magnetic fields suggest small ferromagnetism. At $5 \mathrm{~K}$, it can be clearly inferred that with annealing temperatures, paramagnetic magnetization reduces i.e. as particle size increases paramagnetic magnetization decreases. This suggests the increase in $\mathrm{Ce}^{3+}$ concentration as particle size reduces. This was earlier discussed while deriving Curie constant values in Table 9. Though a very small amount of ferromagnetism is seen, this is attributed to magnetic impurities as follows: The level of Fe 
impurity in undoped cerium oxide annealed at $\mathrm{T}_{\mathrm{a}}=400^{\circ} \mathrm{C}$ was found to be $18 \mathrm{ppm}$ determined by ICPOES (Gailbraith labs as mentioned in chapter 1). Usually Fe oxidizes easily to either $\alpha-\mathrm{Fe}_{2} \mathrm{O}_{3}$ (Maghemite) or $\mathrm{Fe}_{3} \mathrm{O}_{4}$ (Magnetite). $\alpha-\mathrm{Fe}_{2} \mathrm{O}_{3}$ is only weakly magnetic at room temperature where as saturation magnetization of the bulk $\mathrm{Fe}_{3} \mathrm{O}_{4}$ is about $92 \mathrm{emu} / \mathrm{gm}$ with $\mathrm{M}_{\mathrm{S}}$ decreasing with smaller $\mathrm{Fe}_{3} \mathrm{O}_{4}$ particles [31]. Assuming $\mathrm{M}_{\mathrm{S}} \sim 92 \mathrm{emu} / \mathrm{gm}$ and 18ppm of iron impurity concentration it would yield $1.8 \times 10^{-4} \mathrm{emu} / \mathrm{gm}$ as maximum possible magnetization from the $\mathrm{Fe}_{3} \mathrm{O}_{4}$ impurities. The calculated $\mathrm{M}_{\mathrm{S}}$ values are comparable to the observed $\mathrm{M}_{\mathrm{S}}$ in Fig. 20. Therefore it is possible that $\mathrm{Fe}$ impurities are responsible for the observed ferromagnetism in the undoped $\mathrm{CeO}_{2}$. The decrease in the ferromagnetic components with increase in annealing temperature can be explained if $\mathrm{Fe}_{3} \mathrm{O}_{4}$ converts to $\alpha-\mathrm{Fe}_{2} \mathrm{O}_{3}$ at higher temperatures to complete the oxidation process. This conclusion contradicts other claims of intrinsic ferromagnetism in undoped $\mathrm{CeO}_{2}[8]$.

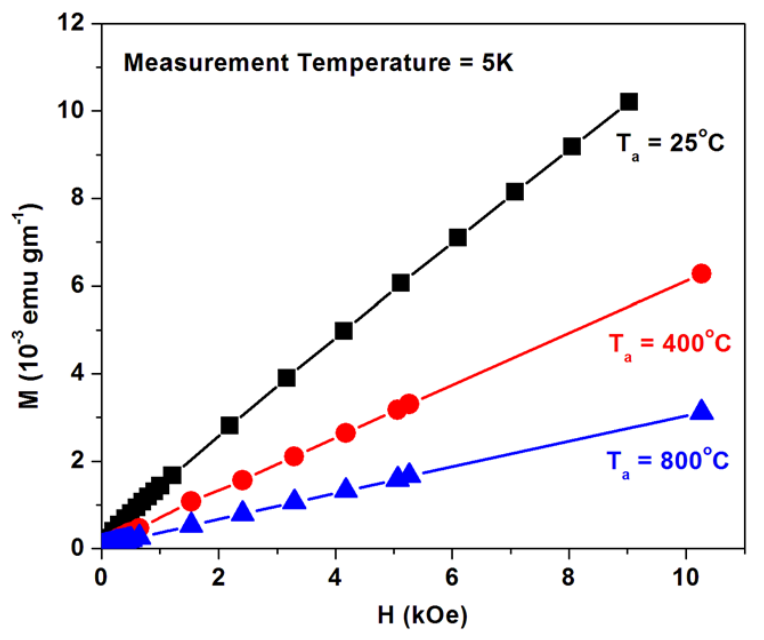

(a)

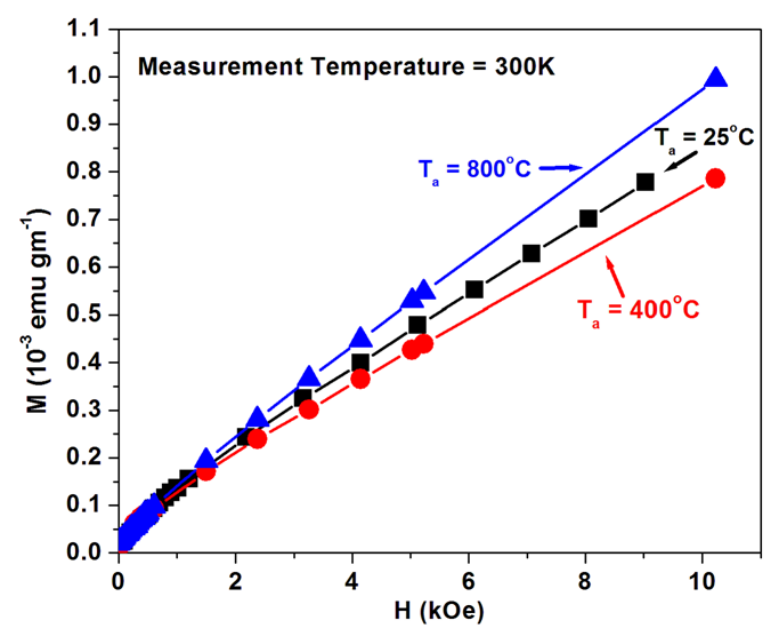

(b)

Figure 21: $\mathrm{M}$ vs $\mathrm{H}$ Comparison Plots of Undoped $\mathrm{CeO}_{2}$ 


\subsubsection{Cu-doped Cerium Oxide}

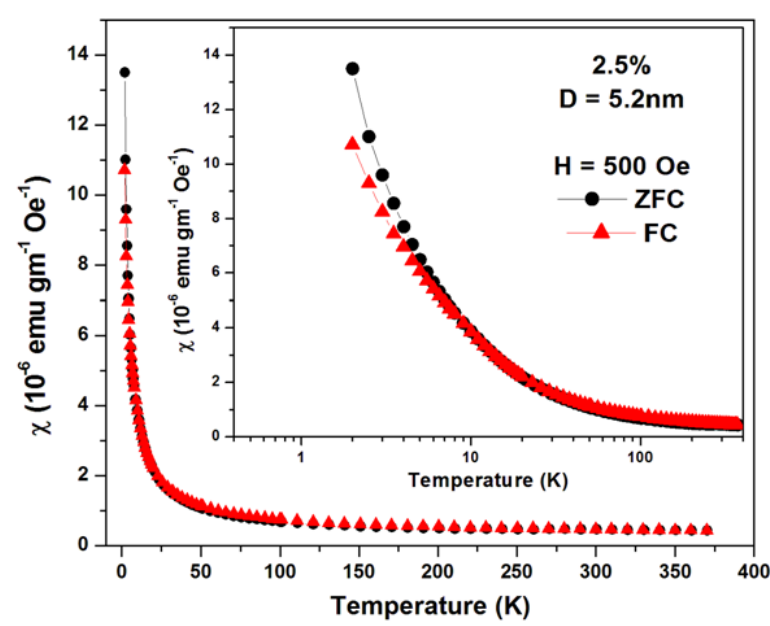

(a)

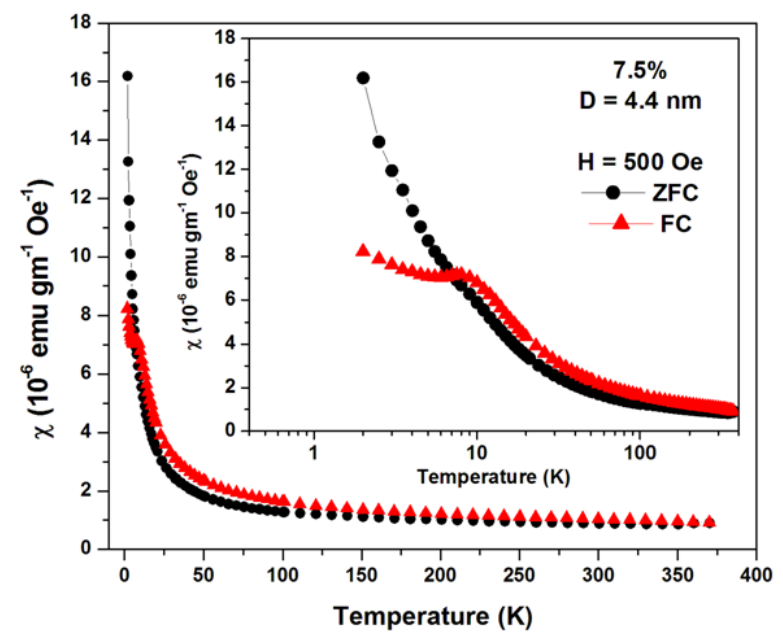

(c)

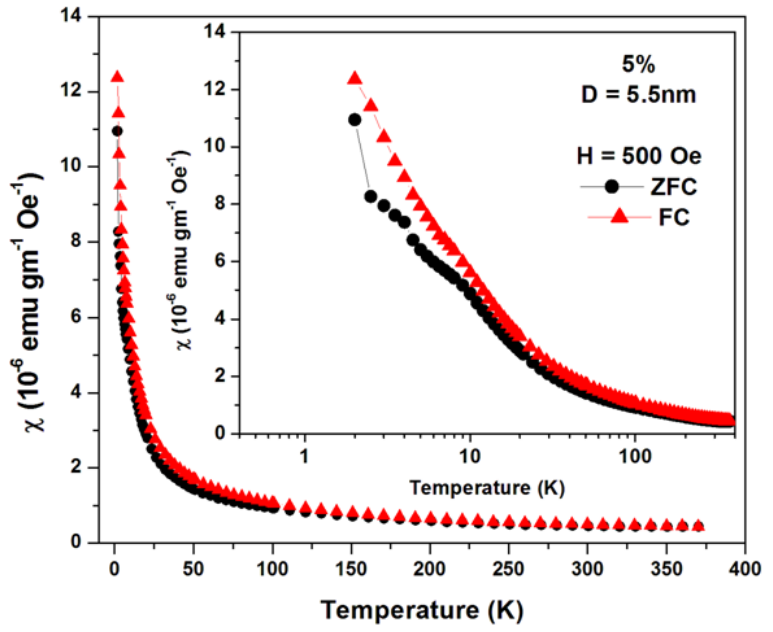

(b)

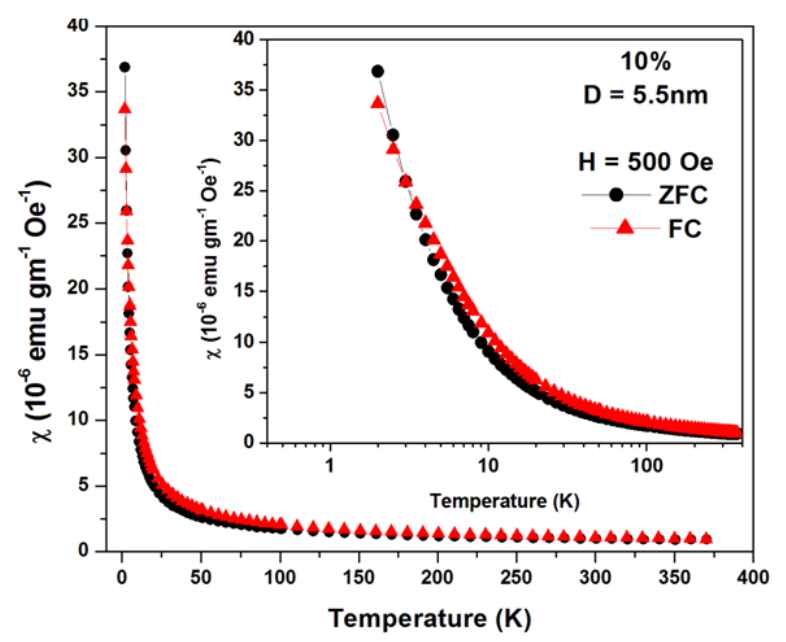

(d)

Figure 22: $\chi$ vs T Plots of $\mathrm{Cu}$-doped $\mathrm{CeO}_{2}$

Figure 22 shows the $\chi$ vs $\mathrm{T}$ plots for the $\mathrm{Cu}$-doped cerium oxides sample. Curie-Weiss law fit is done to find $\theta$ and Curie constant $\mathrm{C}$ from which magnetic moment $(\mu)$ per copper atom can be calculated. To find $\theta$ and $\mathrm{C}$, the same procedure used for the undoped samples have been used here. Next, magnetic moment per Bohr magneton $\left(\mu / \mu_{\mathrm{B}}\right)$ is calculated using the equation:

$$
\frac{\mu}{\mu_{B}}=\sqrt{\frac{3 k_{B} * \text { Mol.Wt } * C}{\left(x * N * \mu^{2}{ }_{B}\right)}}
$$


here $\mathrm{x}$ is the percentage of copper doping and Mol. Wt. is the molecular weight of the copper doped ceria. In Figure 23, the solid line are the fits to the Curie-Weiss law with the parameters of the fit listed in Table 11.

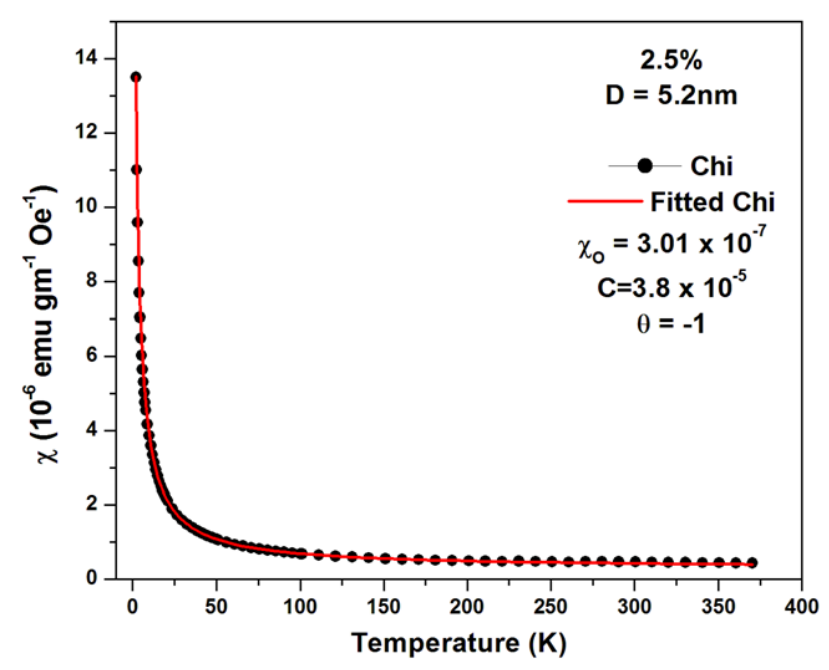

(a)

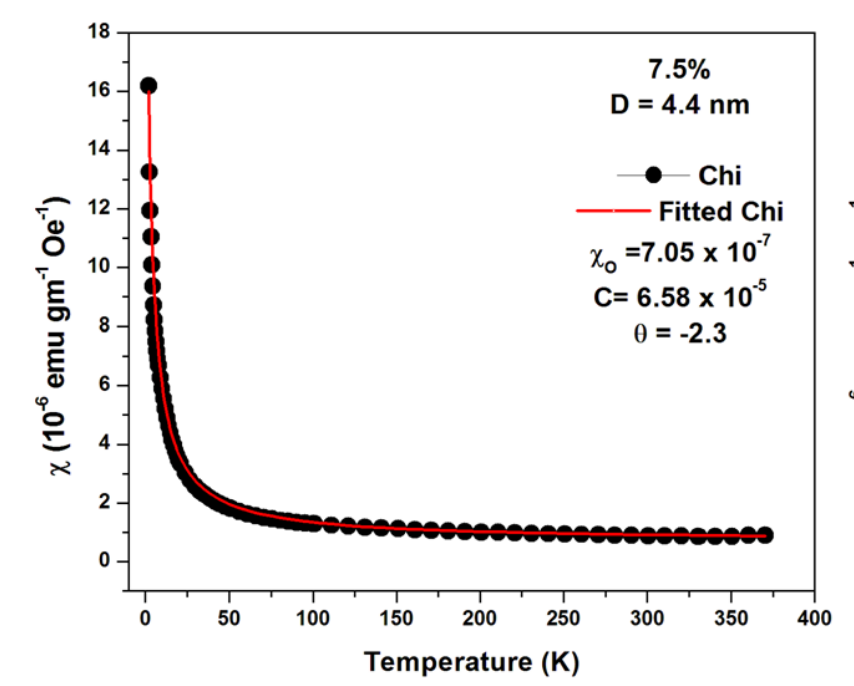

(c)

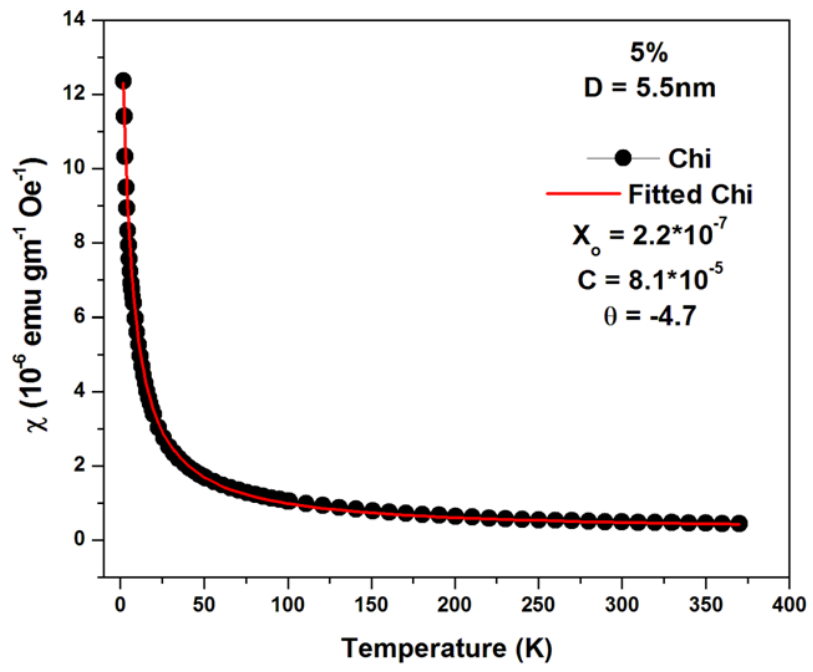

(b)

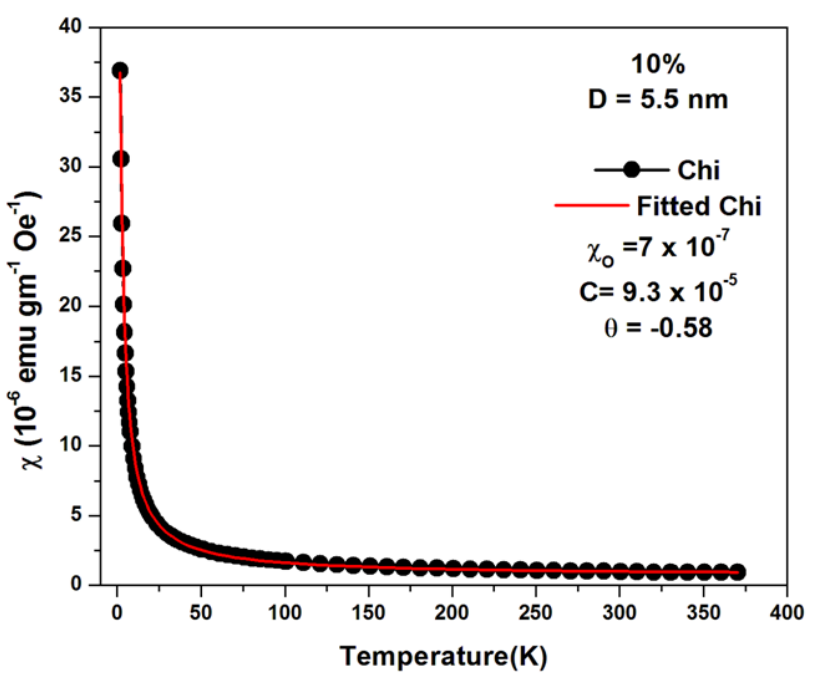

(d)

Figure 23: Curie-Weiss Fits to the $\chi$ vs $\mathrm{T}$ Data in $\mathrm{Cu}$-doped $\mathrm{CeO}_{2}$ Samples. 
Table 9: Magnetic Moment $(\mu)$ per Copper Atom Calculations from $\chi$ vs $T$

\begin{tabular}{|c|c|c|c|c|}
\hline $\mathrm{Cu} \%$ & $\begin{array}{c}\chi_{0} \\
\left(10^{-7} \mathrm{emu} \mathrm{gm}^{-1} \mathrm{Oe}^{-1}\right)\end{array}$ & $\begin{array}{c}\mathrm{C} \\
\left(10^{-5} \text { emu K g } \mathrm{g}^{-1} \mathrm{Oe}^{-1}\right)\end{array}$ & $\begin{array}{c}\Theta \\
(\mathbf{K})\end{array}$ & $\begin{array}{c}\mu / \mu_{B} \\
\left(10^{-4}\right)\end{array}$ \\
\hline 2.5 & $3.0 \pm 0.3$ & $3.9 \pm 0.1$ & $-0.6 \pm 0.2$ & 1.43 \\
\hline 5 & $2.0 \pm 0.2$ & $7.0 \pm 0.8$ & $-3.0 \pm 0.3$ & 1.37 \\
\hline 7.5 & $7.1 \pm 0.1$ & $6.6 \pm 0.3$ & $-2.3 \pm 0.1$ & 1.07 \\
\hline 10 & $7.0 \pm 0.2$ & $9.3 \pm 0.1$ & $-0.6 \pm 0.2$ & 1.04 \\
\hline
\end{tabular}

Comparison with the magnitudes of $\mathrm{C}$ for undoped samples on Table 9 shows that doped samples have larger Curie constant values than undoped samples. This directly indicates the contribution of magnetism from $\mathrm{Cu}^{2+}$ which increases with increasing doping concentration. Decreasing magnetic moment $(\mu)$ with doping percentage indicates the increase in $\mathrm{Cu}-\mathrm{Cu}$ ion antiferromagnetic interaction. This is also supported by the negative values of $\theta$. In Figure $24, \chi$ vs $\mathrm{T}$ plots are compared for the samples with different $\mathrm{Cu}$ doping. The observed increase in $\mathrm{C}$ for larger dopings results in the larger $\chi$.

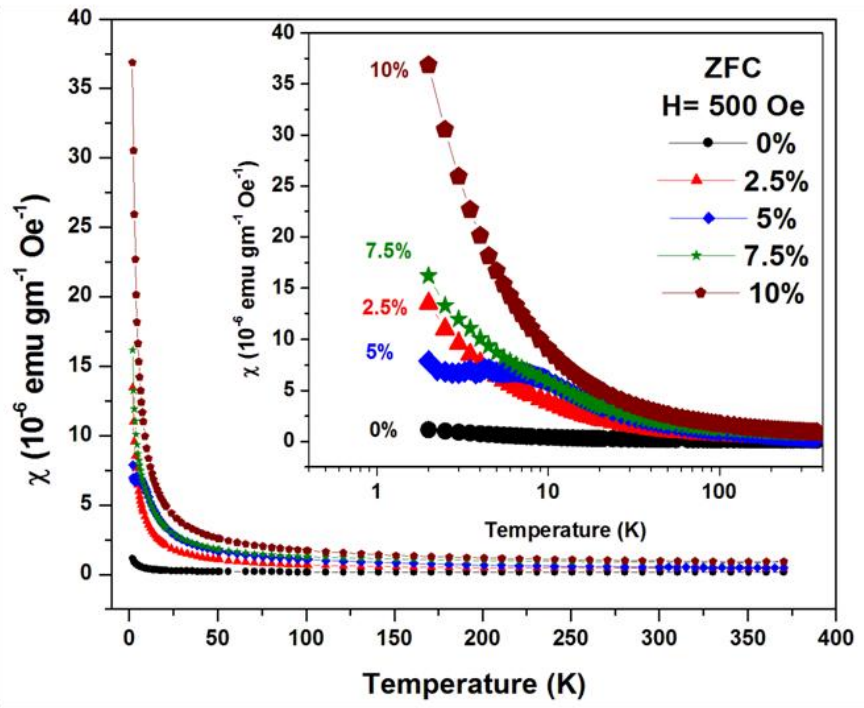

(a)

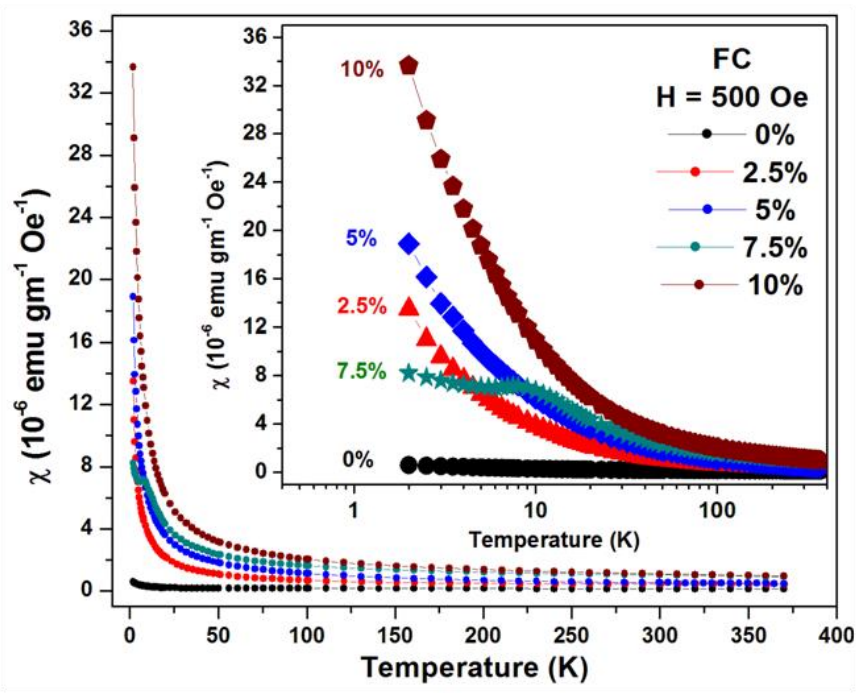

(b)

Figure 24: Comparison of $\mathrm{ZFC}$ and FC Plots of $\mathrm{Cu}-d o p e d \mathrm{CeO}_{2}$ 
Next the hysteresis plots of $\mathrm{Cu}$-doped cerium oxide are plotted in Figure 25 with the evaluated parameters listed in Table 12. Both paramagnetism and ferromagnetism is evident. Magnetic moment per copper atom is calculated by finding saturation magnetization $\mathrm{M}_{\mathrm{S}}$ values. This is done in a similar fashion as done for undoped samples. Magnetic moment is calculated using the equation:

$$
\frac{\mu}{\mu_{B}}=\frac{M_{S} * \text { Mol.Wt }}{x * N * \mu_{B}}
$$

where $\mathrm{x}$ is the percentage of copper doping. 


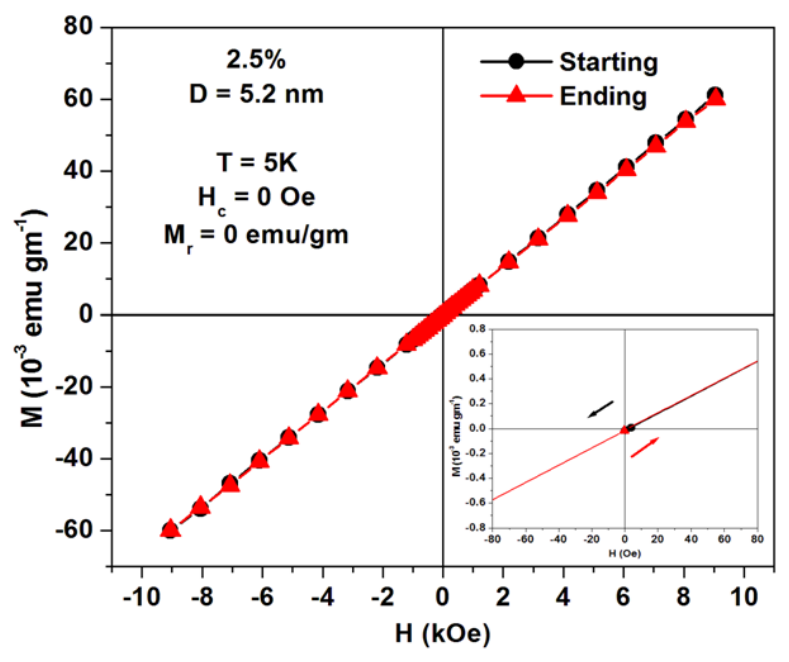

(a)

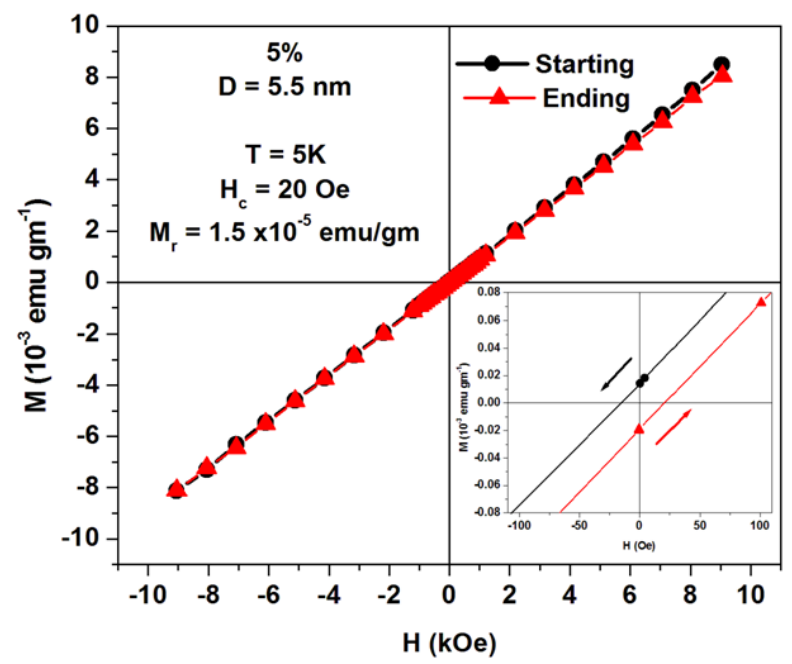

(c)

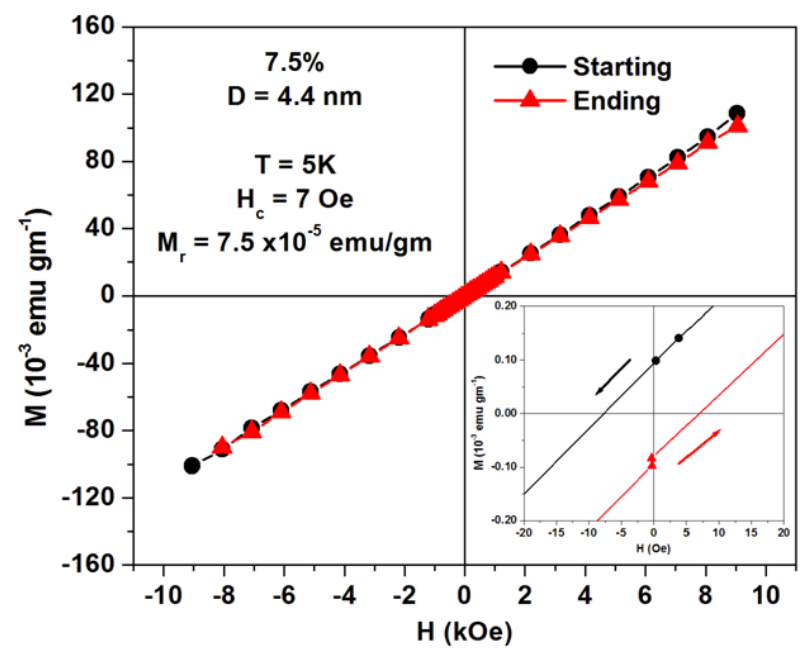

(e)

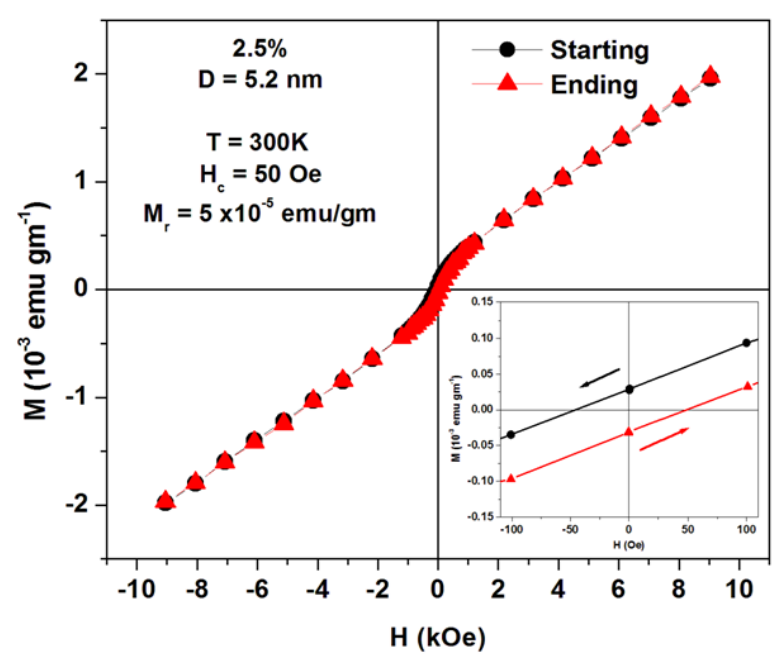

(b)

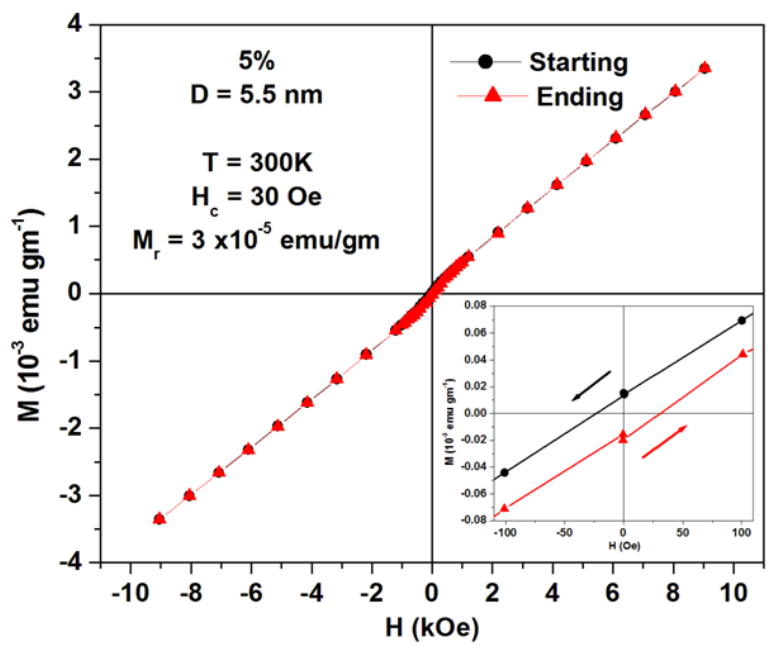

(d)

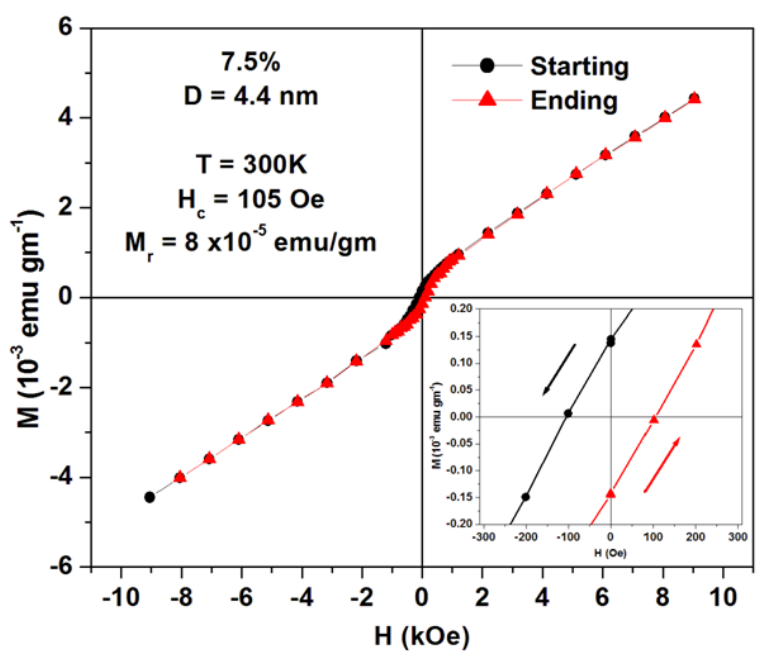

(f) 


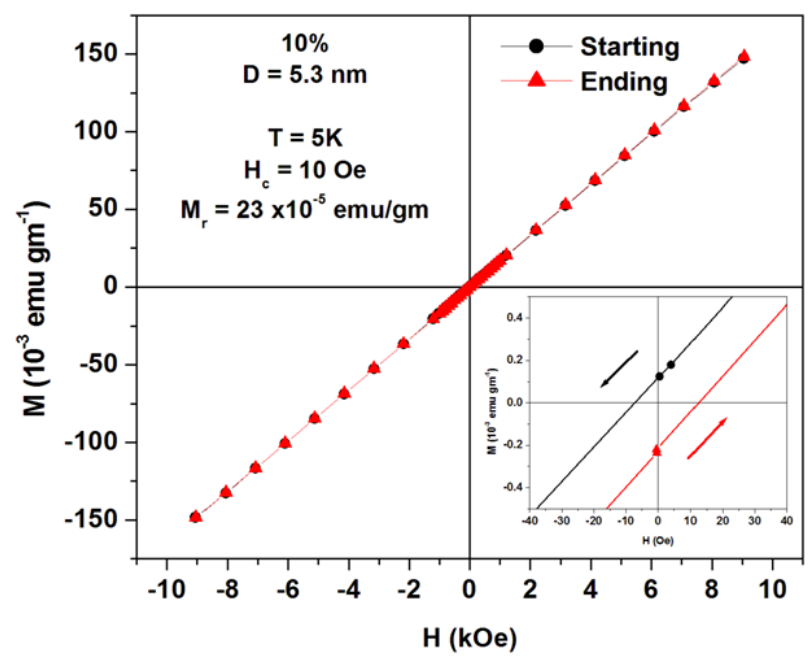

(g)

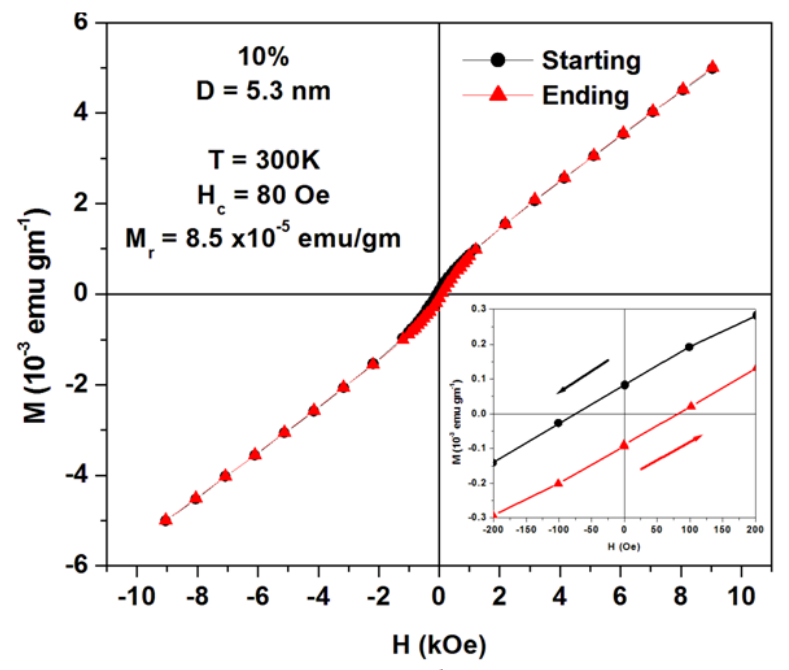

(h)

Figure 25: M vs H Plots for Cu-doped Samples

Table 10: Magnetic Parameters Extracted using M vs H Plots

\begin{tabular}{|c|c|c|c|c|c|}
\hline $\mathrm{Cu} \%$ & $\begin{array}{c}\chi_{P} \\
\left(10^{-7} \text { emu }_{g^{-1}} \mathrm{Om}^{-1}\right)\end{array}$ & $\begin{array}{c}\mathbf{H}_{\mathrm{C}} \\
(\mathbf{O e})\end{array}$ & $\begin{array}{c}\mathrm{M}_{\mathrm{R}} \\
\left(10^{-5} \stackrel{\left.\mathrm{emu} \mathrm{g}^{-1}\right)}{ }\right)\end{array}$ & $\begin{array}{c}\mathrm{M}_{\mathrm{S}} \\
\left(10^{-4} \mathrm{emu}^{-1}\right)\end{array}$ & $\begin{array}{l}\mu / \mu_{B} \\
\left(10^{-4}\right)\end{array}$ \\
\hline 2.5 & 1.9 & 50 & 5.0 & 2.5 & 2.92 \\
\hline 5 & 3.5 & 30 & 3.0 & 1.6 & 1.31 \\
\hline 7.5 & 4.3 & 106 & 8.0 & 5.0 & 2.18 \\
\hline 10 & 5.0 & 80 & 8.5 & 5.7 & 1.66 \\
\hline
\end{tabular}

Derived parameters from the $\mathrm{M}$ vs $\mathrm{H}$ plots show that with increase in doping concentration there is a considerable increase in coercivity $\left(H_{C}\right)$, remanence $\left(M_{R}\right)$ and saturation magnetization $\left(\mathrm{M}_{\mathrm{S}}\right)$. Exception is the 5\% sample. The values of saturation magnetization are larger than those in undoped samples. This is illustrated in Figure 26, suggesting $\mathrm{Cu}^{2+}$ ions are responsible for intrinsic ferromagnetism shown in these samples. The important aspect to note is that when $\mathrm{Cu}^{2+}$ is doped into lattice replacing $\mathrm{Ce}^{4+}$, oxygen vacancies have to be created for the reasons of charge balance. Oxygen vacancies may be one of the factors contributing to the ferromagnetism. As mentioned in first chapter oxygen vacancies are known to be reason for ferromagnetism $[2,7,8,10]$. Although report by Liu et. al. [9] suggest this is not to be the case. 


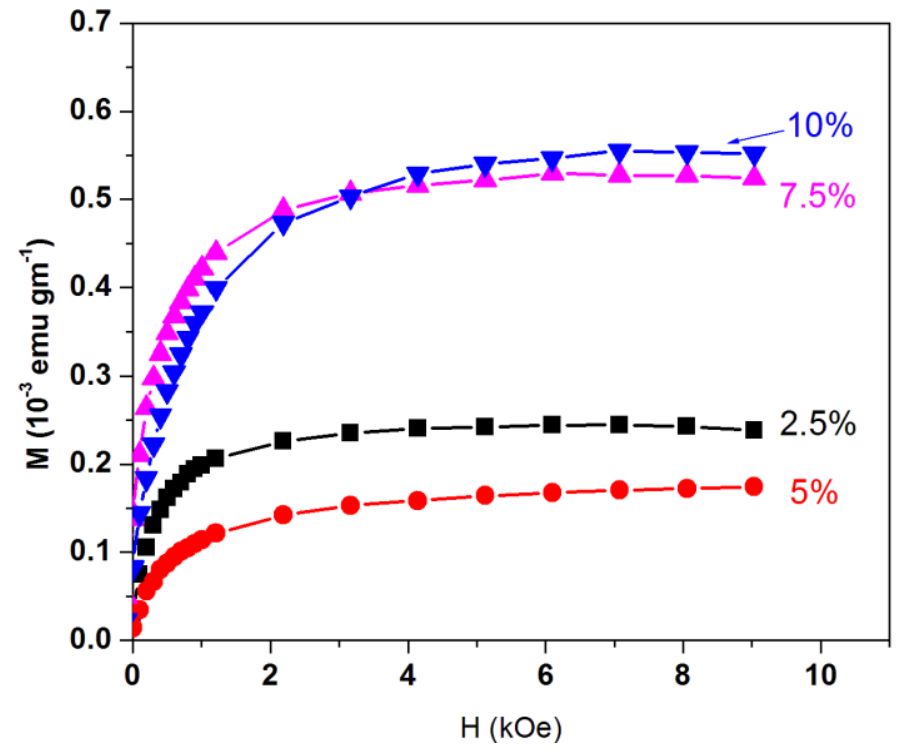

Figure 26: $\mathrm{M}_{\mathrm{S}}$ Comparison in Cu-doped Cerium Oxide Samples

Figure 27 shows the $\mathrm{M}$ vs $\mathrm{H}$ plots of $\mathrm{Cu}$-doped $\mathrm{CeO}_{2}$ measured at $5 \mathrm{~K}$ and $300 \mathrm{~K}$. At both the temperatures net magnetization has increased consistently with increase in doping concentration. This shows that $\mathrm{Cu}^{2+}$ ions are playing an important role in producing intrinsic magnetism in the nanoparticles. Electron magnetic resonance (EMR) studies done on these samples by my colleague, Dr. Vivek Singh, have shown the presence of $\mathrm{Cu}^{2+}$ ions in the $\mathrm{Cu}$ doped samples.
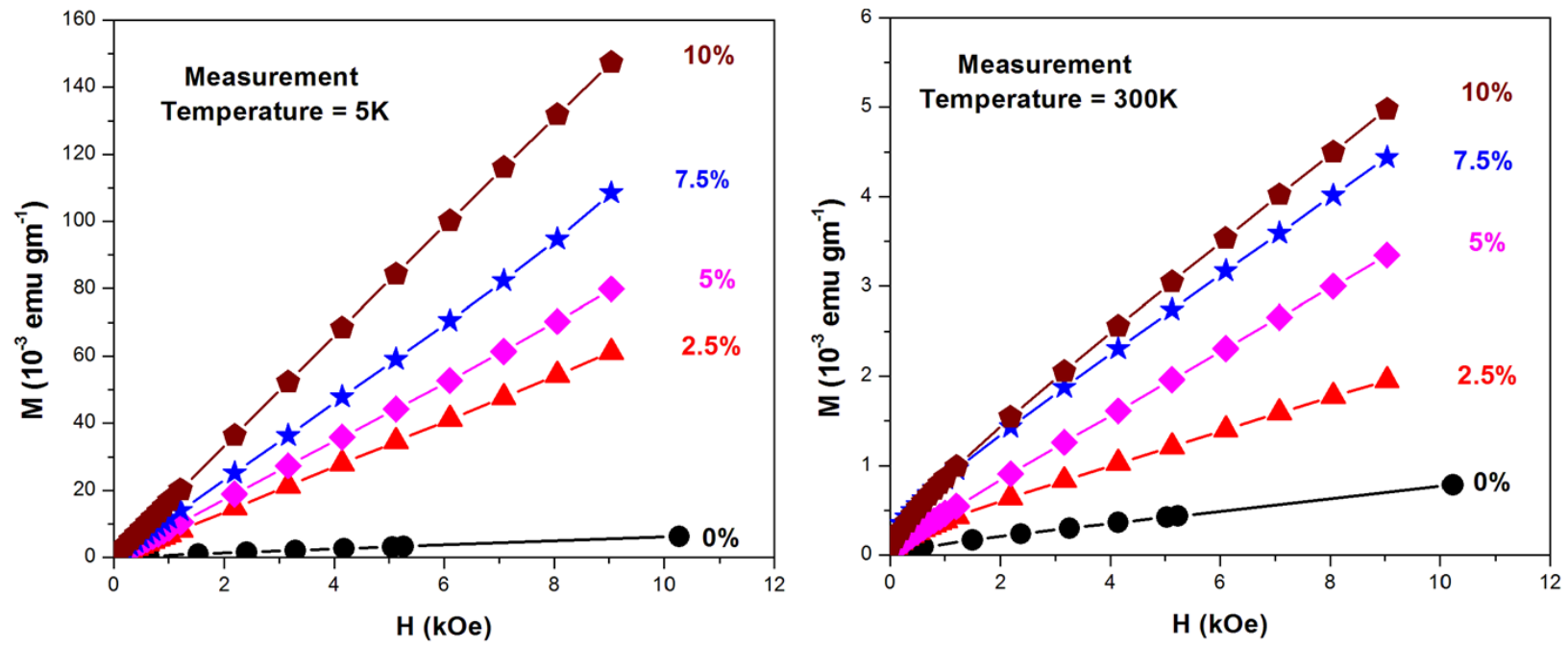

Figure 27: Comparison of $\mathrm{M}$ vs $\mathrm{H}$ in $\mathrm{Cu}$-doped $\mathrm{CeO}_{2}$ Samples 


\section{Summary and Conclusions}

In this thesis, synthesis, structural characterization and magnetic properties of $\mathrm{Cu}$-doped cerium oxide nanoparticles are presented. These results are compared with results from pure or undoped $\mathrm{CeO}_{2}$. Structural properties were studied using transmission electron microscope (TEM) and X-ray diffraction (XRD) studies. Magnetic measurements were done using superconducting quantum interface device (SQUID) magnetometer. An attempt was made to relate the magnetic changes with the structural changes in the nanoparticles. The summary and conclusion of this work are summarized in this chapter.

The nanoparticles of $\mathrm{CeO}_{2}$ and $\mathrm{Cu}$-doped $\mathrm{CeO}_{2}$ were synthesized using a sol-gel process. $\mathrm{CeO}_{2}$ nanoparticles were prepared with different particle sizes without formation of any other phases. Using the XRD and TEM techniques, particle sizes of the nanoparticles were found to be $2.9 \mathrm{~nm}$ for as prepared $\mathrm{CeO}_{2}$ and $3.3 \mathrm{~nm}, 5.7 \mathrm{~nm}, 6.7 \mathrm{~nm}, 19.7 \mathrm{~nm}$ and $41.6 \mathrm{~nm}$ for samples annealed at $\mathrm{Ta}=200^{\circ} \mathrm{C}, 400^{\circ} \mathrm{C}, 550^{\circ} \mathrm{C}, 700^{\circ} \mathrm{C}$ and $800^{\circ} \mathrm{C}$ respectively. Steady increase in particles sizes on increase in $\mathrm{T}_{\mathrm{a}}$ is explained on the basis of Oswald ripening. As in undoped samples, presence of any impurity phases could not be detected in $\mathrm{Cu} / \mathrm{CeO}_{2}$ in $\mathrm{XRD}$. Particle sizes of doped $\mathrm{CeO}_{2}$ were nanoparticles were $5.2 \mathrm{~nm}, 5.5 \mathrm{~nm}, 4.4 \mathrm{~nm}$ and $5.3 \mathrm{~nm}$ for $\mathrm{Cu}_{\mathrm{x}} \mathrm{Ce}_{1-\mathrm{x}} \mathrm{O}_{2}$ with $\mathrm{x}=0.025,0.05,0.075$ and 0.1 respectively annealed at $\mathrm{Ta}=400^{\circ} \mathrm{C}$. Particle sizes from XRD and TEM results are comparable.

Strain and lattice constant value have been derived from XRD patterns. In undoped $\mathrm{CeO}_{2}$, samples a uniform decrease in lattice constant and strain was observed with increase in particle size. The decrease in the lattice constant with increase in particle size is likely due to reduction in the percentage of $\mathrm{Ce}^{3+}$ ions. In $\mathrm{Cu}$-doped $\mathrm{CeO}_{2}$ samples an increase in the lattice constant has 
been observed for $\mathrm{x}$ upto 0.075 followed by a decrease for the $\mathrm{x}=0.10$ sample. This change may be due to $\mathrm{Cu}^{2+}$ going into the interstitial sites for larger dopings.

Magnetic studies on all the samples were done using a SQUID magnetometer both as a function of temperature at a fixed magnetic field and as a function of magnetic field at the fixed temperature of $5 \mathrm{~K}$ and $300 \mathrm{~K}$. The data of $\chi$ vs $\mathrm{T}$ were analyzed using the modified Curie-Weiss law from which the Curie constant is determined. For the undoped sample, decrease in $\mathrm{C}$ with increase in $T_{a}$ and the resulting larger particle size is explained in terms of decrease in the concentration of paramagnetic $\mathrm{Ce}^{3+}$ ions. The observed ferromagnetic part in the hysteresis is likely due to magnetic impurities of $\mathrm{Fe}_{3} \mathrm{O}_{4}$ and $\alpha-\mathrm{Fe}_{2} \mathrm{O}_{3}$ at the ppm level.

Copper doped cerium oxide samples showed consistent increase in magnetization with increase in copper doping concentration both at room temperature and at $5 \mathrm{~K}$. Curie constant $\mathrm{C}$ and saturation magnetization $\mathrm{M}_{\mathrm{S}}$ were found to increase with doping concentration suggesting increase in both paramagnetic part and ferromagnetic part respectively. From both hysteresis and susceptibility curves magnetic moment per copper atom was found to decrease with increasing copper concentration possibility due to increasing $\mathrm{Cu}^{2+}-\mathrm{Cu}^{2+}$ interaction. The saturation magnetization of the ferromagnetic part is found to increase with doping concentration. This is suggested to be due to increase in the $\mathrm{Cu}^{2+}$ ions.

In summary, the room temperature ferromagnetism in undoped $\mathrm{CeO}_{2}$ is very likely due to invariable $\mathrm{Fe}_{3} \mathrm{O}_{4} / \alpha-\mathrm{Fe}_{2} \mathrm{O}_{3}$ impurities present at ppm levels in the starting materials used in the synthesis. However, for the $\mathrm{Cu}$-doped samples, the observed increase in the ferromagnetic component with increasing $\mathrm{Cu}$ concentration can only be explained in terms of intrinsic ferromagnetism due to $\mathrm{Cu}^{2+}$ doping into $\mathrm{CeO}_{2}$. 


\section{Appendix}

\section{Calculation of 5\% Copper doped Cerium Oxide:}

Molecular weight of the cerium nitrate hexahydrate $\left(\mathrm{Ce}\left(\mathrm{NO}_{3}\right)_{3} \cdot 6 \mathrm{H}_{2} \mathrm{O}\right)=\mathbf{4 3 4 . 2 2}$

Molecular weight of the copper nitrate hemipentahydrate $\left(\mathrm{Cu}\left(\mathrm{NO}_{3}\right)_{2} \cdot 2 \frac{1}{2} \mathrm{H}_{2} \mathrm{O}\right)=\mathbf{2 3 6 . 6}$

The nitrate salts are mixed in the atomic ratios of $0.95(\mathrm{Ce})$ and $0.05(\mathrm{Cu})$. Therefore the ratio in which the nitrate salts are mixed is

$$
\frac{\text { Amount of cerium nitrate hexahydrate }(g)}{\text { Amount of copper nitrate hemipentahydrate }(g)}=\frac{0.95 \times 434.22}{0.05 \times 236.6}=\frac{412.509}{11.83}
$$

Therefore to maintain $5 \%$ atomic ratio, $412.509 \mathrm{~g}$ of cerium nitrate hexahydrate is mixed with $11.83 \mathrm{~g}$ of copper nitrate hemipentahydrate is added. Similarly, for $4.34114 \mathrm{~g}$ of cerium nitrate hexahydrate, $0.1245 \mathrm{~g}$ of Copper Nitrate Hemipentahydrate is mixed to maintain 0.95:0.05 atomic ratio. On the basis of similar calculation Table 1 resembles the amounts of samples to be mixed to maintain respective atomic ratios. 


\section{References}

1) R. D. Shannon, Acta Cryst A32, $751-767$ (1976).

2) S. Deshpande, S. Patil, S.V.N.T Kuchibatla and S. Seal, Appl. Phy. Letters 87, 133113 (2005).

3) P. Dutta, S. Pal, M.S. Seehra, Y. Shi, E.M. Erying and R.D. Ernst, Chem. Mater. 18, 5144-5146 (2006).

4) S. Yabe and T. Sato, J. Solid State Chem, 171, 7 (2003).

5) P. Jasinski, T. Suzuki, and H. U. Anderson, Sens. Actuators B 94, 222 (2003).

6) R. J. Gorte, H. Kim, and J. M. Vohs, J. Power Sources 106, 10 (2002).

7) A. Sundaresan, R. Bhargavi, N. Rangarajan, U. Siddesh and C.N.R. Rao, Phys. Rev. B, 74, 161306 (2006).

8) A. Sundaresan and C.N.R. Rao, NanoToday, 4, 1, 96-106 ( 2009) .

9) Y. Liu, Z. Lockman, A. Aziz and J.M. Driscoll, J. Phys.: Condens. Matter 20165201

10) V. Fernandes, R. J. O. Mossanek, P. Schio, J. J. Klein, A. J. A. de Oliveira, W. A. Ortiz, N. Mattoso, J. Varalda, W. H. Schreiner, M. Abbate and D. H. Mosca, Phys. Rev. B 80, 3 (2009).

11) S. Tsunekawa, R. Sahara, Y. Kawazoe and K. Ishikawa, Appl. Surf. Sci. 152, 53 (1999) .

12) S. Tsunekawa, K. Ishikawa, Z. Q. Li, Y. Kawazoe, and Y. Kasuya, Phys. Rev. Lett. 85, 3440 (2000).

13) Feng Zhang, Siu-Wai Chan, Jonathan E. Spanier, Ebru Apak, Qiang Jin, Richard D. Robinson, and Irving P. Herman, Appl. Phys. Lett. 80, 127 (2002).

14) Y. Men, H. Gnaser, R. Zapf, V. Hessel, C. Ziegler and G. Kolb, Appl. Catal. A: General, 277, 83-90 (2004).

15) K. Faungnawakij, Y. Tanaka, N. Shimoda, T. Fukunaga, R. Kikuchi and K. Eguchi, Appl. Catal. B - Environmental, 74, 144-151 (2007).

16) X. Huang, A. Makmal, J.R.Chelikowsky, L. Kroinik, Phys Rev. Lett. 94, 236801, (2005).

17) A. Tiwari, V. M. Bhosle, S. Ramachandran, N. Sudhakar, J. Narayan, S.Budak, and A. Gupta, Appl. Phys. Lett. 88, 142511 (2006).

18) A. Thurber, K. M. Reddy, and A. Punnoose, J. Appl. Phys. 101, 09 N506 (2007).

19) S. K. Sharma, M. Knobel, C. T. Meneses, S. Kumar, Y. J. Kim, B. H. Koo, C. G. Lee, D. K. Shukla, and R. Kumar, J. Korean Phys. Soc. 55, 1018 (2009).

20) L.M. Johnson, A. Thurber, J. Anghel, M. Sabetian, M.H. Engelhard, D. A. Tenne, C.B. Hanna and A. Punnoose, Phys. Rev. B, 82, 054419 (2010)

21) P. Slusser, D. Kumar, A. Tiwari, Appl. Phys. Lett., 96, 142506 (2010).

22) X. Wang, J. A. Rodriguez, J. C. Hanson, D. Gamarra, A. M.Arias, and M.F.García J. Phys. Chem. B 109 (42), 19595-19603 (2005).

23) A. A. Kaïs, A. Bennani, C. F. Aïssi, G. Wrobel and M. Guelton, J. Chem. Soc., Faraday Trans. 88, 1321-1325 (1992).

24) H.P.Klug and L.E. Alexander, $X$-ray diffraction procedures: for polycrystalline and amorphous materials, $2^{\text {nd }}$ Ed., John Willey \& Sons (1974) 
25) R. Witty \& P. Wood, Nature, 163, 323 (1949) .

26) G. K. Williamson and W. H. Hall, Acta. Metall. 1, 22 (1953).

27) H. Zou, Y.S. Lin, N. Rane, and T. Hw, Ind. Eng. Chem. Res 43, 3019 (2004).

28) A. Punnoose, J. Hays, A. Thurber, M.H. Engelhard, R.K. Kukadapu, C. Wang, V. Shuttanandan and S. Thevuthasam, Phys. Rev. B. 72, 054402 (2005).

29) Introduction to Solid state Physics, Seventh Ediion, C. Kittel.

30) P.Dutta, S. Pal and M.S. Seehra, Chem. Mater, 18 (21), 5144-5146 (2006) .

31) P. Dutta, S. Pal, M. S. Seehra, N. Shah and G. P. Huffman, J. Appl.Phys. 105 07B501 (2009).

32) M.M. Ibrahim, J. Zhao, and M.S. Seehra, J. Matter. Res. 7, 1856 (1992). 


\section{Vita}

Name:

Parents:

Birthplace:

Date of Birth:

Education:
Savan Suri

S. L. Murty

S. Krishnaveni

Visakhapatnam, India

August 22, 1986

High School - Kendriya Vidyalaya \# 2, Vizag B.S. - Dr. M.G.R. University, Chennai

\footnotetext{
John H. 